UNIVERSIDADE DE SÃO PAULO

ins.ifuto DE FÍSICA E QUIMICA DE SÃO CARLOS

DEPARTAMENTO DE FISICA E CIENCIA DOS MATERIAIS

\title{
INTERAÇÃO ENTRE PARTÍCULAS COLOIDAIS
}

\author{
ANTONIO CALIRI
}

Tese apresentada ao Instituto de Fisica $\theta$ Química de São Carlos, USP, para obtenção do título de Mestro em Ciências (Física Aplicada).

Orientador: Prof. Dr. Bernhard Joachin Mokross 
UNIVERSIDADE DE SAO PAULO

INSTITUTO DE FISICA E QUIMICA DE SÃO CARLOS

DEPARTAMENTO DE FISICA E CIÉNCIA DOS MATERIAIS

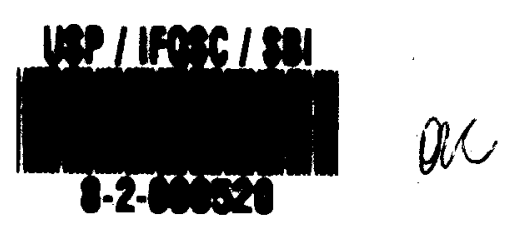

\title{
INTERAÇÃO ENTRE PARTÍCULAS COLOIDAIS
}

\author{
ANTONIO CALIRI \\ Tese apresentada ao Instituto de Fisica e \\ Química de São Carlos, USP, para obtenção \\ do título de Mestre em Ciências (Fisica \\ Aplicada).
}

Orientador: Prof. Dr. Bernhard Joachin Mokross

SẢO CARLOS 
MEMBROS DA COMISSAOO JULGADORA DA DISSERTACAO DE MESTRADO DE ANTONIO CALIRI

APRESENTADA AO INSTITUTO DE FISICA E NUIMICA DE SAO CARLOS, DA UNIVERSIDADE DE SAO PAULO, EM 17 OE junho_ DE 1980.

COMISSAO JULGADORA:

Burntand D. usohuens.

Dr. BERNHARD JOACHIM MOKROSS

- Orientador
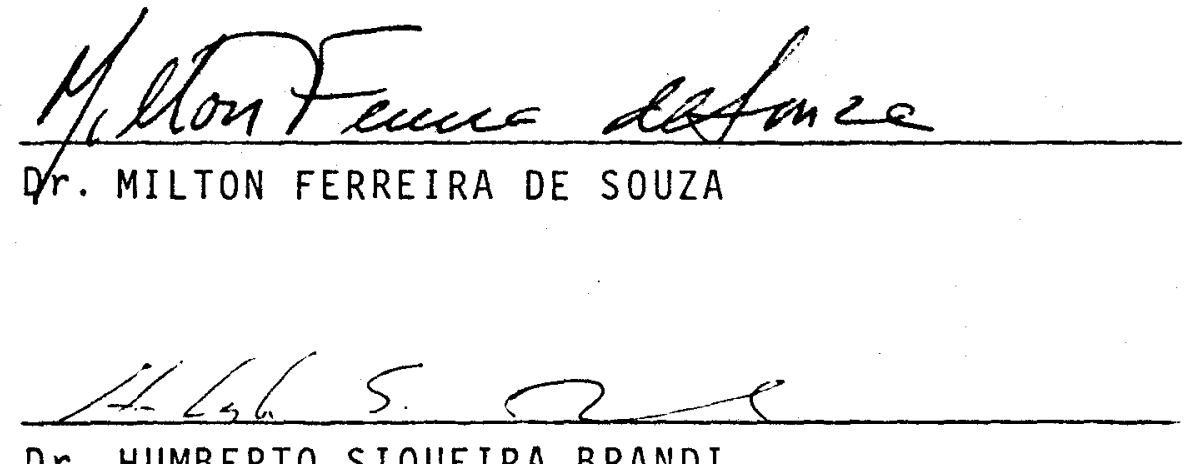

Dr. HUMBERTO SIQUEIRA BRANDI 
Para minha mãe

\section{Lena}

Luisa 


\section{A G R A D E C I MEN TOS}

A B.J. Mokross, pela dināmica orientação.

A J.Medeiros e Silva pela sempre presente disponibilidade.

A M.A.Alves da Silva pelas discussões e sugestões.

A Heloisa Helena Ferreira pela amizade e ajuda financeira.

Aos demais Mestres e colegas do Departamento. 
I N D I C E

Pāg.

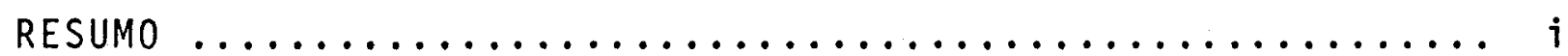

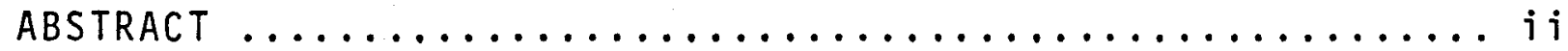

CAPITULO I

INTRODUÇAOO -0 SISTEMA $\ldots \ldots \ldots \ldots \ldots \ldots \ldots \ldots \ldots \ldots \ldots$

- Sobre alguns modelos .................... 2

- Referências ........................... 7

CAPITULO II

POTENCIAIS ATRATIVOS $\ldots \ldots \ldots \ldots \ldots \ldots \ldots \ldots \ldots \ldots$

1 - Interação de Van der Waals-London .............. 9

2- Efeito do retarmentõ na atração Van der Waals-London. . 15

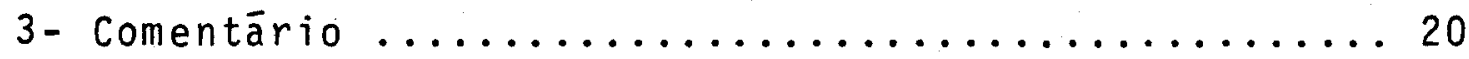

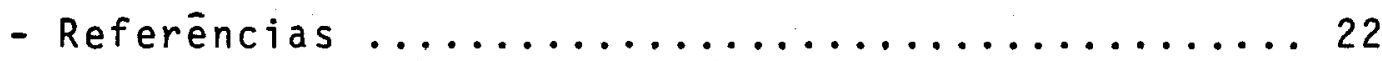

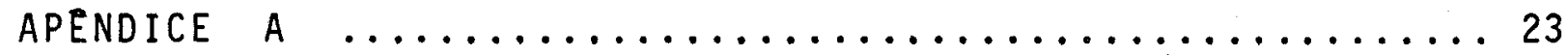

CAPITULO III

POTENCIAL REPULSIVO $\ldots \ldots \ldots \ldots \ldots \ldots \ldots \ldots \ldots \ldots \ldots \ldots \ldots \ldots \ldots$

1- Transição de Fase do tipo Kirkwcod-Alder ......... 28

- Evidencia Experimental da teoria de Kirkwood-Alder. 29

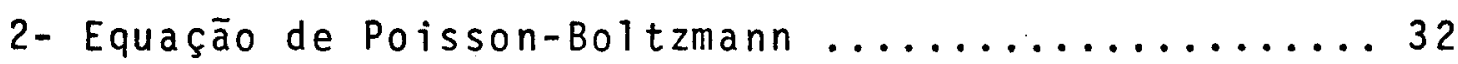

- A dupla camada eletroquimica ................ 32

- A influéncia do tamanho finito dos ions na dis-

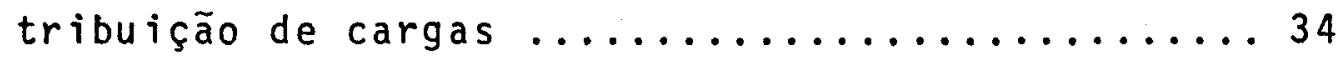

- A dependēncia da constante dielétrica em relação à intensidade do Campo Elētrico .............. 39

3 - 0 modelo da célula - energia repulsiva .........4 43

- A equação de Poisson-Boltzmann para o modelo da cé-

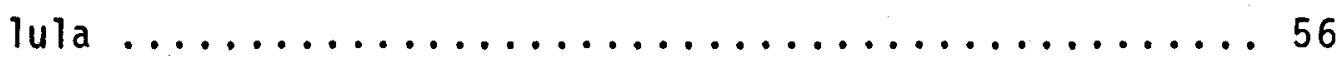

- Referèncias ........................... 59 


\section{CAPITULO IV}

RESOLUÇAO NUMERICA DA E.P.B. ................... 61

- Existência e unicidade da solução ........... 61

- 0 método de Runge-Kutta de $4 a$. ordem: problemas de valores iniciais .................... 65

- Processo interativo para encontrar $\emptyset\left(r=R_{1} ; R_{s}\right) . .69$

- Processo interativo para normalização: $\int \rho d v=Q \quad .72$

- Referēncias ........................ 77

CAPITULO $V$

RESULTADO E DISCUSSOES ................... 78

1 - Potencial na superfície da esfera ........... 78

2- Energia potencial repulsiva ............... 82

3- A cristalização e a transição bcc-fcc ........... 85

- Mecanismo de transição lïquido-sōlido .......... 85

- A transição bcc-fcc .................... 91

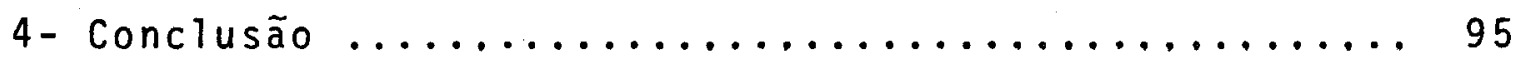

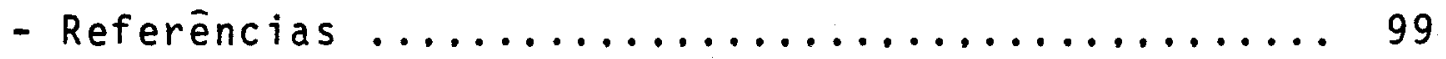

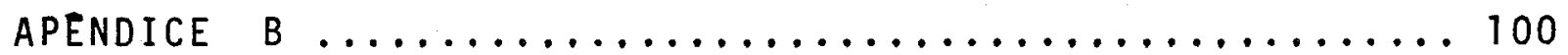


RES U M O

Neste trabalho efetuamos uma anālise quantitativa das forças que atuam entre particulas coloidais. Para is to integramos a Equação de Poisson-Boltzmann não linearizada levando em considera ção o tamanho finito dos ions. Os resultados são aplicados a sis temas formados por esferas de poliestireno em dispersão aquosa. Concluimos que as forças repulsivas são dominantes nestes sistemas permitindo-nos negligenciar as forças atrativas. Também efetuamos algumas comparações dos mesmos resultados com dados expe rimentais. 
We present a quantitative analisis of the forces acting in colloidal particles. For this purpose we integrated the non li nearized Poisson-Boltzmann Equation by a numerical method. We took in accont the finite size of the ions and applied the results to systems formed by polystirene spheres in aqueous disper sion. We were able to conclude that the attractive forces can be neglicted in front of the repulsive forces. We also were able to perform same comparasion com experimental data. 
CAPITULO I

INTRODUÇAO - O SISTEMA

0 assunto inspirador deste trabalho $\bar{e}$ a cristalização de esferas de poliestireno, isto é: esferas de poliestireno-monodispersas (diāmetro na ordem de $10^{3} \AA$, com desvio padrão muito baixo - $2 \%)^{(1)}$, quando em solução aquosa e sob certas condições dis põem-se regularmente, estabelecendo uma estrutura cristalina ${ }^{(2-4)}$.

Estas esferas de poliestireno são obtidas por mētodos es peciais de polimerização(1,3). Durante a polimerização, são incor poradas na cadeia original do polimero grupos $-\left[\mathrm{SO}_{3} \mathrm{H}\right]$, os quais se distribuem regularmente pela superficie da esfera. Desta forma a esfera comporta-se como uma imensa molécula de ācido, desprendendo ions $\mathrm{H}^{+}$quando em solução aquosa, enquanto a mesma adquire uma carga negativa da ordem de $10^{3}$ cargas elementares.

os cristais podem ser obtidos dispersando em ägua deioni zada, e na concentração conveniente, as esferas de poliestireno (4) Após alguns dias (ou semanas) a solução torna-se iridiscente. Esta iridescēncia foi atribuída por Luck e colaboradores (6) à reflexão Bragg da luz visível, nos planos constituidos pelas esferas ordenadas.

A fase não ordenada da dispersão caracteriza-se por uma baixa concentração de esferas de poliestireno, ou pela presença $\underline{a}$ dicional de eletrólito(3) (por exemplo: KCl) junto à solução de esferas. 0 contraste entre estes fatores (concentração de esferas 
- concentração de eletrōlito) proporciona desde a fase totalmente dispersa, passando pela fase de coexistência (isto é: podemos ter um precipitado iridescente, constituido de "cristalites"(7), e um meio de aspecto leitoso, no estado disperso), até a fase de total cristalização.

SOBRE ALGUNS MODELOS.Foram já propostos vārios modelos para expli car a cristalização das esferas de poliestireno. Por exemplo,Luck e colaboradores ${ }^{(6)}$ consideraram que o ordenamento das esferas era devido ao segundo minimo da interação coloidal. Minimo este que $\bar{e}$ determinado pela energia repulsiva proveniente da interação elétrica esfera-esfera, ion-ion e esfera-ion, e pela energia atrativa devido às interações Van der Waals-London (8). Porēm medidas fei tas nestes cristais(2-4), revelaram parâmetro de rede na ordem de até oito vezes o diāmetro da partícula, e como veremos no próximo capitulo, a energia de Van der Waals para estas distāncias é insignificante, sendo da ordem de $10^{-21}$ ergs. Para distāncias menores por exemplo a dois diāmetros a energia serā da ordem de $10^{-17}$ ergs (ver capitulo II).

R.Williams e R.S.Crandal (2), propuseram uma analogia com o Cristal de Wigner, o qual basicamente consta de um fundo de car ga positiva distribuido continuamente e de cargas negativas pontuais de tal forma que a carga liquida $\bar{e}$ nula $(10)$. Mostra-se que tal sistema é estāvel numa configuração cristalina. Medeiros e Si] va, J. e Mokross,B.J. (11) fizeram uma extensão do conceito de Cris tal de Wigner, onde assumiram que a interação carga pontual-carga 
pontual e carga pontual - fundo de carga não era a simples intera ção coulombiana, mas sim coulombiana blindada. Desta forma foi de senvolvido o que denominaram "Cristal de Wigner Blindado". Com is to procuraram explicar a transição de fase bcc-fcc em: sistemasde esferas de poliestireno de baixa densidade.

Em sistemas de esferas de poliestireno de alta densidade, Hashisu S. e Kobayashi Y. (ver capitulo III) puderam verificar a teoria de Kirkwood Alder, mostrando assim que o efeito de empacotamento de esferas duras é o responsāvel pela transição de fase líquido-sōlido.

No presente trabalho estudaremos um sistema especial de esferas de poliestireno. Consideraremos este sistema constituido somente de àgua pura e as esferas de poliestireno. Este sistema $i$ deal, é aproximado na prātica quando se mistura na dispersão de esferas, resina trocadora de ions. M.K. Udo e M.F. Souza $(4,12)$ efetuaram medidas do parāmetro de rede neste sistema,pelo métodode Debye-Scherrer, utilizando luz de laser de argōnio. Alguns resultados destas medidas estão na tabela $1-1$ e 1-2.

No Capitulo II, efetuaremos um cālculo minucioso da ener gia atrativa entre duas partículas esféricas, devido interação de Van der Waals-London. A finalidade deste capītulo foi, através de resultados quantitativos, verificar a importância das forças de Van der Waals-London na cristalização das esferas, conforme foi invocado por Luck $(7)$.

As experiências de Hashisu $S$. e Kobayashi $Y .(3)$ e KoseA. e Hashisu $s .{ }^{(13)}$ nos pareceram decisivas para a explicação do me- 
canismo de cristalização das esferas de poliestireno. No capitulo III reproduzimos os resultados por eles obtidos e introduzimos 0 que denominamos "modelo da célula", com a finalidade de calcularmos a energia repulsiva entre as esferas. Também no mesmo capitu10, estabelecemos a "Equação de Poisson-Boltzmann" para o modelo da cêtula.

A equação de Poisson-Boltzmann referida no parāgrafo anterior, è uma equação de segunda ordem não linear. Desta forma sua resolução estā vinculada a processos numéricos. 0 capittulo IV é destinado a mētodos numéricos para resolução desta equação, que envolve processos interativos para a transformação de valores de contorno em valores iniciais, assim como para a normalização da solução. 0 programa completo estā no apêndice B.

0 mecanismo da cristalização proposto por Hashisu, Kobay ashi e Kose ${ }^{(3,13)}$ è discutido no capītulo $V$ juntamente com os resultados obtidos no capitulo IV. Fizemos os cálculos para dois ti pos de esferas de poliestireno, para os quais temos os dados completos, e estes dados estão na tabela 1-1 e 1-2. As esferas foram adquiridas comercialmente da "Dow Chemical Company". 
TABELA 1-1 - Diâmetro = $1090 \AA$ A, (desvio padrão $-2,5 \%$ )

$\sigma=6,3 \cdot 10^{3} \mathrm{St}$. Coul $/ \mathrm{cm}^{2}$ (densidade de carga superficial)

$Z=4898 \quad$ (NQ total de cargas elementares na superfície)

\begin{tabular}{|c|c|c|}
\hline \multicolumn{2}{|c|}{$N\left(\right.$ esferas $\left./ \mathrm{cm}^{3}\right)$} & \multirow{2}{*}{$\frac{a(\mathrm{~cm})}{3.6 \times 10^{-5}}$} \\
\hline$(f c c)$ & $6.2 \times 10^{13}$ & \\
\hline$(f \subset c)$ & $5.56 \times 10^{13}$ & $3.7 \times 10^{-5}$ \\
\hline$(f c c)$ & $4.9 \times 10^{13}$ & $3.9 \times 10^{-5}$ \\
\hline$(f c c)$ & $3.88 \times 10^{13}$ & $4.2 \times 10^{-5}$ \\
\hline$\langle f(c)$ & $2.63 \times 10^{13}$ & $4.8 \times 10^{-5}$ \\
\hline$(f c c)$ & $2.53 \times 10^{13}$ & $4.9 \times 10^{-5}$ \\
\hline$(b c c)$ & $1.91 \times 10^{13}$ & $4.2 \times 10^{-5}$ \\
\hline$(b c c)$ & $1.32 \times 10^{13}$ & $4.7 \times 10^{-5}$ \\
\hline$(b c c)$ & $1.2 \times 10^{13}$ & $4.9 \times 10^{-5}$ \\
\hline$(b c c)$ & $1.1 \times 10^{13}$ & $5.0 \times 10^{-5}$ \\
\hline$(b c c)$ & $9.55 \times 10^{12}$ & $5.3 \times 10^{-5}$ \\
\hline$(b c c)$ & $8.53 \times 10^{12}$ & $5.5 \times 10^{-5}$ \\
\hline$\langle b c c\rangle$ & $6.55 \times 10^{12}$ & $5.9 \times 10^{-5}$ \\
\hline$(b c c)$ & $6.03 \times 10^{12}$ & $6.1 \times 10^{-5}$ \\
\hline$(b c c)$ & $1.31 \times 10^{12}$ & $8.8 \times 10^{-5}$ \\
\hline$(b c c)$ & $1.14 \times 10^{12}$ & $8.7 \times 10^{-5}$ \\
\hline
\end{tabular}


TABELA 1-2 - Diâmetro = $910 \AA$, (desvio padrão - 6,5\%) $\sigma=8,7.10^{3} \mathrm{st}$.Coul $/ \mathrm{cm}^{2}$ (densidade de carga superficial) $Z=7625$ (No total de cargas elementares na superfície).

\begin{tabular}{|lll|}
\hline N(esferas $\left./ \mathrm{cm}^{3}\right)$ & $a(\mathrm{~cm})$ \\
\hline$(f c c)$ & $9.64 \times 10^{13}$ & $3.0 \times 10^{-5}$ \\
$(f c c)$ & $4.82 \times 10^{13}$ & $3.6 \times 10^{-5}$ \\
$(b c c)$ & $2.41 \times 10^{13}$ & $3.7 \times 10^{-5}$ \\
$(b c c)$ & $1.21 \times 10^{13}$ & $4.6 \times 10^{-5}$ \\
$(b c c)$ & $9.64 \times 10^{12}$ & $5.2 \times 10^{-5}$ \\
$(b c c)$ & $8.68 \times 10^{12}$ & $5.3 \times 10^{-5}$ \\
$(b c c)$ & $7.71 \times 10^{12}$ & $5.5 \times 10^{-5}$ \\
$(b c c)$ & $7.23 \times 10^{12}$ & $5.5 \times 10^{-5}$ \\
$(b c c)$ & $6.75 \times 10^{12}$ & $5.6 \times 10^{-5}$ \\
$(b c c)$ & $5.78 \times 10^{12}$ & $6.2 \times 10^{-5}$ \\
$(b c c)$ & $3.04 \times 10^{12}$ & $7.6 \times 10^{-5}$ \\
$(b c c)$ & $2.41 \times 10^{12}$ & $8.1 \times 10^{-5}$ \\
\hline
\end{tabular}




\section{REFERENCIAS}

1 - VAN DE HUL, H.J. and VANDERHOFF, J.W., Br. POlym.J.,vol. 2, 121, (1970)

2 - WILliams, R. and CRANDAL, R.S., Phys. Letters, Vol, $48 A_{1} 3$, $225,(1974)$

3 - HASHISU, S., KOBAUASHI, Y. and KOSE,A., Journal of Colloid and Interface Science. Vol. 12,2, (1973)

4 - UDO,M.K., Tese para obtenção do tỉtulo de Mestres em Ciēncias apresentada no Departamento de Física e Ciência dos Materiais, USP, São Carlos (1979)

5 - WERWEY, E.J.W. and OVERBEEK,J.T.H.G., "Tehory of Stability of Lyophobic Colloids", Elsevier, Amsterdan, (1948)

6 - LUCK,W., KLIER,M., Wesslau,W., Ber. Bunsenges Phys. Chem. $50,485,(1963)$

7 - TAKANO,K. and HASHISU, S., Journal of Colloid and Interface Science, Vol. 68,1, (1978)

8 - Ver referência 5, Capítulo VII, pag. 106

9 - VAN HEgEN, W. and SNOOD, I., Chemical Phy . Letters, Vol.35,3 (1975)

10 - WIGNER, E., Trans. For. SOc., 34, 678, (1938)

11 - Medeiros e Silva,J., Mokross, B.J., Solid State Commun. Vol.33 $493,(1980)$ 


$$
-08-
$$

12 - UDO, M.K. and de SOUZA, M.F., aceito para publicação na Solid State Commun. (1980)

13 - KOSE, A. and HASHISU, S., Journal of Colloid and Interface Science, vol. 46,3, (1974) 
CAPITULO II

\section{POTENCIAIS ATRATIVOS}

1 - Interação de Van Der Waals-London

A intenção deste capitulo é obter a energia atrativa de vido as interações do tipo Van Der Waals-London, para o sistema de particulas de poliestireno esféricas.

No apêndice $A$, mostramos uma maneira para se obter a relação para a energia potencial entre dois àtomos:

$$
E=\frac{-\mu}{R^{6}}
$$

Então, seguindo H.C. Hamaker(1), obteremos a energia de interação entre duas partículas constituidas de igual substância, contendo $q$ àtomos por $\mathrm{cm}^{3}$. Mediante a förmula $(2-1)$, teremos:

$$
E=\int_{v_{1}} q d v_{1} \int_{v_{2}}\left(-\frac{\mu}{r^{6}}\right) q d v_{2},
$$

onde $\quad v_{1}=$ volume da partícula 1

$v_{2}=$ volume da partīcula 2

$\mu=$ constante de London - Van der Waals (veja apêndice A)

$r=$ distância entre os elementos de volume $d v_{1}$ e $d v_{2}$

Para o caso de duas particulas esféricas, podemos efetu 
$-10-$

ar a integral (2-2), observando a figura 2-1,

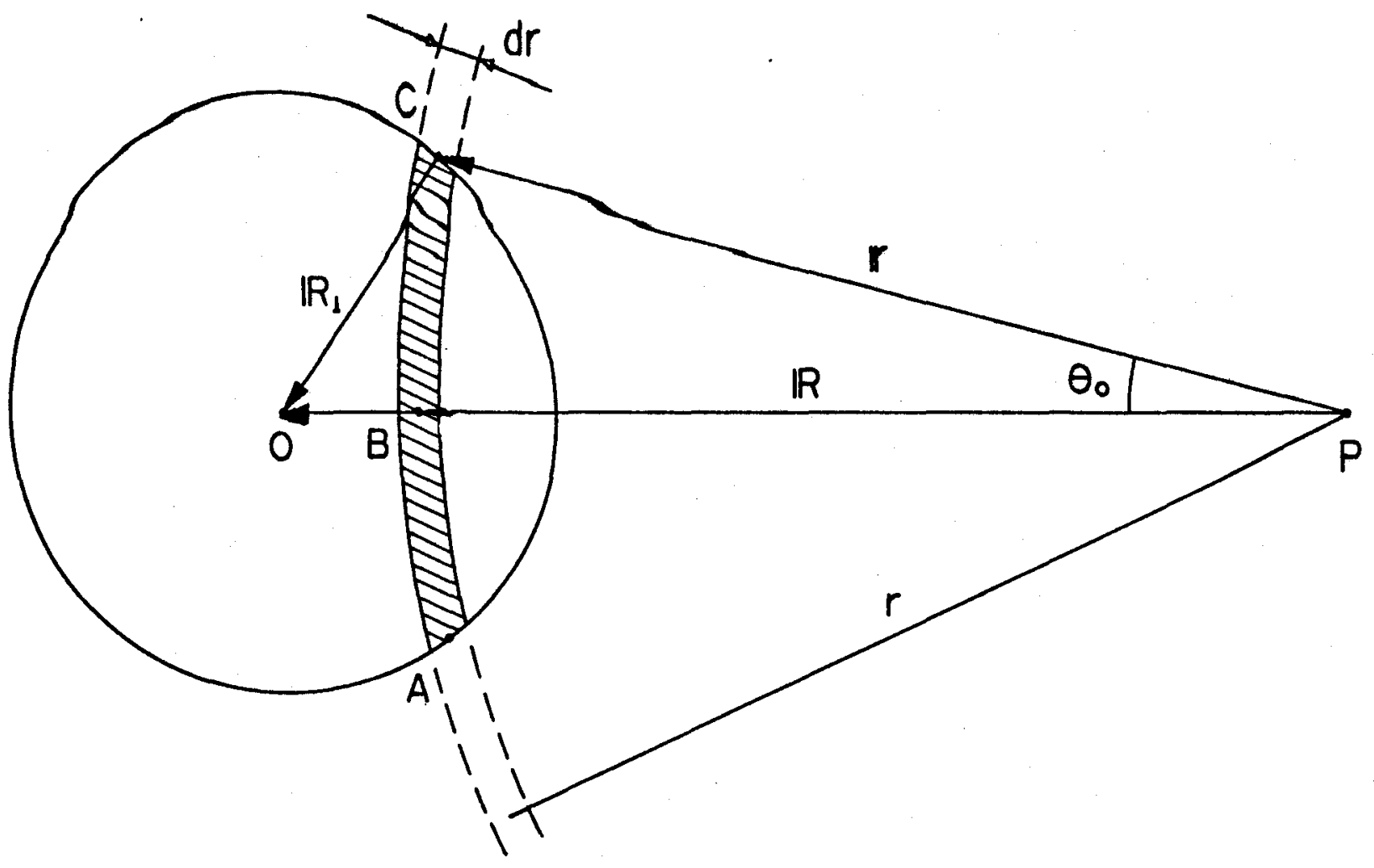

Figura 2-1

Elemento de volume na esfera 1.

onde consideraremos inicialmente a energia potencial de interação $E_{p}$, entre um àtomo em $P$ e uma esfera de raio $R_{1}$, centrada em 0 .

Para esse intento, consideraremos a superficie $(A B C)$ que pode ser calculada por:

$$
S_{A B C}=\int_{0}^{2 \pi} d \psi \int_{0}^{\theta_{0}} d \theta r^{2} \operatorname{sen} \theta,
$$

donde 


$$
S_{A B C}=-2 \pi r^{2}\left(\cos \theta_{0}-1\right) \text {. }
$$

Porēm

$$
\left(\mathbb{R}_{1}\right)^{2}=(\mathbb{R}-r)^{2} \text {, ou } R_{1}^{2}=R^{2}+r^{2}-2 r \cos \theta_{0},
$$

donde

$$
S_{A B C}=\pi \frac{r}{R}\left[R_{1}^{2}-(R-r)^{2}\right] .
$$

Assim podemos escrever, utilizando as equações (2-1) e (2-4)

$$
d E_{p}=-\pi \frac{\mu}{r^{6}} q \frac{r}{R}\left[R_{1}^{2}-(R-r)^{2}\right] d r \text {, }
$$

e integrando obtemos,

$$
E_{p}=-\pi \mu \frac{q}{R} \cdot \frac{1}{12}\left[\frac{2 R_{1}}{\left(R+R_{1}\right)^{3}}+\frac{2 R_{1}}{\left(R-R_{1}\right)^{3}}+\frac{1}{\left(R+R_{1}\right)^{2}}-\frac{1}{\left(R-R_{1}\right)^{2}}\right] .
$$

Agora considerando a figura (2-2), faremos a outra parte da integral (2-2).

Procedendo da mesma maneira que o caso anterior, podemos escrever:

$$
E=\int_{r-R_{2}}^{r+R_{2}} E_{p} q \pi \frac{R}{r}\left[R_{2}^{2}-(r-R)^{2}\right] d R,
$$


onde $E_{p} \bar{e}$ a energia potencial entre a esfera de raio $R_{1}$ e qual quer átomo sobre a superficie (DFP), dada por $\frac{\pi R}{r}\left[R_{2}^{2}-(r-R)^{2}\right]$ onde $R$ é sua distância ao centro da esfera 1 .

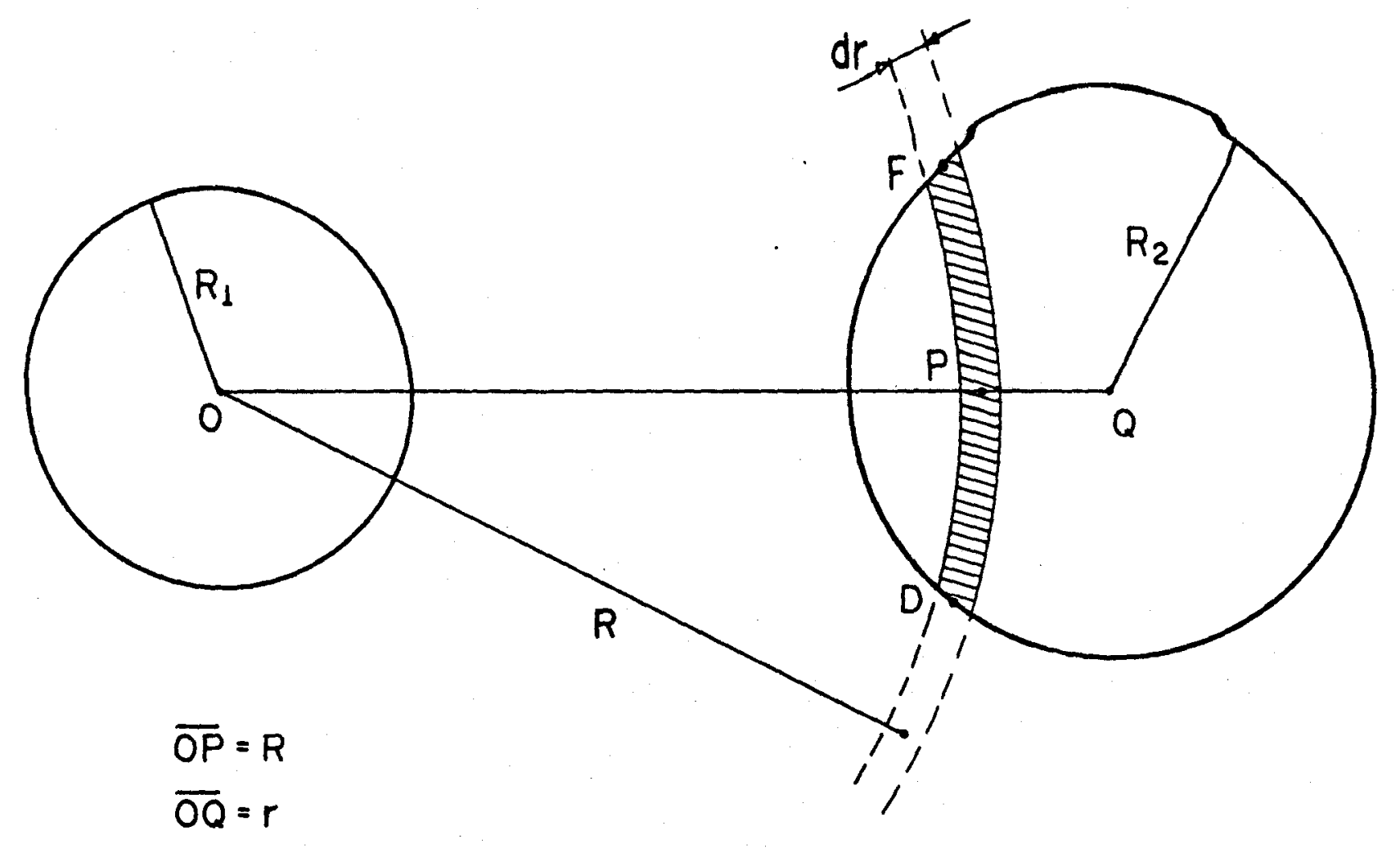

Figura 2-2

Elemento de volume na esfera 2

Explicitando a equação anterior teremos:

$E=-\frac{\pi^{2} q^{2} \mu}{12 r} \int_{r-R_{2}}^{r+R_{2}}\left[R_{2}^{2}-(r-R)^{2}\right]\left[\frac{2 R}{\left(R+R_{1}\right)^{3}}+\frac{2 R}{\left(R-R_{1}\right)^{3}}+\frac{1}{\left(R+R_{1}\right)^{2}}-\frac{1}{\left(R-R_{1}\right)^{2}}\right] d R$

que fornece 
$E=-\pi^{2} q \mu \cdot \frac{1}{6}\left[\frac{2 R_{1} R_{2}}{r^{2}-\left(R_{1}+R_{2}\right)^{2}}+\frac{2 R_{1} R_{2}}{r^{2}-\left(R_{1}-R_{2}\right)^{2}}+\ln \frac{r^{2}-\left(R_{1}+R_{2}\right)^{2}}{r^{2}-\left(R_{1}-R_{2}\right)^{2}}\right]$.

Esta expressão ficarā muito mais simples depois que consi derarmos $R_{2}=R_{1}$ (que é 0 nosso caso), e definirmos $C=r / 2 R_{1}$.

Desta forma podemos escrever a equação (2-8) usando como unidade de comprimento, o próprio diâmetro das esferas.

$$
E=-\pi^{2} q^{2} \mu \cdot \frac{1}{12}\left[\frac{1}{c^{2}-1}+\frac{1}{c^{2}}+2 \ln \frac{c^{2}-1}{c^{2}}\right] .
$$

Na Figura 2.3 apresentamos os resultados numéricos para $\varepsilon(c)=E / A$ (equação 2.9), onde

$$
A=\pi^{2} q^{2} \mu \text {, }
$$

é a constante de Hamaker. (Ver apēndice A).

0 resultado apresentado pela equação 2-9 é o mesmo obtido por Hamaker(1). Para utilizarmos este resultado na obtenção da energia potencial entre duas esferas, faz-se necessārio que conhe çamos o valor da constante $A$ (equação 2-10). No apêndice $A$, apresentamos um procedimento para estimar a constante de Hamaker, A. Este valor varia de substāncia para substāncia e sua ordem de gran deza ${ }^{(3,4)} \bar{e}$ de $10^{-13}$ ergs.

Outro fator a ser levado em conta para o cálculo de $A$, é 0 meio onde as esferas estão imersas. Se $A_{11}$ se refere à intera - 
(a)
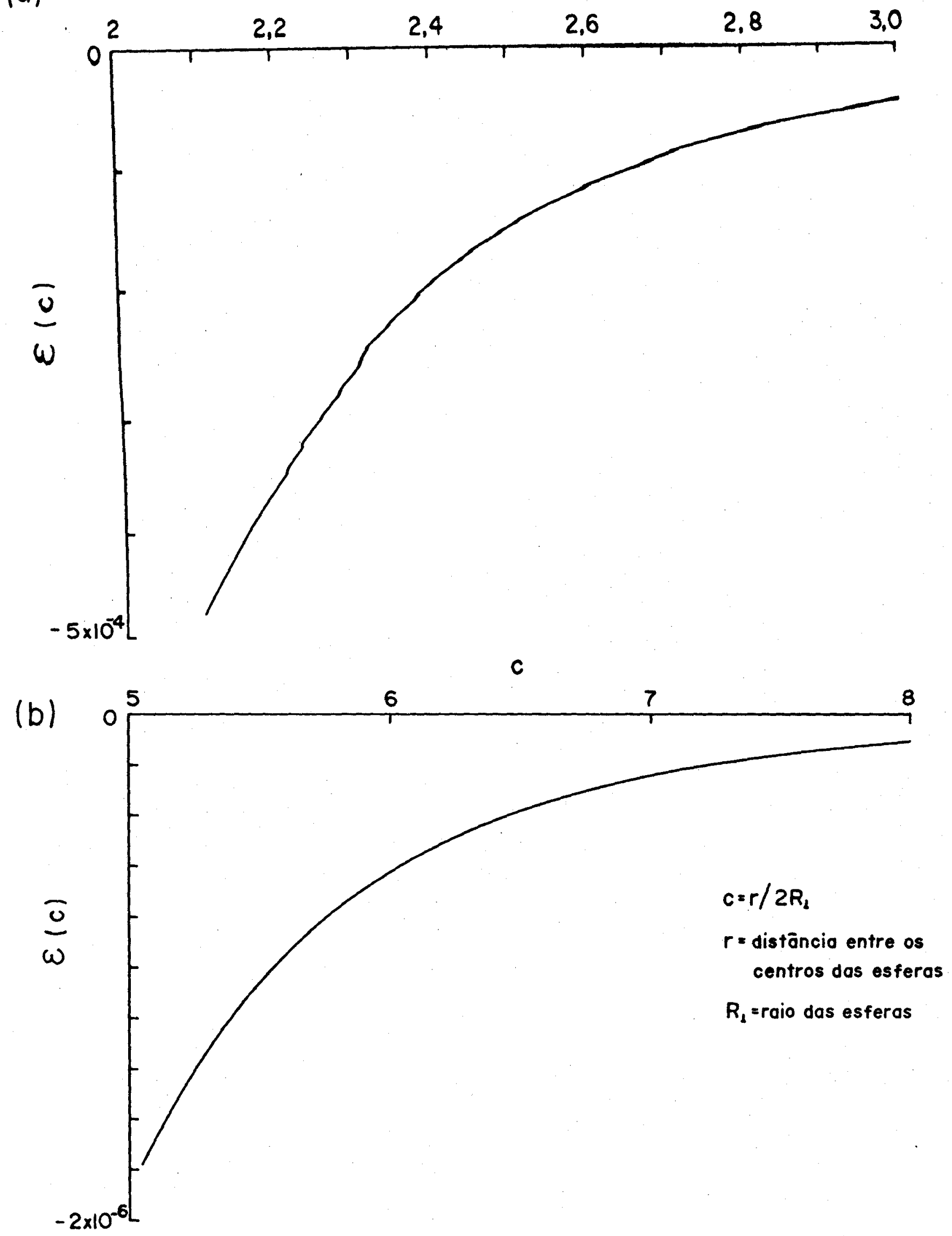

Figura 2-3

Energia Potencial devido a interação Van der Waals-London 
ção entre àtomos da esfera, $A_{22}$ entre os do meio e $A_{12}$ entre átomos da esfera e os do meio, utiliza-se para a constante de Hamaker a expressão equivalente $(1,5)$

$$
A=A_{11}+A_{22}-2 A_{12}
$$

2 - Efeito do retardamento na Atração "Van der Waals-London"

As forças Van der Waals-London são de natureza elétrica, e necessitam de um certo tempo para sua propagação. Na teoria de London o tempo é completamente negligenciado, uma vez que ele faz uso da equação de Schrödinger não relativistica(3). Quando as dis tâncias vão se tornando grandes faz-se necessāria uma correção relativistica.

As forças de Van der Waals-London são determinadas admitindo-se que um dipolo temporário de um àtomo pode induzir um dipolo num segundo àtomo. Porēm a velocidade finita de propagação da ação eletromagnētica, faz com que o dipolo induzido sofra a a ção do dipolo indutor atrasadamente, por um tempo igual a $r n / c$ con de $r$ é a distância entre os ātomos, $n$ o indice de refração do meio, e c, a velocidade da luz.) A reação dó dipolo induzido sobre o primeiro é retardado pelo mesmo tempo, e se ao cabo do tempo total de $2 r n / c$ a direção do primeiro dipolo é alterado por $90^{\circ}$, a força exercida é nula, e se é alterada por $180^{\circ}$, ao invés de uma a tração, teremos uma repulsão. 
Casimir e Polder (2) conseguiram dar uma descrição quāntica exata da influēncia do efeito do retardamento na teoria de Van der Waals-London. Eles mostraram que para distāncias relativamente grandes, a energia potencial na realidade é menor que a dada pela equação (2-1). A relação que obtiveram foi:

$$
E_{\text {ret }}=E_{\text {London }} \cdot f(p) \text {, }
$$

onde

$$
\begin{aligned}
p= & \frac{2 \pi r}{\lambda} \\
\lambda= & \text { comprimento de onda correspondente à fre- } \\
& \text { quência } \nu \text { das oscilações eletrōnicas prō- } \\
& \text { prias do àtomo. }
\end{aligned}
$$

e

$$
\begin{array}{ll}
f(p)=1,01-0,14 p ; & 0<p<3 \\
f(p)=\frac{2,45}{p}-\frac{2,04}{p^{2}} ; & 3<p
\end{array}
$$

Para valores grandes de $p$, a equação (2-13 b) ficarā:

$$
f(p)=\frac{2,45}{p}=\frac{2,45 \lambda}{2 \pi r}
$$


que levado à equação (2-12) dá

$$
E_{r t}=-\frac{2,45 \mu \lambda}{2 \pi r^{7}}
$$

onde usamos também a equação (2-1)

A ordem de grandeza de $\lambda \bar{e}: 10^{-5} \mathrm{~cm}$. Assim para $p \sim 10$, que corresponde a $r-200 \AA$, teremos

$$
E_{\text {ret }}=E \cdot(0,245)
$$

Desta forma para $p>10$, ou para $r>200 \AA$, o efeito do retardamento na energia entre dois átomos iguais, devido à intera ção de Van der Waals-London é significativa e, não é mais proporcional ao inverso da sexta potencia que os separa, mas sim da sétima potēncia.

Neste caso a equação equivalente à (2.2) ficarā:

$$
E_{\text {ret }}=\int_{v_{1}} q d v_{1} \int_{v_{2}}\left(-\frac{\mu \lambda}{r^{7}}\right) q d v_{2}
$$

e procedendo como no caso anterior, obteremos:

$$
E_{p}=-\pi \mu \lambda q \int_{R-R_{1}}^{R+R_{1}^{2}} \frac{1}{R r^{6}}\left[R_{1}^{2}-(R-r)^{2}\right] d r,
$$

onde $E_{p}$ é a energia potencial entre um àtomo e uma esfera de raio 
$R_{1}$ composta de $q$ àtomos por $\mathrm{cm}^{3}$, sendo que a distāncia entre seu centro e o àtomo é dado por R.

Integrando a equação (2-16) obteremos

$$
E_{p}=\frac{-\pi \mu \lambda q}{30 R}\left[\frac{3 R_{1}}{\left(R+R_{1}\right)^{4}}+\frac{3 R_{1}}{\left(R-R_{1}\right)^{4}}+\frac{1}{\left(R+R_{1}\right)^{3}}-\frac{1}{\left(R-R_{1}\right)^{3}}\right] .
$$

Assim, levando este resultado à equação (2-15) temos:

$$
E_{\text {ret }}=\int_{r-R_{2}}^{r+R^{2}} E_{p} \cdot q \pi \frac{R}{r}\left[R_{2}^{2}-(r-R)^{2}\right] d R
$$

ou

$E_{r e t}=\int_{r-R_{2}}^{r+R_{2}}\left[\frac{3 R_{1}}{\left(R+R_{1}\right)^{4}}+\frac{3 R_{1}}{\left(R-R_{1}\right)^{4}}+\frac{1}{\left(R+R_{1}\right)^{3}}-\frac{1}{\left(R-R_{1}\right)^{3}}\right] \cdot\left[R_{2}^{2}-(r-R)^{2}\right] d R$.

Novamente se fizermos $r=2 R_{1} C$, teremos:

$E_{\text {ret }}=-\frac{\pi^{2} \mu \lambda q^{2}}{R_{1}}\left\{\frac{1}{60 c}\left[\frac{-3 c^{4}+8 c^{2}-5}{\left(c^{2}-1\right)^{3}}+\frac{1}{c^{2}}+2 \ln \frac{c^{2}}{c^{2}-1}\right]\right\}$.

Na Figura (2-4), damos os resultados numéricos de

$$
\varepsilon_{R}=E_{\text {ret }} / B \text {, }
$$


onde $B$ equivale à constante de Hamaker e è definida por:

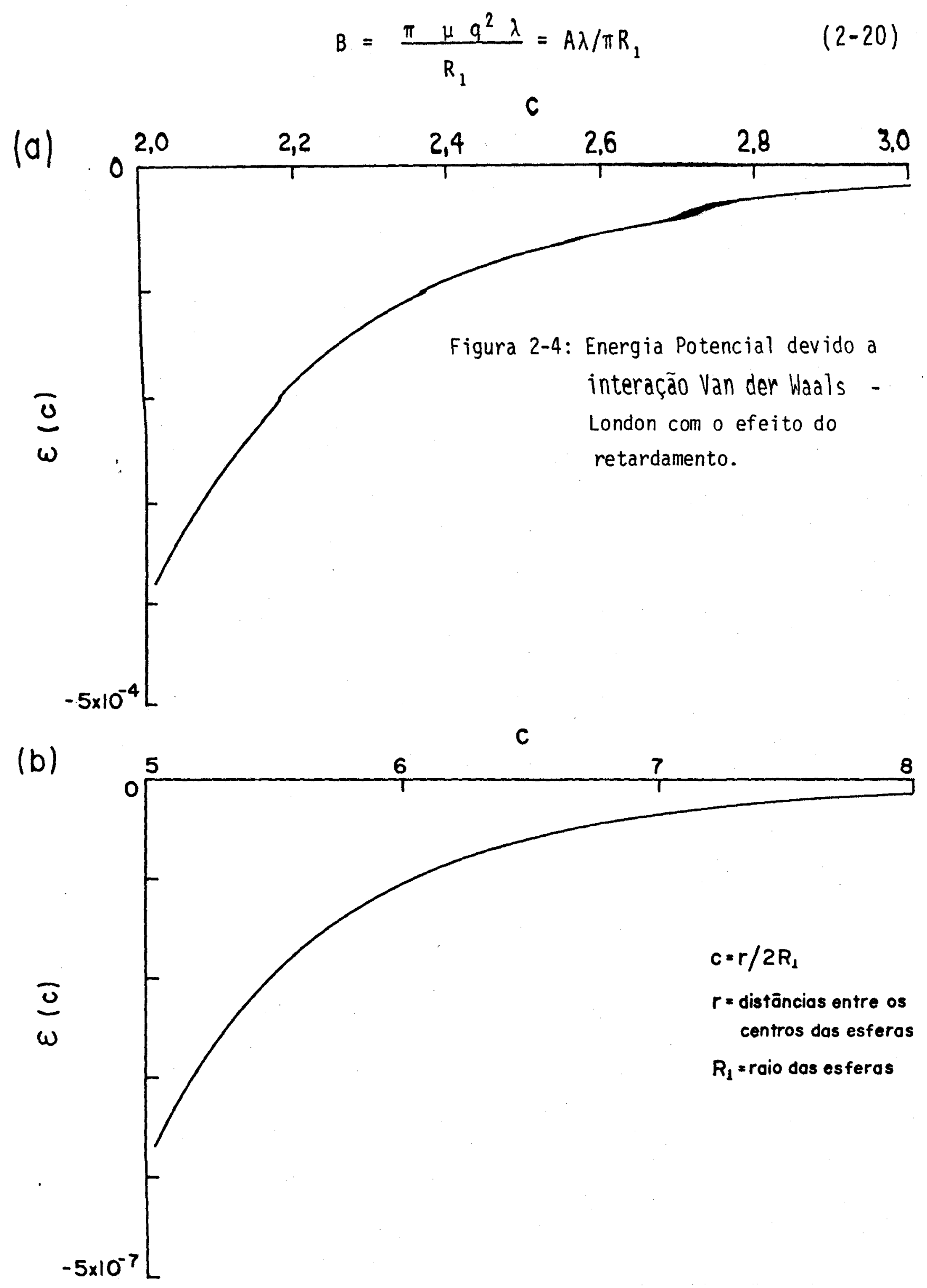




\section{Comentārio}

Para as considerações finais a respeito das interaçõesde Van der Waals-London em nosso sistema, consideraremos a equação $(2-19)$, is to $\bar{e}:$ levaremos em conta o efeito do retardamento. Is to $\bar{e}$ necessārio uma vez que as esferas de poliestireno começam a se cristalizar, quando a constante de rede $\bar{e}$ da ordem de oito vezes o diâmetro das esferas $(6,7)$, isto é: cerca de $8000 \AA$. Como vimos na equação (2-15) para distāncias maiores que $200 \AA$, o efeito da retardação é marcante.

Usando os valores para $A=10^{-13}$ ergs, $R_{1}=5.10^{-6} \mathrm{~cm} \mathrm{e}$ $\lambda=10^{-5} \mathrm{~cm}$, podemos então calcular a energia potencial entre duas esferas. Consideremos $C=2$, isto $\bar{e}$ a distància entre os centros das esferas igual a dois diâmetros das mesmas:

$$
E_{\text {ret }}(C=2) \approx-10^{-17} \text { ergs }
$$

Este valor vai diminuindo à medida que $C$ aumenta. Para $c=8$, teremos:

$$
E_{\text {ret }}(C=8)=-10^{-21} \text { ergs }
$$

Agora, consideremos a energia cinētica mēdia de translação por esfera, como sendo

$$
E_{T}=\frac{3}{2} k_{T}=10^{-13} \mathrm{ergs}
$$


De posse destes valores, podemos adiantar uma importante conclusão. Como vemos pela equação acima a energia potencial por partícula, em módulo é muito menor que a energia fornecida pela $\underline{a}$ gitação térmica. Portanto com estes valores nunca poderemos ter um sistema ordenado estāvel, mostrando assim a incompeténcia da força de Van der Waals-London para explicar a cristalização das esferas de poliestireno. 


\section{REFERENCIAS}

1. HAMAKER, H.C; Physica IV, n! 10, (1937)

2 - CASIMIR, H.B.G. and POLDER, D., Phys. Rev. 73, (4), 360, (1948); ZEICHNER, G.R. and SCHOWALTER, W.R.; J. of Colloid and Int. Science, vol. 71, 2, 239, (1979)

3 - LONDON, F., Transv. Faraday Soc. 33,19, (1937)

4 - SCHENKEL,J.H. and KITCHENER, J.A.; Trans. Faraday Soc., 56, 161 (1960)

5 - VERWEY, E.J.W. and OVERBEEK, G.; Theory of Stability of Lgophobic Colloids - Elsevier Publishing Company, Imc.- Amsterdan (1948)

6 - WILLIAMS, R. and CRANDALL, R.S., Phys. Letters Vol. 48A, no 3 , 225 (1974)

7 - UDO,M.K. Sobre a Cristalização de esferas de Poliestireno em suspensão aquosa. Tese apresentada para obtenção do titulo de Mestre em Ciências apresentada no Instituto de física e Ciēncias dos Materiais de São Carlos, USP, em Agosto/1979. 


\section{APENDICE A}

\section{FORÇAS DE VAN DER LONDON PARA O ATOMO DE HIDROGENIO}

Por questão de simplicidade obteremos o valor da energia de interação entre dois átomos de hidrogènio *.

Se a distäncia inter-nuclear entre dois àtomos de hidrogênio $R=r_{A B}$ for suficientemente grande, poderemos assumir para o sistema uma função de onda não perturbada do tipo produto de duas funções de onda de hidrogènio (1s).

$$
\psi^{0}=U_{1 S A}(1) \cdot U_{1 S B}(2)
$$

A perturbação para esta função consiste dos termos da energia potencial

$$
H^{\prime}=-\frac{e_{0}^{2}}{r_{B_{1}}}-\frac{e_{0}^{2}}{r_{A_{2}}}+\frac{e_{0}^{2}}{r_{A B}}+\frac{e_{0}^{2}}{r_{12}}
$$

onde

$$
\begin{aligned}
& r_{B_{1}} \text { : distāncia entre o nūcleo de } B \text { e o eletron de } A \\
& r_{A_{2}} \text { : distāncia entre o núcleo de } A \text { e o eletron de } B \\
& r_{A B} \text { : distāncia inter-nuclear } \\
& r_{12} \text { : distāncia entre os dois elétrons }
\end{aligned}
$$

Se os dois àtomos estiverem sobre o eixo $z$, poderemos ex 
pandir (A-2) em uma sērie de Taylor em potēncias inversas de $R=r_{A B}$.

$$
\begin{aligned}
H^{\prime}= & \frac{e_{0}^{2}}{R^{3}}\left(x_{1} x_{2}+y_{1} y_{2}-2 z_{1} z_{2}\right)+\frac{3}{2} \frac{e_{0}^{2}}{R^{4}}\left\{r_{1}^{2} z_{2}-r_{2}^{2} z_{1}+\right. \\
& \left.+\left(2 x_{1} x_{2}+2 y_{1} y_{2}-3 z_{1} z_{2}\right)\left(z_{1}-z_{2}\right)\right\}+ \\
& +\frac{3}{4} \frac{e_{0}}{R^{5}}\left\{r_{1}^{2} r_{2}^{2}-5 r_{2}^{2} z_{1}^{2}-5 r_{1}^{2} z_{2}^{2}-15 z_{1}^{2} z_{2}^{2}+\right. \\
& \left.+2\left(x_{1} x_{2}+y_{1} y_{2}+4 z_{1} z_{2}\right)^{2}\right\}+\ldots
\end{aligned}
$$

onde assumimos $R=r_{A B} \gg$ que as dimensões do àtomo e $x_{1}, y_{1}, z_{1}$ se refere as coordenadas do elētron do primeiro átomo relativamen te a seu nūcleo; $x_{2}, y_{2}, z_{2}$ são coordenadas do segundo elétron relativamente a seu nūcleo.

A primeira parcela do segundo membro da equação $(A-3)$, se refere à interação dos momentos de dipolo dos dois àtomos, a segunda, a interação de dipolo e quadripolo, a terceira de quadripo 10 quadripolo, etc...

Faremos somente os cālculos para a interação dipolo-dipo 10. Usaremos para isto a equação seguinte para perturbação de $2 a$. ordem :

$$
W_{K}^{\prime \prime}=\frac{\left(H_{1}^{\prime 2}{ }_{K K}\right)}{W_{K}^{0}}-\frac{\left(H_{K K}^{\prime}\right)^{2}}{W_{K}^{0}}+H^{\prime \prime}{ }_{K K}+\sum \frac{W_{\ell}^{0}}{W_{K}^{0}} \frac{H_{K \ell}^{\prime} H_{\ell K}^{H^{\prime}}}{W_{K}^{0}\left(W_{K}^{0}-W_{\ell}\right)}
$$


onde em nosso caso, $K=0$, e dai :

$$
\begin{aligned}
& \left(H^{\prime 2}\right)_{00}=\int_{V} \psi^{0 *\left(H^{\prime}\right)^{2} \psi^{0} d \tau} \\
& W_{0}^{0}=-\frac{l_{0}^{2}}{a_{0}}, \text { etc... }
\end{aligned}
$$

Então precisamos resolver a equação $(A-5)$, com

$$
H^{\prime}=\frac{e_{0}^{2}}{R^{3}}\left(x_{1} x_{2}+y_{1} y_{2}-2 z_{1} z_{2}\right)
$$

donde

$$
\left(H^{\prime 2}\right)_{\partial_{0}}=\frac{e_{0}^{4}}{R^{6}} \int \psi^{0 *}\left(x_{1}^{2} x_{2}^{2}+y_{1}^{2} y_{2}^{2}+4 z_{1}^{2} z_{2}^{2}\right) \psi^{0} d \tau
$$

onde excluimos os termos cruzados, pois suas integrais são nulas, ou

$$
\left(H^{\prime 2}\right)_{00}=\frac{2 e_{0}^{4}}{3 R^{6}} \int \psi^{0} * r_{1}^{2} r_{2}^{2} \psi^{0} d \tau=\frac{2 e^{4}}{3 R} \overline{r_{1}^{2}} \overline{r_{2}^{2}}
$$

Temos que o valor para $\overline{r^{2}} \bar{e}$ dado por:

$$
\overline{r^{2}}=\frac{a_{0}^{2} n^{4}}{Z^{2}}\left\{1+\frac{3}{2}\left[1-\frac{\ell(l+1)-1 / 3}{r^{2}}\right]\right\}
$$




$$
=-26-
$$

onde $a_{0} \bar{e}$ o raio de Bohr., e para o nosso caso

$$
\overline{r^{2}}=3 a_{0}^{2}
$$

assim, a equação (A-8) ficará:

$$
\left(H^{12}\right)_{00}=\frac{6 e_{0}^{4} 3_{0}^{4}}{R^{6}}
$$

Agora levando estes valores, equação $(A-6)$, e $(A-10)$ na equação $(A-4)$, teremos

$$
W_{0}^{\prime \prime}=-\frac{6 \mathrm{e}_{0}^{2} a_{0}^{5}}{R^{6}}
$$

Se fizermos $6 \mathrm{e}_{0}{ }^{2} \mathrm{a}_{0}{ }^{5} \rightarrow \mu, W_{0}^{\prime \prime} \rightarrow E$, teremos finalmente

$$
E=-\frac{\mu}{R^{6}}
$$

$$
\text { Com os valores } a_{0}=0,5285 \AA \text { e de } e_{0}=4,8 \cdot 10^{-10}
$$

St Coul, teremos

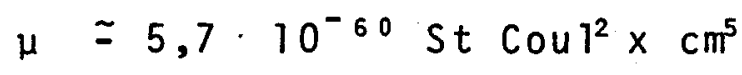

Agora se considerarmos $q-10^{23}$, podemos estimar o valor da constante de Hamaker**. 


$$
\begin{aligned}
& A=\pi^{2} q^{2} \mu \\
& A=5.10^{-13} \mathrm{ergs}
\end{aligned}
$$

* PAULING and WILSON, Introduction to Quantun Mechanics - McGraw Hill - New York - 1935

** HAMAKER, H.C., Physika 4, 1058 - 1937 


\section{CAPITULO III}

\section{POTENCIAL REPULSIVO}

\section{1 - Transição de Fase do Tipo "KIRKWOOD-ALDER"}

Em 1939 Kirkwood $^{(1)}$ verificou a interessante possibilida de de havertransição de fase num sistema de esferas duras, entre 0 estado líquido e o sōlido na ausēncia de potencial atrativo. Ele mencionou que num sistema constituido de esferas duras, a transição pode ocorrer quando a fração volumétrica das partículas excede um certo valor.

A partir de 1959 B.J. Alder (2) iniciou uma série de publicações sobre estudos em "Dinâmica Molecular". Acompanhando o crescente desenvolvimento dos computadores, foi possivel a Alder simular gases, lïquidos e um tipo especial de sōlido cristalino, constituido de esferas duras.

Neste processo, "Dināmica Molecular", cada elemento do sistema (que pode ser uma esfera) è acompanhado no intento de a cada instante conhecer sua posição e velocidade. Assim muitas pro priedades do sistema podem ser conhecidas. Por causa desta caracterīstica dināmica este processo foi inicialmente proposto para se estudar fenōmenos de relaxação e propriedades de transporte.

Utilizando este método Alder, Hoover e Young ${ }^{(3)}$ determinaram que no sistema de esferas duras, quando se tem uma fração volumētrica ao redor de 0,5 a transição $1 \overline{i q u i d o ~-~ s o ̄ l i d o ~ t e m ~ i n i ́-~}$ 
cio e se completa totalmente, quando temos uma fração volumétrica ao redor de 0,55 .

Evidència Experimental da Teoria de Kirkwood-Alder - Trabalhando com esferas de latex, Kose e Hashisu(4) conseguiram mostrar que a cristalização de esferas de latex monodispersas era devido ao empacotamento de esferas duras, conforme a teoria de Kirkwood-Alder. Num primeiro trabalho Kose e Hashisu(4) fizeram uma dispersão em benzeno $\left(\mathrm{C}_{6} \mathrm{H}_{6}\right)$, das esferas de latex, e verificaram que a transição lịquido - sólido teve inicio ao redor da fração volumétrica de 0,5 e quando a mesma atingiu a proximidade de 0,55 , to da dispersão encontrou-se na fase sōlida.

Algumas observações sobre esta experiēncia são importantes. Primeiramente o liquido dispersante, no caso o benzeno, foi escolhido a fim de não haver nenhuma interação elétrica entre as esferas do tipo dupla camada, pois não hă dissolução iōnica no benzeno. Em segundo lugar a semelhança na estrutura molecular entre o benzeno e o material escolnido por eles para as particulas, assegura que a interação de Van der Walls seja quase nula (ver equação (2-11) do capitulo anterior). E finalmente, para concentra ções cuja fração volumétrica se situa entre 0,5 e 0,55 há a coe xistēncia das duas fases, sōlido e lĩquido. "Cristalites" vão se formando e precipitam devido a sua maior densidade em relação ao meio ${ }^{(4)}$.

Hashisu S. e Kobayashi, Y. ${ }^{(5)}$, repetiram a experiēncia, 
só que agora com dispersão aquosa em que variavam a concentração de eletrōlitos. Eles prepararam uma dispersão de esferas de poliestireno com diāmetro mēdio de $1820 \AA$, em àgua com diferentes con centrações de $K C$. Obtiveram assim o diagrama de fase mostrado na Figura $(3-1)$.

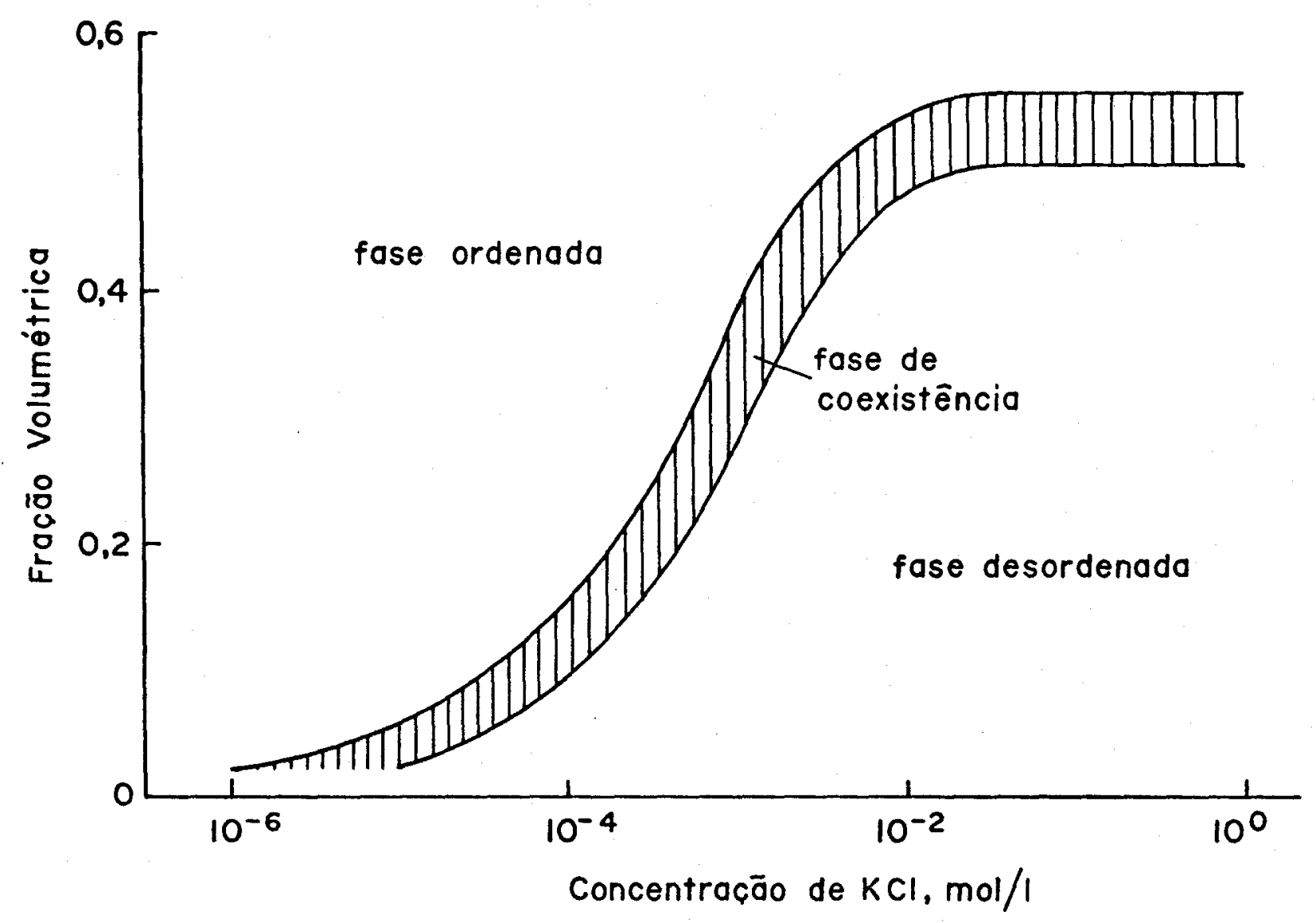

\author{
Figura $3-1$ \\ Diagrama de Fase
}

Neste ponto temos que fazer importantes conclusões basea das nos resultados apresentados pela Figura (3-1). Em primeiro lu 
gar podemos reforçar a ineficācia das forças de Van der Waals-Lon don para explicar a cristalização, pois, se a cristalização è causada por alguma força atrativa, com a diminuição da concentração de eletrōlito (que corresponde a um aumento na força repulsiva), precisaríamos de um aumento na concentração de esferas, e o que temos é exatamente o contrário. Por outro lado podemos interpre tar este resultado à luz da teoria de Kirkwood-Alder. Para altas concentrações de eletrōlitos, a parte difusa da dupla camada ao redor da partīcula, praticamente não existe. A medida que a concentração de eletrólito vai diminuindo a camada difusa vai se pro nunciando cada vez mais. Desta forma vemos pela figura (3-1) que para concentrações baixas de eletrōlito a fração volumētrica exi gida para obtenção da fase ordenada è muito inferior à prevista por Kirkwood-Alder sugerindo que as esferas passassem a ter um raio efetivo maior que o raio prōprio da esfera. Já no outro extremo, para concentrações superiores a $10^{-2}$ vol/litro de KCl, a camada difusa é praticamente inexistente e o volume a considerar è o volume prōprio de cada esfera, e a $\bar{i}$, a fração volumētrica exigida para o começo da cristalização é muito prōxima à prevista por Kirkwood-Alder.

Desta forma assumiremos que o mecanismo responsāvel pela transição de fase líquido-sólido no sistema de esferas de poliestireno é devido ao efeito Kirkwood-Alder, e nosso intento a par tir daqui é o de fazer um tratamento quantitativo deste sistema. Assim calcularemos a energia repulsiva do sistema, (e com 
esta finalidade dedicaremos o restante deste capitulo e o seguinte) com a intenção de confrontā-la com a energia atrativa devido às interações de Van der Waals-London, e evidenciar quantitativamente a ineficācia destas forças para a explicação da cristalização, alēm de nos fornecer elementos para explicarmos o ordena mento das esferas.

\section{2 - A Equação de Poisson-Boltzman}

A Dupla Camada Eletroquimica - O conceito da dupla camada foi introduzida por Gouy ${ }^{(6)}$ e Chapman $(7-18)$, e a representação matemát ca desta idēia é a equação de Poisson-Boltzmann. Esta equação sur ge, por exemplo, quando imaginamos uma partícula no interior de um liquido, e assumimos que algumas cargas da particula podem sair da mesma e ir para o liquido. Se admitirmos que a estatistica de Boltzmann vale, poderemos escrever:

19) A equação de Poisson deve ser verificada:

$\nabla_{0}(\varepsilon \mathbb{E})=4 \pi \rho$

$\varepsilon=$ constante dielétrica

$\rho=$ densidade de carga elétrica

20) As cargas que saem da partícula formam como se fosse uma nuvem ao seu redor. Agora se admitirmos que o meio onde se encontra a particula tem uma certa concentração de eletrōlito, teremos: 


$$
\rho=e_{0} \sum_{i=1}^{N} n_{i}^{0} z_{i} \exp \left(-U_{i} / k T\right)
$$

onde

$$
\begin{aligned}
& e_{0}=\text { carga elementar } \\
& N=n \text { o de espécies de ions } \\
& n_{i}^{0}=\text { concentração do ion "i" quando } U_{i}=0 \\
& z_{i}=\text { valência do ion "i" com seu respectivo sinal. } \\
& U_{i}=\text { energia do ion "i" } \\
& k=\text { constante de Boltzmann } \\
& T=\text { temperatura absoluta }
\end{aligned}
$$

Usando a relação $E=-\nabla \emptyset \mathrm{ma}$ is as equações $(3-1)$ e $(3-2)$ teremos:

$$
\nabla_{0}(\varepsilon \nabla \emptyset)=-4 \pi e_{0} \sum_{i=1}^{N} n_{i}^{0} z_{i} \exp \left(-U_{i} / k T\right),
$$

onde $\emptyset$ é o potencial elétrico mēdio

Esta é a equação de "Poisson-Boltzmann Generalizada".

Seu carāter geral reside no fato de não termos ainda explicitado a dependência da constante dielētrica $\varepsilon$ com o campo elétrico, nem o modelo para a energia $U_{i}$.

No nossocaso especīfico, usaremos coordenadas esféricas e faremos a aproximação $U_{i}=e_{0} z_{i} \emptyset$, isto é usaremos somente a energia de interação ion-campo. 
A Influência do Tamanho Finito dos fons na Distribuigão de Cargas Um fator que a equação de Poisson Boltzmann, da forma que está es crita em (3-3), não leva em conta é o tamanho finito dos ions. Em (3-3) é assumido que os ĩons são pontuais, porém em muitos casos, principalmente quando o valor (em módulo)do potencial elétrico é elevado, hegamos a valores para a concentração iônica muito acima de valores fisicamente possiveis. Por este motivo faremos uma correção na equação de Poisson-Boltzmann generalizada.

Vārias tentativas foram feitas, para levar em conta o ta manho finito dos jons, no cālculo da distribuição de íons (equa ção 3-2) $(10-12)$. Nōs empregaremos o mētodo desenvolvido por Wick e Eigen(11). Este método tem sido criticado(12), por não levar em conta a interação entre os ions positivos $\left(\mathrm{H}_{3}^{+} 0\right)$. As interações entre os ions positivos tornam-se significativas à medida que sua concentração aumenta, porém as altas concentraçōes ocorrem,em nos so sistema, nas proximidades da esfera numa fina camada. Também, resultados obtidos por esta aproximação tem-se comportado harmoni osamente com dados experimentais obtidos em medidas de capacidade de dupla camada(13). Além do mais esta é, sem dūvida, uma aproximação melhor que a de ions pontuais.

Usando a aproximação $U_{i}=e_{0} Z_{i} \emptyset$ na equação (3-2) teremos,

$$
\rho=e_{0} \sum_{i}^{N} z_{i} n_{i}(r)
$$


onde

$$
n_{i}(r)=n_{i}^{0} \exp \left(-e_{0} z_{j} \theta(r) / k T\right) \text {, }
$$

isto $\bar{e}: n_{i}(r) \bar{e}$ a concentração de ions do tipo $i$ no ponto $\underline{r}$.

E esta a equação, (3-5), que devemos modificar, pois a concentração $n_{j}(r)$ pode crescer indefinidamente, quando - e $e_{0} \emptyset(r) / k T>0$ cresce. Porém, os ions tem tamanho finito, e assim, por maior que seja o valor de $-e_{0} z_{j} \emptyset(r) / k T$, a concentra ção precisa atingir um valor māximo, determinado pelo volume ocupado por cada ion.

Vamos considerar uma camada esférica ao redor da esfera de poliestireno, com espessura $\Delta r$ o suficiente para que possamos

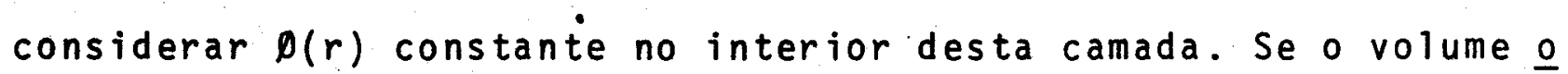
cupado pelo ion "i" $\bar{e} v$, teremos $N=1 / v$ células que devem ser ocupadas por $n_{j}(r)$ ions por unidade de volume. Então o número de céplulas vazias por unidade de volume será: $N-n_{j}(r)$. Agora se $\Delta V$ é o volume da camada esférica teremos $\Delta V / V=N \Delta V$ células, das quais $n_{j}(r) \Delta V$ são ocupados pelos ions de tipo "i" e $\left(N-n_{j}(r) \Delta V\right.$ restantes são vazias.

A função partição serā

$$
z=\sum_{i} g_{i} e^{-\varepsilon_{i} / e T}
$$

porēm, consideraremos um único tipo de ion na solução. Então $\varepsilon$ não precisa mais ser indexado, e $e^{(3-6)}$ fica sendo 


$$
z=g e^{-\varepsilon / k T}
$$

onde o peso estatîstico "g" é o número de combinações possīveis dos $n(r)$ ions ocuparem os NaV células disponiveis. $\varepsilon \bar{e}$ a energia do ion quando dentro da camada considerada.

Como estamos assumindo que a energia $\varepsilon \bar{e}$ apenas a ener gia de interação ion-campo, teremos:

$$
z=\left(\begin{array}{c}
\Delta V N \\
\Delta V n(r)
\end{array}\right) \cdot \exp \left[\begin{array}{llll}
-\Delta V e_{0} & n(r) \emptyset(r) / k T]
\end{array}\right.
$$

ou

$$
z=\frac{[\Delta V N] !}{[\Delta V n(r)] ! \cdot[\Delta V N-\Delta V n(r)] !} \exp \left[-\Delta V e_{0} Z n(r) \varnothing(r) / k T\right]
$$

Considerando a aproximação de Stirling: $x:=x^{x} e^{-x}$, teremos:

$$
z=\frac{(\Delta V N)^{\Delta V N} \cdot \exp [-\Delta V N] \cdot \exp \left[-\Delta V e_{0} Z n(r) \emptyset(r) / k T\right]}{[\Delta V n(r)]^{\Delta V n(r)} \cdot \exp [-\Delta V n(r)] \cdot[\Delta V(N-n(r))]^{\Delta V(N-n(r))} \cdot \exp [-\Delta V(N-n(r))]}
$$

A energia livre sendo dada por

$$
F(r)=-k T \frac{\partial \ln z}{\partial n(r)} \text {, }
$$

teremos efetuando a derivada 
$\frac{\partial \ln Z}{\partial n(r)}=\frac{\partial}{\partial n(r)}\left\{\ln \left[(\Delta V N)^{\Delta V N} \exp (-\Delta V N)\right]-\Delta V e_{0} Z n(r) D(r) / k T-\Delta V n(r) \ln [\Delta V n(r)]+\right.$

$$
+\Delta V n(r)-\Delta V(N-n(r)) \cdot \ln [\Delta V(N-n(r))]+\Delta V(N-n(r))\}
$$

ou,

$$
\frac{\partial \ln z}{\partial n(r)}=-\Delta V\left\{e_{b} \cdot z \emptyset(r) / k T+\ln \left[\frac{n(r)}{N-n(r)}\right]\right\} \text {, }
$$

fornecendo-nos a energia livre na forma

$$
F(r)=\Delta V k T \cdot\left\{e_{0} \cdot z \emptyset(r) / k T+\ln \left[\frac{n(r)}{N-n(r)}\right]\right\} \text {. }
$$

Considerando o sistema em equilibrio, todas as camadas devem ter a mesma energia livre. Tomando uma camada em $r$ e outra em $r_{S} \gg r$, teremos:

$$
e_{0} \cdot Z \varphi(r)+k T \ln \left[\frac{n(r)}{N-n(r)}\right]=e_{0} \cdot Z \varphi\left(r_{S}\right)+k T \ln \left[\frac{n\left(r_{S}\right)}{N-n\left(r_{S}\right)}\right]
$$

então

$$
\frac{n(r)}{n\left(r_{S}\right)} \cdot \frac{N-n\left(r_{S}\right)}{N-n(r)}=e^{-e \cdot \cdot 2\left[\emptyset(r)-\emptyset\left(r_{S}\right) / k T\right]} \text {, }
$$


e explicitando $n(r)$, teremos finalmente:

$$
n(r)=\frac{n\left(r_{S}\right) e^{-e_{0} \cdot z \Delta \phi / k T}}{1+\frac{n(r S)}{N}\left[e^{-e_{0} \cdot \Delta \theta / k T}-1\right]}
$$

onde

$$
\Delta \theta=\emptyset(r)-\emptyset\left(r_{S}\right)
$$

Assim sendo obtivemos a concentração $n(r)$ dos ions na posição $r$, em função da concentração dos ĩons na posição $n\left(r_{S}\right)$. Posteriormente escolheremos $r_{S}$ adequado para esta expressão. Podemos analisar agora os dois extremos:

a) Para $-e_{0} \cdot Z \Delta \emptyset / k T \gg 0$.

Neste caso teremos:

$$
n(r)=N
$$

portanto fornecendo um valor limite para a concentração.

b) Para $-e_{0} \cdot z \Delta \emptyset / k T \sim 0$, teremos:

$$
n(r)=n\left(r_{S}\right)\left[1-\frac{e_{0} \cdot Z \Delta \emptyset}{k T}\left(1-\frac{n\left(r_{S}\right)}{N}\right)\right] \text {, }
$$

mostrando assim, que também neste limite o tamanho dos ions têm 
importância.

Assim sendo, na equação de Poisson-Boltzmann generalizada (equação 3-3)

$\nabla 0(\varepsilon \nabla \theta)=-4 \pi e_{0} \cdot \sum_{i=1}^{N} n i(r)$,

pelo fato de estarmos considerando o caso particular em que a solução sō possui um tipo de ion, a somatōrica ni(r) fica sendo

$$
\sum_{i=1}^{N} n i(r)=n(r)=\frac{n\left(r_{S}\right) e^{-e_{j} Z \Delta \phi / k T}}{1+\frac{n}{N}\left[e^{-e_{S} \cdot Z \Delta \phi / k T}-T\right]}
$$

onde usamos a equação (3-14).

Então (3-3) com este resultado ficarā

$$
\nabla 0(\varepsilon \nabla \emptyset(r))=\frac{-4 \pi e_{0} \cdot n\left(r_{S}\right) e^{-e \cdot Z \Delta \emptyset / k T}}{1+\frac{n}{N}\left[e^{-e \cdot Z \Delta \emptyset / k T}-1\right]}
$$

A Dependência da Constante dielétrica em relaşão à intensidade do Campo Elétrico. Para desenvolvermos o membro esquerdo da equação (3-17), precisamos explicitar a dependencia de $\varepsilon$ (constante dielétrica da água) em relação a $r$. Em princīpio, pensamos em usar uma förmula obtida por Booth(19), porēm encontramos algumas faThas no procedimento por ele adotado, o que levou-nos a derivar $\underline{u}$ 
ma nova equação que relaciona $\varepsilon$ com o campo elétrico (15). A equação assim obtida foi:

$\varepsilon=n_{\infty}^{2}+4 \pi(N / V) \cdot \frac{3 \mu^{2}}{2 k T} \cdot \frac{\sum_{n=0}^{\infty} F_{1}(n) \sum_{p=0}^{n} P(n, p) \sum_{q=0}^{p} Q_{1}(p, q)}{\sum_{n=0}^{\infty} F_{2}(n) \sum_{p=0}^{n} P(n, p) \sum_{q=0}^{p} Q_{2}(p, q)}$

onde

$$
F_{2}(n)=\left[\frac{3}{2 k}\right]^{2 n} \cdot \frac{E^{2 n}}{(2 n+1) !} ; \quad F_{1}(n)=\frac{F_{2}(n)}{(2 n+3)} ;
$$

$P(n, p)=\left(\begin{array}{l}n \\ p\end{array}\right) 5^{n-p} ; Q_{1}(p, q)=\left(\begin{array}{l}p \\ q\end{array}\right) 8^{p-q} 12^{q} \cdot\left[\frac{1}{\xi(p-q)}+\frac{1}{3 \xi(q)}\right] ;$

$$
Q_{2}(p, q)=\left(\begin{array}{l}
p \\
q
\end{array}\right) 8^{p-q} 12^{q} \cdot\left[\frac{1}{\xi(p-q) \xi(p)}\right] ;
$$

$\xi(n)= \begin{cases}1 & \text { se } x=0 \\ 3 & \text { se } x \neq 0\end{cases}$

$n_{\infty}^{2}=$ indice de refração da āgua para comprimento de onda longos

$N / V=$ nūmero de moléculas por unidade de volume

$\mu$ = momento de dipolo da água na fase gasosa

$k=$ constante de Boltzmann

$T=$ temperatura absoluta. 
Como podemos ver, esta expressão é demasiadamente compli cada para se usar em cálculos computacionais quando estamos interessados em resolver juntamente outro problema, como no caso, a equação (3-17). Devido a estrutura de $(3-18)$ lembrar a função de Langevin, podemos aproximar esta equação por outra mais simples.

$$
\varepsilon=n_{\infty}^{2}+\frac{4 \pi N \mu_{v}\left(N_{\infty}^{2}+2\right)}{3 E V} \frac{A}{B} L\left(B \frac{\left(n_{\infty}^{2}+2\right)^{\mu_{V E}}}{2 k T}\right)
$$

onde

L é a função de Langevin $(L(x)=\operatorname{coth} x-1 / x)$, A e B são parâmetros ajustāveis e

$n_{\infty}=$ indice de refração da àgua para comprimento de onda longa.

$\mu_{v}=$ momento de dipolo da àgua no väcuo.

A figura 3-2, mostra o comportamento das duas equações $(3-18)$ e $(3-19)$. Os valores $A=2,18$ e $B=2,35$ foram ajustados de tal forma a se obter a melhor aproximação entre as duas equações. Usando as abreviações

$$
\begin{aligned}
& a=\frac{2 \pi \mu_{V}^{2}\left(n_{\infty}+2\right)^{2}}{9 \cdot V k T} A, \\
& B=\frac{\mu_{V}^{2}\left(n_{\omega}+2\right)}{2 k T} B
\end{aligned}
$$


e o fato que $I E=-\nabla D$, e para o nosso caso $E=-\frac{\partial \emptyset}{\partial r}=-\emptyset^{\prime}$, te remos

$$
\varepsilon=n_{\infty}^{2}-\frac{3 \alpha}{\beta \theta^{\prime}}\left[\operatorname{coth}\left(-\beta \phi^{\prime}\right)+1 / \beta \phi^{\prime}\right]
$$

Levando então este resultado à equação (3-17), e utịizando $\frac{\partial \emptyset}{\partial r}=\emptyset^{\prime} ; \frac{\partial^{2} \emptyset}{\partial r^{2}}=\emptyset^{\prime \prime}$ teremos

$$
\theta^{\prime \prime}+\left(\frac{2}{r}+\frac{\varepsilon^{\prime}\left(\phi^{\prime}\right)}{\varepsilon\left(\phi^{\prime}\right)}\right) \emptyset^{\prime}+\frac{4 \pi}{\varepsilon\left(\emptyset^{\prime}\right)} \rho(r)=0
$$

onde

$$
\varepsilon^{\prime}\left(\emptyset^{\prime}\right)=\frac{\partial}{\partial r}\left[\varepsilon\left(\phi^{\prime}\right)\right]
$$

$$
\rho(r)=\frac{e_{0} n\left(r_{S}\right) \exp \left(-e_{0} Z \Delta \emptyset / k T\right)}{1-\frac{n\left(r_{S}\right)}{N}\left[\exp \left(-e_{0} Z \Delta \theta / k T\right)-1\right]}
$$

Agora explicitando $\varepsilon^{\prime}\left(0^{\prime}\right)$ através da equação $(3-20)$ te remos,

$$
\varepsilon^{\prime}\left(\emptyset^{\prime}\right)=-3 \alpha \frac{\theta^{\prime \prime}}{\emptyset^{\prime}} \frac{1}{\operatorname{senh}^{2}\left(-\beta \emptyset^{\prime}\right)}+\frac{6 \alpha}{\beta} \frac{\theta^{\prime \prime}}{\emptyset^{\prime 3}}+\frac{3 \alpha}{\beta} \frac{\emptyset^{\prime \prime}}{\emptyset^{\prime 2}} \operatorname{coth}\left(-\beta \theta^{\prime}\right)
$$


Assim levando as equações $(3-19)$ e $(3-22)$ em $(3-21)$ teremos:

$$
\theta^{\prime \prime}+F\left(r, \phi, \theta^{\prime}\right)=0
$$

onde

$$
F\left(r, D \emptyset^{\prime}\right)=\frac{2 \phi / r+4 \pi \rho / \varepsilon\left(\emptyset^{\prime}\right)}{1-\frac{3 \alpha}{\varepsilon\left(\emptyset^{\prime}\right) \operatorname{senh}^{2}\left(-B \phi^{\prime}\right)}+\frac{6 \alpha}{\varepsilon\left(\emptyset^{\prime}\right) \beta \emptyset^{\prime 2}}+\frac{3 \alpha}{\varepsilon\left(\emptyset^{\prime}\right) \beta \emptyset^{\prime}} \operatorname{coth}\left(-\beta \emptyset^{\prime}\right)}
$$

A equação (3-23) è uma equação diferencial de segunda or dem não linear. A solução da mesma serā assunto do prōximo capītú 10 .

\section{3 - O Modelo da Célula - Energia Repulsiva}

Consideremos uma única esfera de poliestireno colocada na àgua. Ions $\mathrm{H}^{+}$oriundos dos radicais $-\left[\mathrm{SO}_{3} \mathrm{H}\right]$ presos à superfīcie da esfera se desprenderão e irão naturalmente para o meio aquoso na forma de $\mathrm{H}_{3}^{+} 0$. A agitação tērmica por sua vez tentarā espalhar os ions $\mathrm{H}_{3}^{+} 0$ por todo o volume Porém existe a atração elétrica entre os ions $\mathrm{H}_{3}^{+} \mathrm{O}$ e os radicais $-\left[\mathrm{SO}_{3}^{-}\right]$presos na superficie da esfera. Desta forma estabelecido o equilibrio, a situação se nos apresenta por uma esfera carregada negativamente, cir- 


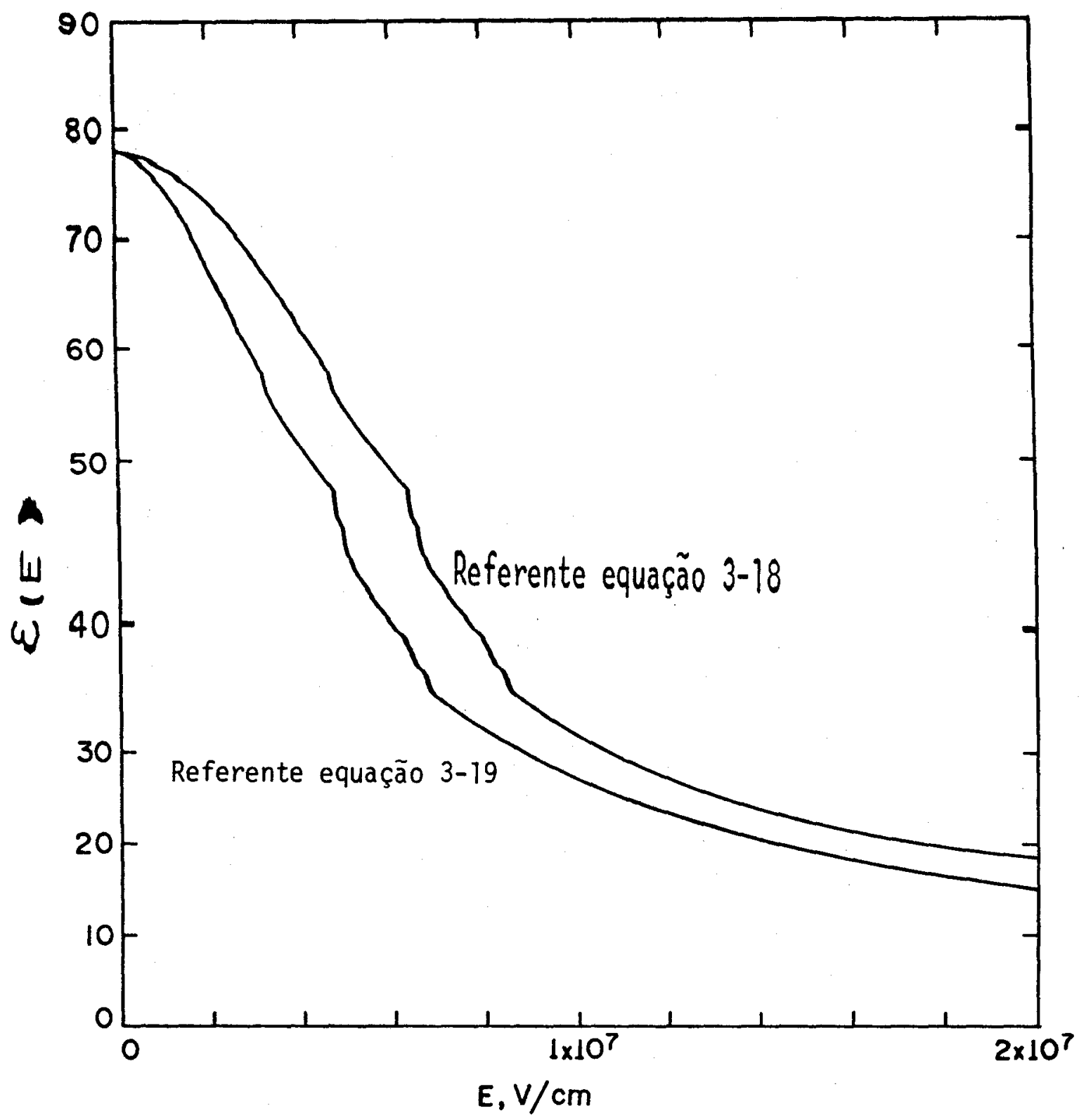

Figura $3-2$

Constante dielētrica da āgua

cundada por uma nuvem tambēm esférica de cargas positivas, cuja densidade vai decrescendo à medida que nos afastamos da esfera.

De posse destas idéias podemos agora estabelecer que para qualquer mudança na forma da nuvem, ou seja na distribuição de cargas, criarā forças que tenderão levar o sistema para o antigo equilibrio, pois aquele foi assumido naturalmente. 
Neste ponto introduziremos o que rotulamos de "modelo da cēlula".

Imaginemos inicialmente uma dispersão de muito baixa den sidade de esferas de poliestireno. Estas esferas, juntamente com sua camada difusa constituída de hidrōnio $\left(\mathrm{H}_{3}^{+} \mathrm{O}\right)$,permanecem em movimento no interior do liqquido dispersante (no nosso caso a $\bar{a}-$ gua). Eventualmente uma esfera se aproxima de outra, porém, logo que as camadas difusas de hidrogēnio começam a se sobrepor, uma força começa a agir no sentido de afastā-las. Podemos imaginar ca da esfera dispersa, com uma energia cinētica mēdia, fornecida pe la agitação tērmica. Desta forma a aproximação māxima, em mēdia, que uma esfera pode alcançar em relação a outra, serā determinada por sua energia cinētica e pela força de repulsão oriunda da superposição das camadas difusas de niarōnio. Neste sentido podemos falar de um "raio efetivo" da esfera de poliestireno.

Agora tomaremos o outro extremo, e imaginaremos uma solú ção de alta concentração, e vamos nos valer do fato que estas esferas nestas condições (al ta concentração; ausēncia de qualquer ou tro ion, a não ser o hidrōnio; etc.), se arranjam periodicamente, isto é, constituem um cristal. Nesta condição, a de cristal, pode mos então procurar ver como as cargas de $\mathrm{H}_{3}^{+} 0$ se arranjam por entre as esferas de poliestireno. Como a carga total é nula, e os ions ocupam lugares regulares, podemos imaginar uma superficie fe chada envolvendocada esfera de poliestireno, de forma que contenha um número tal de ions $\mathrm{H}_{3}^{+} 0$ que faça com que sua carga total seja igual, em mōdulo, à carga da esfera. Evidentemente esta superfí - 
cie deve ser igual para todas as esferas de poliestireno.

Esta superfície com o seu conteúdo, é o que constitui a "cèlula".

No presente trabalho, faremos a aproximação na qual esta superficie é esférica. Isto pode ser sugerido pelo desenho abaixo (figura 3-3). A presença de vārias esferas distribuidas por todos os lados, farão com que esta superficie se aproxime da de uma esfera.

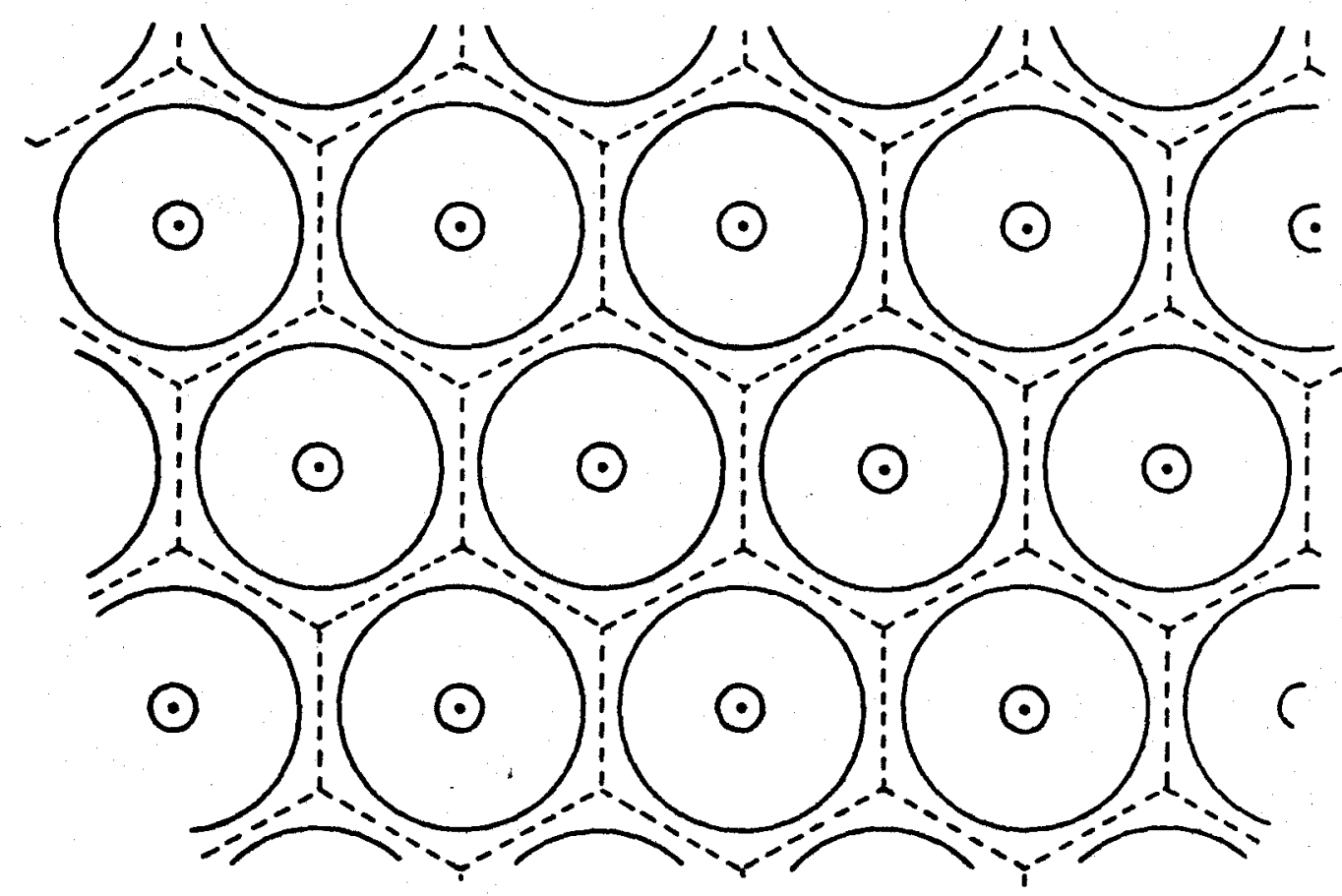

Figura $3-3$

o Modelo da Cétula

Cālculo da energia repulsiva para o modelo da célula. Imaginemos um sistema constituĩdo de uma ūnica esfera de poliestireno com sua dupla camada elétrica, no interior de um certo volume de água. Suponhamos que este volume seja esférico e que este, com a esfera de poliestireno, seja concēntrico. Vamos supor também que 
este volume de āgua seja suficientemente grande para que as paredes do recepiente que o contēm não venha influir significativamen te na distribuição de ĩons.

Feito isto calcularemos a energia do sistema de dupla ca mada, is to é a energia de formação da distribuição de ions, na sua conforma ção natural. Chamaremos esta energia de $E_{\infty}$. Podemos agora pensar numa superfície esférica semipermeāvel hipotética, que permita pas sar por ela moléculas de $\mathrm{H}_{2}{ }^{0}$, porém não permita passar as moléculas de $\mathrm{H}_{3}^{+} 0$. Inicialmente esta superficie tem o mesmo raio que 0 recipiente do nosso sistema, mas faremos seu raio diminuir muito vagarosamente, de tal modo que atinjamos um outro estado, reversí vel e isotermicamente.

Agora nosso sistema estā perturbado, no sentido que a ca mada difusa exerce uma pressão sobre a superfície semipermeāvel. Neste ponto calcularemos a energia do sistema de dupla camada,que chamaremos ES.

Desta forma definiremos a energia potencial repulsiva do sistema como:

$$
V_{R}=E_{S}-E_{\infty}
$$

que è a energia necessāria para comprimir os ions $\mathrm{H}_{3}^{+} 0$, no sentido estabelecido acima.

Vamos agora imaginar este sistema acima descrito, representando a célula do nosso sistema de esferas de poliestireno. As sim sendo calcularemos a energia potencial da célula através da 
definição feita na equação (3-25).

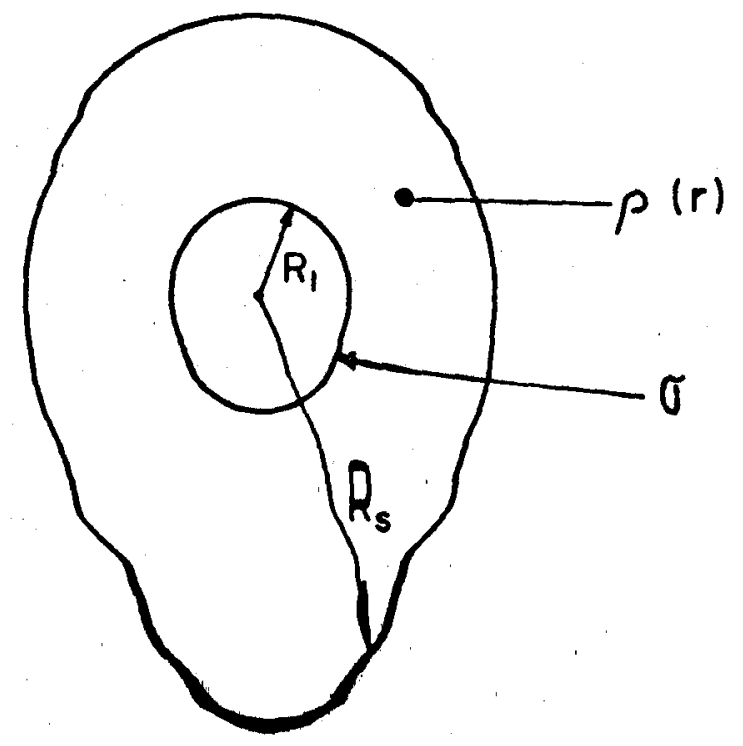

Figura $3-4$

Uma cēlula com distribuição de cargas na

camada difusa dada por $\rho(r)$ e na camada

superficial por $\sigma$

Tomemos como referéncia a figura (3-4), onde procuramos representar uma cêlula de raio $R_{S}$ com a esfera de poliestireno tendo raio $R_{1}$.

Para o cālculo da energia de formação deste sistema, procederemos da seguinte maneira:

a) Inicialmente, calcularemos a energia Wa necessāria para construir a camada difusa, constituida de hidrōnio, contendo carga total $+Q$

b) Depois calcularemos a energia wb para se distribuir $\underline{u}$ ma carga -Q uniformemente sobre a esfera de raio $R_{j}$.

Assim sendo a energia total do sistema serā: 


$$
E_{s}=W a+W b
$$

a) Podemos expressar wa como:

$$
W_{a}=\frac{1}{8 \pi} \int_{v} E^{2} d v
$$

o campo elétrico E, por causa da simetria esférica da distribuição de cargas $\rho(r)$, é nulo para $r<R_{1}$, e se estendede $r=R_{1}$ até $r \rightarrow \infty$.

Então expressaremos a equação (3-27), em duas parcelas:

$$
W a=\frac{1}{8 \pi} \int_{R_{1}}^{R_{S}} E^{2} 4 \pi r^{2} d r+\frac{1}{8 \pi} \int_{R_{S}}^{\infty} E^{2} 4 \pi r^{2} d r
$$

Para $R_{1} \leqq r<R_{S}$, o campo elétrico será dado por:

$$
E(r)=\frac{\int_{1}^{r} 4 \pi r^{\prime 2} \rho\left(r^{\prime}\right) d r^{\prime}}{\varepsilon r^{2}}
$$

Mas, usando a equação de Poisson para simetria esférica:

$$
\frac{1}{r^{2}} \frac{d}{d r}\left(r^{2} \frac{d \emptyset}{d r}\right)=-\frac{4 \pi}{\varepsilon} \rho(r)
$$




$$
\begin{aligned}
& E(r)=\frac{-\left[r^{\prime 2} \frac{d \phi}{d r}\right]^{r} R_{1}}{r^{2}} \\
& E(r)=\frac{\alpha}{r^{2}}-\phi^{\prime}(r)
\end{aligned}
$$

onde $\quad \phi^{\prime}=\frac{d \emptyset}{d r^{\prime}} \quad\left(\emptyset(r)\right.$ e $\emptyset^{\prime}(r)$ devidos à camada difusa $)$

$$
\alpha=R_{1}^{2} \emptyset^{\prime}\left(R_{1}\right) ; \varphi^{\prime}=\frac{d \emptyset}{d r}
$$

Assim sendo

$$
E^{2}(r)=\frac{\alpha^{2}}{r^{4}}-\frac{2 \alpha \theta^{\prime}(r)}{r^{2}}+\phi^{2}(r)
$$

$$
\begin{aligned}
\text { Para } r \geqq R_{S} \text {, a expressão para o campo elétrico serā } \\
E(r)=\frac{Q}{\varepsilon r^{2}}
\end{aligned}
$$

Da $\mathfrak{i}$

$$
E^{2}(r)=\frac{Q^{2}}{\varepsilon^{2} r^{4}}
$$

Portanto a equação (3-28) ficarā: 
$W a=\frac{1}{2}\left\{\alpha^{2} \int_{R_{1}}^{R_{S}} \frac{d r}{r^{2}}-2 \alpha \int_{R_{1}}^{R_{S}}\left(\frac{d \emptyset}{d r}\right) \cdot d r+\int_{R_{1}}^{R_{S}} r^{2}\left(\frac{d \emptyset}{d r}\right)^{2} d r+\frac{Q^{2}}{\varepsilon^{2}} \int_{R_{S}}^{\infty} \frac{d r}{r^{2}}\right\}$

$W a=\frac{1}{2}\left\{\alpha^{2}\left[\frac{1}{R_{1}}-\frac{1}{R_{S}}\right]+2 \alpha\left[\varphi\left(R_{1}\right)-\emptyset\left(R_{S}\right)\right]+\int_{R_{1}}^{R_{S}} r^{2}\left(\frac{d \emptyset}{d r}\right)^{2} d r+\frac{Q^{2}}{\varepsilon^{2} R_{S}}\right\}$,

Consideremos a desigualdade:

$$
\int_{Q_{1}}^{Q_{S}} r^{2}\left(\frac{d \emptyset}{d r}\right)^{2} d r<\int_{R_{1}}^{R_{S}} 4 \pi r^{2}\left(\frac{Q}{\varepsilon r^{2}}\right)^{2} d r=\frac{4 \pi Q}{\varepsilon^{2}}\left(\frac{1}{R_{1}} \cdot \frac{1}{R_{S}}\right)
$$

que se verifica pois o segundo membro da desigualdade acima, se refere a uma distribuição superficial das cargas sobre a esferade raio $R_{1}$, e o primeiro membro se refere a uma distribuição de car gas entre as duas superficies esféricas de raio $R_{1}$ e $R_{S}$.

Definiremos uma quantidade de Wa', onde usaremos no lü gar do valor da integral do lado esquerdo da desigualdade (3-36)o valor da integral do lado direito da mesma desigualdade. Portanto $W^{\prime}{ }^{\prime}>$ Wa, e teremos isto em mente quando formos somar as energias para obtermos a energia total do sistema, logo mais. Da $i$ 
$W a^{\prime}=\frac{1}{2}\left\{\alpha^{2}\left[\frac{1}{R_{1}}-\frac{1}{R_{S}}\right]+\frac{2 \alpha}{\varepsilon}\left[\theta\left(R_{1}\right)-\theta\left(R_{S}\right)\right]+\frac{4 \pi Q^{2}}{\varepsilon^{2}}\left[\frac{1}{R_{1}}-\frac{1}{R_{s}}\right]+\frac{Q^{2}}{\varepsilon^{2} R_{S}}\right\}$

b) Quando da resolução da equação de Poisson-Boltzmann, um dado que resulta conhecido, é o do potencial na superficie da esfera de poliestireno.

Pressupondo este conhecimento é que escolhemos este méto do para obtermos a energia do sistema.

Seja então $\emptyset_{+}$o potencial na superficie interna da distribuição de cargas $\rho(r)$ da célula, devido a prōpria distribui ção $\rho(r)$. Wb serā então a energia necessāria para trazer a carga - Q desde o infinito, em porções infinitesimais -dQ, até a superfície da esfera de poliestireno de raio $R_{1}$, onde ela è dis tribuida uniformemente. Desta forma teremos:

$$
\begin{aligned}
& \Delta E_{0}=\theta_{+}(-\Delta Q) \\
& \Delta E_{1}=\left(\theta_{+}-\frac{\Delta Q}{\varepsilon R_{1}}\right)(-\Delta Q) \\
& \Delta E_{2}=\left(\theta_{+}-\frac{2 \Delta Q}{\varepsilon R_{1}}\right)(-\Delta Q) \\
& \cdot \\
& \cdot \\
& \Delta E_{m}=\left(\theta_{+}-\frac{m \Delta Q}{\varepsilon R_{1}}\right)(-\Delta Q)
\end{aligned}
$$


Assim sendo

$$
W b=\theta_{+} \sum_{n-1}^{m}(-\Delta Q)+\sum_{n=1}^{m} \frac{n \Delta Q}{\varepsilon R_{1}} \Delta Q
$$

Agora passando ao limite, is to $\bar{e} \Delta Q \rightarrow 0$, e fazendo

$$
\left.\begin{array}{rl}
n Q & =\alpha Q \\
\Delta Q & =Q d \alpha
\end{array}\right\} \quad \alpha \rightarrow(0,1)
$$

teremos

$$
W b=-Q \theta_{+}+\int_{0}^{1} \frac{\alpha Q^{2}}{\varepsilon R_{1}} d \alpha
$$

donde

$$
W b=-Q Q_{+}+\frac{1}{2} \frac{Q^{2}}{\varepsilon R_{1}}
$$

Porēm, podemos escrever:

$$
\theta_{R_{S}}=\theta_{+}-\frac{Q}{\varepsilon R_{1}}
$$

onde $\emptyset_{R_{s}} \bar{e}$, o referido acima, potencial na superficie da esfera. Desta forma: 


$$
W b=-Q \theta_{R_{S}}-\frac{1}{2} \frac{Q^{2}}{\varepsilon R_{2}}
$$

Assim sendo, $E_{s}^{\prime}=W^{\prime}+W b \operatorname{ser} \bar{a}$

$$
\begin{aligned}
E_{S}^{\prime}=-\left\{Q Q_{R_{S}}\right. & \left.+\frac{1}{2} \frac{Q^{2}}{\varepsilon R_{1}}\right\}+\frac{1}{2}\left\{\alpha^{2}\left[\frac{1}{R_{1}}-\frac{1}{R_{S}}\right]+\frac{2 \alpha}{\varepsilon}\left[\phi\left(R_{1}\right)-\theta\left(R_{S}\right)\right]\right. \\
& \left.+\frac{4 \pi Q^{2}}{\varepsilon^{2}}\left[\frac{1}{R_{1}}-\frac{1}{R_{S}}\right]+\frac{Q^{2}}{\varepsilon^{2} R_{S}}\right\}
\end{aligned}
$$

Quando $R_{S} \rightarrow \infty$, teremos

$$
\begin{aligned}
E_{\infty}^{\prime}=-\left\{Q Q_{\infty}+\frac{1}{2} \frac{Q^{2}}{\varepsilon R_{1}}\right\}+ & \frac{1}{2}\left\{\alpha^{2} \cdot \frac{1}{R_{1}}+\frac{2 \alpha}{\varepsilon}\left[\emptyset\left(R_{1}\right)-\emptyset(\infty)\right]+\right. \\
& \left.+\frac{4 \pi Q^{2}}{\varepsilon^{2}} \cdot \frac{1}{R_{1}}+\frac{Q^{2}}{\varepsilon^{2} R_{S}}\right\}
\end{aligned}
$$

onde $\emptyset_{\infty}$ significa o potencial na superficie da esfera, quando $R_{s}+\infty$. Assim podemos calcular a energia potencial definida na equação $(3-25)$ :

$$
V_{R}^{\prime}=E_{S}^{\prime}-E_{\infty}^{\prime}
$$




$$
V_{R}=Q\left(\theta_{\infty}-\theta_{R_{S}}\right)+\frac{1}{2}\left\{-\frac{\alpha^{2}}{R_{S}}-\frac{2 \alpha}{\varepsilon} O\left(R_{S}\right)-\frac{4 \pi Q^{2}}{\varepsilon^{2} R_{S}}\right\}
$$

Agora vamos comparar os valores da primeira parcela com os da segunda no segundo membro da equação (3-45).

Para is to relacionamos abaixo a ordem de grandeza paraos valores da equação $(3-45)$
i) $Q\left(\emptyset_{\infty}-\emptyset_{R_{S}}\right)-10^{-9}$ ergs para $R_{S}=5 R_{1}$
ii) $Q\left(\emptyset_{\infty}-\emptyset_{R_{S}}\right) \sim 10^{-10}$ ergs para $R_{S}=15 R_{1}$

(Obs.: Os dados acima, i e ii, estão no capitulo V)

$$
\alpha=R_{1}^{2} \phi^{\prime}\left(R_{1}\right)=0
$$

$$
\begin{aligned}
& \frac{4 \pi Q^{2}}{\varepsilon^{2} R_{S}}-2.10^{-12} \text { ergs para } R_{S}=5 R_{1} \\
& \frac{4 \pi Q^{2}}{\varepsilon^{2} R_{S}}-6,6.10^{-13} \text { ergs para } R_{S}=15 R_{1}
\end{aligned}
$$


Assim vemos que a segundaparcela do segundo membro da equação (3-45) è despresível em relação a primeira parcela. Como a discrepāncia anunciada na equação $(3-36)$ e $(3-37)$ está contida nes ta segunda parcela posso por

$$
\begin{gathered}
v_{R}^{\prime}=v_{R}, e \\
V_{R}=Q\left(\theta_{\infty}-\theta_{R_{S}}\right)
\end{gathered}
$$

onde $Q$ è a carga total em módulo da esfera

$D_{\infty}$ é o valor do potencial na superficie da esfera quando $R_{S} \rightarrow \infty$

DR $S$ è o valor do potencial na superficie da esfera para um dado $R_{S}$

Desta forma a equação (3-46) é a energia potencial de uma célula, ou a "Energia Potencial do Sistema por Esfera".

A Equąão de Poisson-Boltzmann para o Modelo da Célula. A crista1 ização de esferas de poliestireno ocorre quando principalmente dois fatores tomam valores adequados. Estes fatores são: a concentração de esferas (nūmero de esferas por $\mathrm{cm}^{3}$ ) e a concentração de ions estranhos (eletrōlitos) no sistema. Quando os ions estranhos são removidos do sistema por tratamento com resina trocadora de ions $(16,17)$ a cristalização começa a ocorrer a partir da concentra 
ção de $\sim 10^{12}$ esferas $/ \mathrm{cm}^{3}$, para esferas de $1090 \AA$ de diāmetro (16) Desta forma assumiremos em nosso modelo, a não existēn ciade ions estranhos. Assim somente os ions $\mathrm{H}_{3}^{+} \mathrm{O}$ estarão presen tes no sistema, alēm das esferas carregadas negativamente.

Faremos tambēm a aproximação de que a constante dielétri ca é invariāvel de ponto a ponto. Isto é razoāvel pois como veremos a seguir, para o caso que estamos estudando o campo elétrico no interior da solução não é suficientemente grande para alterar significantemente o valor da constante dielétrica. Desta forma cal cularemos o valor do campo elétrico na superfície da partículaque por causa da esferecidade sua e da dupla camada o campo elétrico aí, è mais intenso.

$$
E_{0}=\frac{-4 \pi \sigma}{\varepsilon\left(E_{0}\right)}, \sigma>0
$$

Aqui surge a dificuldade de não termos uma relação linear entre a carga superficial $\sigma$, e a intensidade do campo elétri co $E_{0}$, na superfície. Porém, quanto menor $\varepsilon\left(E_{0}\right)$, maior $E_{0}$. Desta forma usando a Figura 3-2, assumiremos o valor da saturação da constante dielétrica que é ao redor de 20 . Como para o nosso caso $\sigma=6,3$. St.Coul $/ \mathrm{cm}^{2}$ (ver cap. I) teremos seguramente que:

$$
E_{0}<1,5 \cdot 10^{6} \mathrm{Volts} / \mathrm{cm} \text {. }
$$

Desta forma vemos que este campo é insuficiente para al- 
terar a constante dielétrica significantemente pois conforme a Figura 3-2, vemos que o valor da constante dielétrica para este valor é muito prōximo de 78 .

Então usando constante dielētrica invariāvel, admitindo um só tipo de ions, os $\mathrm{H}_{3}^{+} 0$, e usando a equação (3-21), teremos:

$$
\emptyset^{\prime \prime}+\frac{2 \emptyset^{\prime}}{r}+\frac{4 \pi}{\varepsilon} \rho(r)=0
$$

E usaremos as condições de contorno:

$$
\begin{aligned}
& \emptyset_{0}^{\prime}=E_{0} \\
& \emptyset_{R_{S}}^{\prime}=0
\end{aligned}
$$

onde

$$
\begin{aligned}
& \emptyset_{0}^{\prime}=\left(\frac{d}{d r} \emptyset\right)_{r=R_{1}}=\frac{4 \pi \sigma}{\varepsilon} \\
& \emptyset_{R_{S}}=\left(\frac{d}{d r} \emptyset\right)_{r=R_{S}},
\end{aligned}
$$

ou seja, usaremos os conhecidos valores do campo elétrico na su perficie e o valor nulo para o campo elétrico na superficie exter na da célula. Aí o campo elétrico deve ser nulo (em média) pois a carga liqquida dentro de cada célula é nula. 


\section{REFERENCIAS}

1 - KIRKWO0D, J.G., J. Chem, Phys. 7, $919-(1939)$

2 - ALDER, B.J. and WAINWRIGHT,T.E., J. Chem. Phys. 31,2,459 (1959)

3 - ALDER, B.J., HOOVER,W.G., and YOUNG,D.A., J.Chem. Phys. $49,8,3.688(1968)$

4 - KOSE, A. and HASHISU,S,, J. Colloid and Interf. Science. $46,3,460(1974)$

5- HASHISU, S., KOBAYASHI, Y., J. Colloid and Interf. Science. $46,3,470(1974)$

6 - GOUY,G., J. Phys. 9, 457 (1970)

7 - CHAPMAN, D.Z., Phyl. Mag. 25, 475 (1913)

8 - VERWEY and OVERBEEK. "Theory of the Stability of Lyophobic Colloids" Elsevier Publishing Company, Inc. - Amsterdam (1948)

9 - Referência 8 - pag. 41

10 - LEVINE,S., and BELL, G.M., "J.Phys. Chem. 64, 1188 (190)

11 - WICKE,E., and Eigen, M.Z. Elektro Chem. 56, 551 (1952)

12 - HUCKEL,E., and KROFFt,g.Z. Phys. Chem. NF 3,135 (1955)

13 - BRODOWSKY, H., and STREHLOW, H.Z. Elektro Chem. 63,262(1959)

- BRODOWSKY, H., and STREHLOW, H.Z. Elektro Chem. 64,891(1960)

- STREHLOW, H., and KNOCHE,W.Z.Phys Chem. NF 36,133 (1963)

14 - BOOTH, F.J. Chem. Phys. 19, 391 (1951) 
15 - A ser publicado.

16 -WILLIAMS, R., and CRANDALL,R.S., Phys.Letters, vo1.48-A, nọ, $225-1974$

17 - UDO, M.K., Tese de Mestrado apresentada no Inst. F.Q. de São Carlos - 1979 .

18 - A primeira teoria quantitativa da estrutura da dupla-camada $\dot{e}$ usualmente associada ao nome de HELMHOLTZ (2853) em trabalhos sobre interface metal-solucão. De acordo com Helmholtz esta dupla camada pode ser representada por duas superficies paralezas carregadas com a mesma quantidade de carga porém de sinal diferente. Posteriormente GOUY e CHAPMAN introduziram a dupla camada com uma delas, sendo difusa. 


\section{CAPITULO IV}

RESOLUÇAO NUMERICA DA E.P.B.

Existência e Unicidade da Solução. Verificaremos a existēncia e unicidade da solução para um intervalo finito $\left(0, R_{p}\right)$. Seja a equação diferencial não linear de segunda ordem, na forma.

$$
\theta^{\prime \prime}=f\left(r, \emptyset, \theta^{\prime}\right)
$$

e a questão de existência e unicidade de solução satisfazendo as condições de contorno

$$
\left\{\begin{array}{l}
\emptyset(0)=\emptyset_{0} \\
\phi\left(R_{p}\right)=\emptyset_{p}
\end{array}\right.
$$

Então enunciaremos o seguinte teorema*:

"Seja $f\left(r, \emptyset, \theta^{\prime}\right)$ contīnua para $0 \leqq r \leqq R_{p}$ para todos $\left(\varphi, \theta^{\prime}\right)$ e satisfazendo uma condição de Lipschitz com respeito a $\emptyset$ e $\emptyset^{\prime}$ na forma

$\left\|f\left(r, \theta_{1}, \theta_{1}^{\prime}\right)-f\left(r, \theta_{2}, \theta_{2}^{\prime}\right)\right\| \leqq \theta_{0} \cdot\left\|\theta_{1}-\theta_{2}\right\|+\theta_{1} \cdot\left\|\theta_{i}-\emptyset_{2}^{\prime}\right\|(4-2)$ com constantes de Lipschitz $\theta_{0}$ e $\theta_{1}$ tão pequenos que : 


$$
\frac{\theta_{0} R_{p}^{2}}{8}+\frac{\theta_{1} R_{p}}{2}<1
$$

Então (4-1) tem uma ünica solução que satisfaz (4-1 a)!"

Se tomarmos a igualdade (4-2) teremos o teorema da média. Portanto a desigualdade é satisfeita em geral quando

$$
\left\{\begin{array}{l}
\theta_{0}=\max \frac{\partial f}{\partial \emptyset} \\
\theta_{1}=\max \frac{\partial f}{\partial \theta^{\prime}}
\end{array}\right.
$$

A equação (4-1) para o nosso caso é da forma

$$
\theta^{\prime \prime}=-\left\{\frac{2 \theta^{\prime}}{r}+\frac{A \exp (-\alpha \theta)}{B+C\left(\exp \left(-\alpha \theta^{\prime}\right)\right.}\right\}=f\left(r, \emptyset, \theta^{\prime}\right)
$$

Com A, B, C, $\alpha>0$.

Assim para obtermos (4-3 a) e (4-3 b) teremos que fazer

$$
\begin{aligned}
& \frac{\partial f}{\partial \emptyset}=0 \\
& \frac{\partial f}{\partial \emptyset^{\prime}}=0
\end{aligned}
$$


Destas equações obtemos as condições

$$
\begin{aligned}
& \theta_{0}=\frac{\alpha A(B-C)}{B^{2}} \quad e \\
& \theta_{1}=\varepsilon_{1} \text { (tão pequeno quanto se queira) }
\end{aligned}
$$

Agora levando estes resultados à equação(4-2 a) temos

$$
\frac{\alpha A(B-C)}{8^{2}} \cdot \frac{R_{p}^{2}}{8}+\frac{\varepsilon_{1}{ }^{R} p}{2}<1
$$

que nos fornece

$$
R_{p}^{2}<\frac{8 B^{2}}{\alpha A(B-C)}
$$

ou seja, conseguimos um intervalo para $0<r<R_{p}$ onde a solução $\bar{e}$ única**, em função dos parāmetros A,B,C, e $\alpha$.

Para o nosso caso específico (ver equação (4-5) à frente)

temos que

$$
\begin{aligned}
& A=4 \pi n\left(R_{S} \varepsilon_{0},\right. \\
& B=\varepsilon, \quad(\text { constante dielétrica da à gua) } \\
& C=\frac{\varepsilon n\left(R_{S}\right)}{N}, e \\
& \alpha=e_{0} / k T
\end{aligned}
$$


0 intervalo da concentração de esferas de poliestireno que estamos interessados neste trabalho é de $\left[10^{12}-10^{14}\right]$ esferas/ $\mathrm{cm}^{3}$. Desta forma as constantes acima residem no intervalo

$$
\begin{aligned}
& A+\left[10^{2}-10^{6}\right] \\
& B \rightarrow 78 \\
& C+-10^{-6} \\
& \alpha+-10^{4}
\end{aligned}
$$

que resulta:

a) No extremo esquerdo do intervalo para $A$ :

$$
R_{p} \cong 2 \cdot 510^{-2} \mathrm{~cm}
$$

b) No extremo direito do intervalo para $A$ :

$$
R_{p} \equiv 2 \cdot 510^{-4} \mathrm{~cm}
$$

que em termos do raio $R_{1}$ das esferas $1090 \AA$ significa no caso:
a) $R_{p} \cong 4,6 \cdot 10^{3} R_{1}$
b) $R_{p} \cong 46 R_{1}$,

valores estes que estão dentro do intervalo que pretendemos integrar a equação (4-1). 
o Método de RUNGE-KUTTA de 4a. Ordem: Problemas de valores iniciais. Como é do conhecimento, não existem métodos analíticos gerais para integrar equações diferenciais não lineares sujeitas a condições de contorno. Portanto precisamos aplicar um método numé rico para integrar a equação $(3-49)$.

Quando se pode escolher um método definido de integração dā-se preferéncia ao método que reduz o problema de valores de contorno para um problema equivalente de valores iniciais. Estes métodos são razoavelmente seguros e jä estão bem desenvolvidos (1) Por isso aplicaremos o método de Runge-Kutta de 4 a. ordem(2). Primeiramente colocaremos a equação (3-49) em sua forma mais explicita:

$$
\theta^{\prime \prime}=-\left\{\frac{2 \phi^{\prime}}{r}+\frac{4 \pi e_{0} n\left(r_{s}\right) \exp \left(-e_{0} z \Delta \emptyset / k T\right.}{\varepsilon\left[1+\frac{n\left(r_{s}\right)}{N}\left(\exp \left(-e_{0} \Delta \emptyset / k T\right)-1\right)\right]}\right\} \text {. }
$$

Cada esfera ocupa um volume $\Omega=1 / \eta$ (onde $\eta \bar{e}$ a concentração de esferas de poliestireno). No caso do nosso problema

* Philip Hartman - Ordinary Diferencial Equations. John Wiley \& Sons, Inc., New York - London - Sydney - pag. 422

** Is to não quer dizer que a solução não seja ūnica para $R_{p}$ maio res. 0 teorema aqui apresentado garante que neste intervalo $\left(0-R_{p}\right)$ a solução ē única, mas nada garante para $R_{p}$ maior. 
$n\left(r_{S}\right)$ se refere à concentração de ions na posição $r_{S}=R_{S}$, onde $R_{s}$ è o raio do volume esférico $\Omega\left(\frac{4 \pi}{3} R_{S}^{3}=\Omega\right)$. Como estamos considerando um único tipo de ion, o hidrōnio $\left(H_{3}^{+} 0\right)$, teremos que $Z=1$. Assim,

$$
\emptyset^{\prime \prime}=-\left\{\frac{2 D^{\prime}}{R}+\frac{4 \pi e_{0} n\left(R_{S}\right) \exp \left(-e_{0} \Delta \varphi / k T\right.}{\varepsilon\left[1+\frac{n\left(R_{S}\right)}{N}\left(\exp \left(-e_{0} \Delta \varphi / k T\right)-1\right]\right.}\right\} \text {. }
$$

As condições de contorno são:

$$
\left\{\begin{array}{l}
\dot{\rho}^{\prime}\left(r=R_{1} ; R_{S}\right)=\frac{4 \pi \sigma}{\varepsilon} ; \sigma>0 \\
\emptyset^{\prime}\left(r=R_{S} ; R_{S}\right)=0,
\end{array}\right.
$$

onde evidenciaremos em $\emptyset$, além da variāvel de posição $r$, tambēm o parâmetro $R_{s}$. Assim procederemos, pois nossos cālculos serão efetuados para diversas concentrações, cujo valor exprimimos em termos de $R_{S}$.

Entretanto o método de Runge-Kutta implica no conhecimen to do valor do potencial e de sua derivada em um dado ponto. Infe lizmente as equações (4-6) nos fornecem somente valores da deriva da do potencial em pontos distintos. Por isto, utilizaremos a equação (4.6 a) e determinaremos o valor inicial $\emptyset\left(r=R_{1} ; R_{S}\right)$ inte rativamente, como veremos adiante. 
Portanto, pressupondo conhecidos $D$ e $\theta^{\prime}$ no ponto $r=R_{1}$, prosseguiremos nosso cālculo da seguinte maneira:

A equação (4-5) pode ser posta na forma

$$
\theta^{\prime \prime}=F\left(r, \phi, \phi^{\prime}\right)
$$

onde

$$
F\left(r, \phi, \theta^{\prime}\right)=-\left\{\frac{2 \varphi^{\prime}}{r}+\frac{4 \pi e_{0} n\left(R_{s}\right) \exp \left(-e_{0} \Delta \theta / k T\right)}{\varepsilon\left[1+\frac{n\left(R_{s}\right)}{N}\left(\exp \left(-e_{0} \Delta \theta / k T\right)-1\right)\right]}\right\},
$$

que é uma equação diferencial de $2 a$. ordem e, pode ser facilmente transformada num sistema de duas equações diferenciais de la. ordem.

$$
\text { Fazendo } \begin{aligned}
u \equiv \emptyset^{\prime} ; \quad v \equiv \emptyset \text { teremos: } \\
\left\{\begin{array}{l}
u^{\prime}-F(u, v)=0 \\
v^{\prime}=u
\end{array}\right.
\end{aligned}
$$

com valores iniciais,

$$
\left\{\begin{array}{l}
v_{0}=\theta\left(r=R_{1} ; R_{S}\right), \\
u_{0}=\theta^{\prime}\left(r=R_{1} ; R_{S}\right) .
\end{array}\right.
$$

Agora podemos aplicar o Método de Runge-Kutta de 4 a. ordem. Este método numérico para resolver um problema de valor ini- 
cial é um processo que dá soluções aproximadas em pontos particulares utilizando somente as operações de adição, subtração, multi plicação e divisão e cālculos funcionais. Quando dizemos que um método numērico é de $4 a$. ordem, isto significa que o mesmo só é exato para polinōmios de grau $\leqq 4$.

0 Mētodo de Runge-Kutta para o sistema de equações (4-8) com valores iniciais dados por (4-9), consiste em obter os valores de $u=D^{\prime}$ e $v=\emptyset$ para um ponto $R_{1}+h$, uma vez conhecidos os valores de $\emptyset\left(R_{1}\right)$ e $\emptyset^{\prime}\left(R_{1}\right)$. De posse dos valores de $\emptyset\left(R_{1}+h\right)$ e $D^{\prime}\left(R_{1}+h\right)$ podemos calcular, reaplicando o método, os valores de $\emptyset(r)$ e $\emptyset^{\prime}(r)$ para $r=R_{1}+2 h$. E assim sucessivamente.

os valores de $\emptyset(r+h)$ e $\emptyset^{\prime}(r+h)$ em função de $\emptyset(r)$ e $\emptyset^{\prime}(r)$ são dados por:

$$
\begin{aligned}
& \theta_{n+1}=\theta_{n}+\frac{1}{6}\left(k_{1}+2 k_{2}+2 k_{3}+k_{4}\right) ; \theta_{n}=v_{n} \\
& \theta_{n+1}^{\prime}=\theta_{n}+\frac{1}{6}\left(l_{1}+2 l_{2}+2 l_{3}+l_{4}\right) ; \theta_{n}^{\prime}=u_{n},
\end{aligned}
$$

onde

$$
\begin{aligned}
& k_{1}=h \cdot u_{n} \\
& l_{1}=h \cdot F\left(r_{n}, \theta_{n} \cdot \theta_{n}\right) \\
& k_{2}=h \cdot\left(u_{n}+\frac{1}{2} \ell_{1}\right) \\
& l_{2}=h \cdot F\left(R_{n}+\frac{1}{2} h \cdot \theta_{n}+\frac{1}{2} k_{1}, \theta_{n}+\frac{1}{2} l_{1}\right)
\end{aligned}
$$




$$
\begin{aligned}
& k_{3}=h \cdot\left(u_{n}+\frac{1}{2} \ell_{2}\right) \\
& \ell_{3}=h \cdot F\left(r_{n}+\frac{1}{2} h, \theta_{n}+\frac{1}{2} R_{2}, \theta_{n}+\frac{1}{2} \ell_{2}\right) \\
& k_{4}=h \cdot\left(u_{n}+l_{3}\right) \\
& \ell_{4}=h \cdot F\left(r_{n}+h, \theta_{n}+k_{3} ; \theta_{n}^{1}+l_{3}\right)
\end{aligned}
$$

sendo que "h" è o passo de integração, e o processo è facilmente compreendido pela anālise das equações (4-10 a 4-12).

Processo Interativo para encontrar $\phi\left(r=R_{1} ; R_{s}\right)$. Conforme pressupomos que conhecemos $\emptyset\left(r=R_{1} ; R_{S}\right)$ e $\theta^{\prime}\left(r=R_{1} ; R_{S}\right)$, falta discutirmos a maneira para determinar $\emptyset\left(r=R_{1} ; R_{s}\right)$ consistentemente de maneira que a condição de contorno (4-6 b) se verifique.

De acordo com a unicidade da solução teremos que para um dado valor de $\emptyset^{\prime}\left(r=R_{l}, R_{S}\right)$, is to é para um dado valor do campo e létrico na superfície da esfera, somente existirá um único valor de $\emptyset\left(r=R_{1} ; R_{S}\right)$, isto é um único valor do potencial na superficieda esfera, que fará com que o campo elétrico no limite da cēlula em $R_{S}$ seja nulo, is to é $D^{\prime}\left(r=R_{S} ; R_{S}\right)=0$.

Desta forma, com algum critério, escolhemos um valor para o potencial $\emptyset\left(r=R_{1} ; R_{S}\right)$ e integraremos a equação $(4-5)$ pelo mê todo contido em (4-10). Se o valor escolnido não for o correto, o campo elétrico em $R_{S}$ (isto é, no extremo da cēlula) não serā nulo.

Apōs algumas integrações da equação (4-5) notamos que se escolhermos para $\emptyset\left(r=R_{l}, R_{S}\right)$ um valor menor que o correto,o cam 
po elētrico faz-se zero $\left(\theta^{\prime}(r)=0\right)$ para $r<R_{S}$. Se por outro la do $\theta\left(r=R_{j} ; R_{S}\right)$ for maior que o valor correto, o campo elétrico seră nulo para $r>R_{S}$. Este comportamento está ilustrado na Figura (4-1) abaixo:

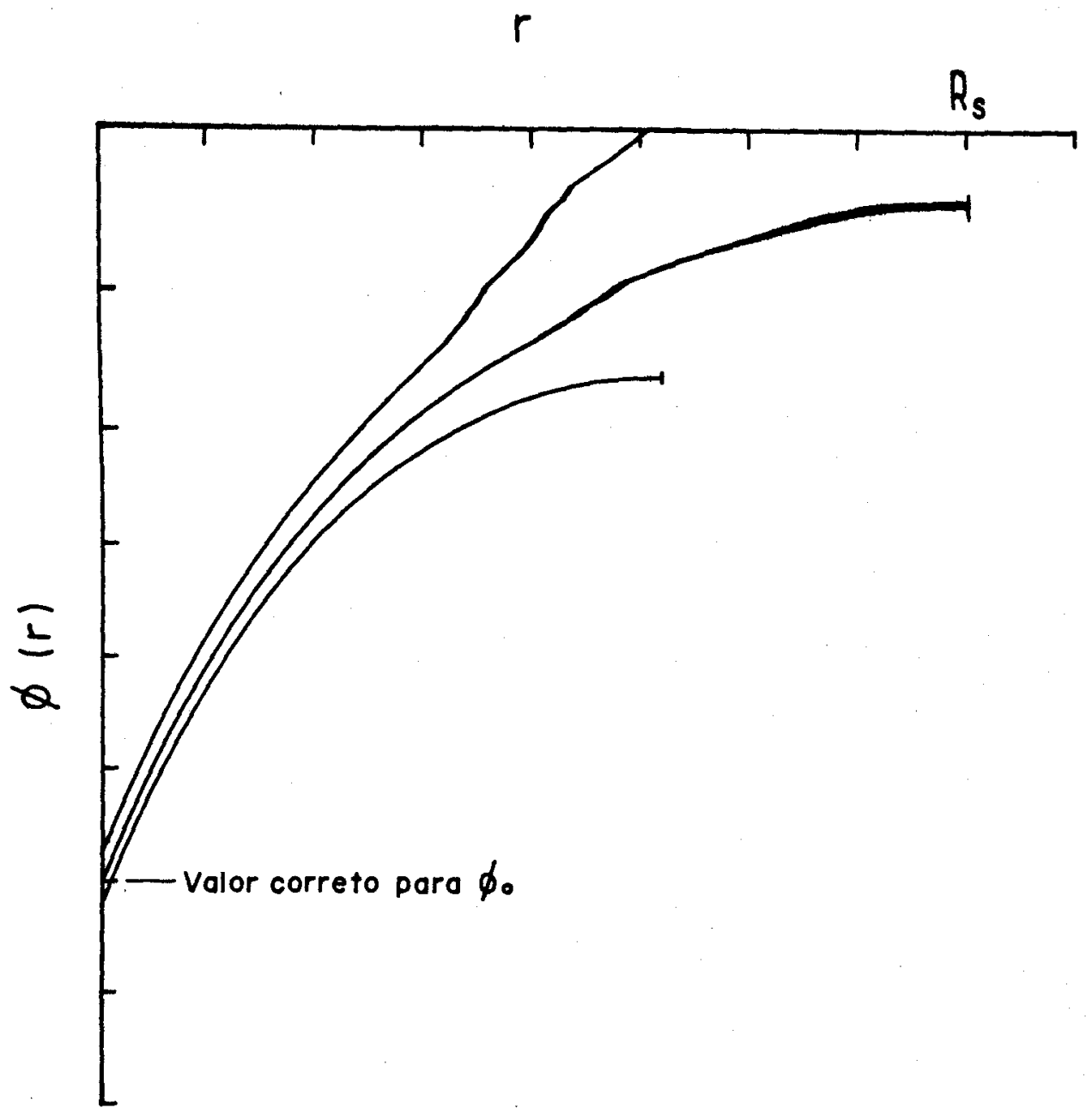

Figura 4-1

0 valor para o potencial na superficie $\emptyset\left(r=R_{1} ; R_{S}\right)$, com que começamos a resolução da equação (4-5), foi a metado do valor minimo para o potencial fisicamente possivel na superficie da esfera. Este potencial é aquele que se obtém quando consideramos so mente a esfera carregada sem sua camada difusa 


$$
\theta_{\text {min }}=\frac{-11-}{\varepsilon R_{1}}=5,7 \times 10^{-3} \text { StVolts, }
$$

onde

$$
\begin{aligned}
& Q=\text { carga total da esfera } \\
& R_{1}=\text { raio da esfera } \\
& \varepsilon=\text { constante dielétrica do meio }(\equiv 78)
\end{aligned}
$$

Lançando este valor inicial, e se a condição de $\emptyset\left(r=R_{S}\right.$; $\left.R_{S}\right)=0$ não for satisfeita, verifica-se se $\phi^{\prime}(r)=0$ está ocorren do antes ou depois de $R_{S}$. Se ocorrer antes, um acréscimo de $50 \%$ $\bar{e}$ adicionado ao potencial inicial. Se $\phi^{\prime}(r)=0$ esta ocorrendo depois de $R_{S}$, subtrai-se $50 \%$ do valor do potencial.

De posse do novo valor para $\emptyset\left(r=R_{l} ; R_{S}\right)$ o processo se repete, no intento de obter uma nova solução da equação (4-5). A partir deste ponto toda correção a ser feita em $\emptyset\left(r=R_{1}, R_{s}\right)$ será adicionando ou subtraindo metade do ūltimo valor adicionado em (ou subtraĩdo de) $\theta\left(r=R_{1} ; R_{S}\right)$.

Desta forma, cada correção em $\theta\left(r=R_{1} ; R_{5}\right)$ que é feita, le va a um valor mais prōximo do $\emptyset\left(r=R_{1} ; R_{s}\right)$ correto, com a única exceção da primeira correção, que pode levar a um valor mais distante do valor correto.

Na Figura 4-2 damos o fluxograma deste processo interati vo. E importante notar que o fluxo segue sempre no sentido descen dente e da esquerda para a direita, a menos que se indique o contrārio através de uma seta. Outra observação è a de que os peque- 
nos circulos numerados, significam ponto de união quando dois des tes cīrculos possuem o mesmo número.

O Processo Interativo para Normalizacão: $\int \rho d r=-Q$. Parte do pro blema está resolvido quando encontramos o valor correto para $O\left(r=R_{1} ; R_{s}\right)$. Porém a solução obtida, $\theta(r)$, deve ser tal que se verifique:

$$
\int_{v} \rho d N=\int_{R_{1}}^{R_{S}} \frac{4 \pi e_{0} n\left(R_{S}\right) \exp \left[-e_{0} \emptyset / k T\right]}{\varepsilon\left(1+\frac{n\left(R_{S}\right)}{N}\left(\exp \left[-e_{0} \emptyset / k T\right]-1\right)\right)}=Q
$$

onde

$$
Q=0 \text { mōdulo da carga total na superficie da esfera }
$$

o único parāmetro que podemos variar agora e que em prin cipio é desconhecido, $\bar{e} n\left(R_{S}\right)$ que é o valor da concentração de ions $\mathrm{H}_{3}^{+} 0$ no extremo da célula.

Desta forma iniciaremos a solução da Equação de Poisson-Boltzz mann (4-5), com um determinado valor de $n\left(R_{S}\right)$, e depois. de encon trar o valor do potencial na superficie, $\varphi\left(r=R_{1} ; R_{S}\right)$ e obtermos a solução da E.P.B.,procederemosa integral (4-14). Se o valor da inte gral for diferente de $Q$ por uma quantidade maior que um certo valor pré-determinado, criteriosamente mudamos $n\left(R_{s}\right)$, e retorna mos ao estágio inicial das contas. 
o processo interativo que usaremos para encontrar o valor de $n\left(R_{s}\right)$ que satisfaça $(4-14)$ é muito parecido ao processo pa ra se determinar $\emptyset\left(r=R_{1} ; R_{S}\right)$.

0 fluxograma do processo interativo referente à normalização da solução da E.P.B. estā feito na Figura 4-3.

Para o caso que queremos analisar, a esfera tem uma carga total $-Q=-5.10^{3} \mathrm{e}_{0}$, de forma que aceitaremos como boa apro $x$ imação quando

$$
\left|-Q+\int_{r} \rho d v\right|<10 e_{0} .
$$

Desta forma se a condição acima (equação (4-15)) não foi satisfeita, nōs precisamos verificar os dois casos:
a) $-Q+\int_{V} \rho d v<0$
b) $-Q+\int_{V} \rho d v>0$.

Vamos supor que tenha ocorrido o caso (a). Então faz-se necessārio alterar o valor de $n\left(R_{s}\right)$ e resolver a Equação de Poisson-Boltzmann (4-15) novamente. Nós verificamos que se resolver mos a E.P.B. agora com um valor $n\left(R_{s}\right)$ maior que o anterior (aquele que levou ao resultado (a)), o valor da integral 4.14 aumentou.Por tanto: 


$$
\begin{aligned}
& \text { se }-Q+\int_{V} \rho d v<0+n\left(R_{S}\right)+\Delta n\left(R_{S}\right) \quad \text { ou } \\
& \text { se }-Q+\int_{V} \rho d v>0+n\left(R_{S}\right)-\Delta n\left(R_{S}\right),
\end{aligned}
$$

onde

$$
n\left(R_{s}\right) \text { e } \Delta n\left(R_{s}\right)>0 \text {. }
$$

0 programa completo para a resolução da E.P.B. para o modelo da célula estā no Apêndice B. 0 tempo médio para a determí nação de 1500 valores do potencial, e 1500 valores para o campo e Tétrico no intervalo $\left[R_{1}, R_{S}\right]$ para um dado $n\left(R_{S}\right)$ foi de 18 minu tos. Por isto calculamos apenas uma média de 20 pontos para cada curva (mostradas no prōximo capítulo) totalizando uma média para cada curva de 6 horas. Foram utilizados os equipamentos da DIGITAL. PDP 11 . 


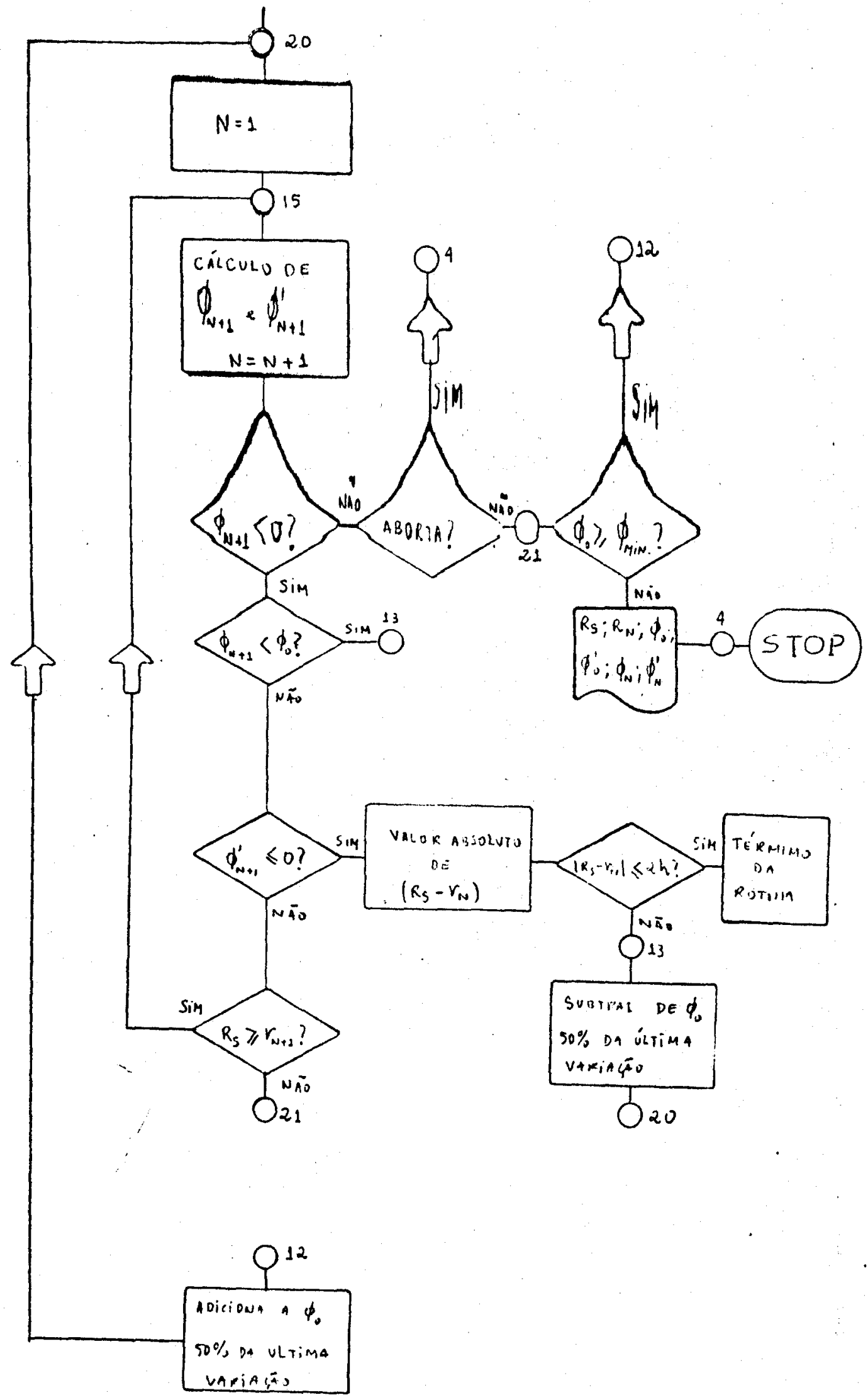

Figura 4-2

Processo Interativo para encontrar $\emptyset\left(r=R_{l} ; R_{s}\right)$ 


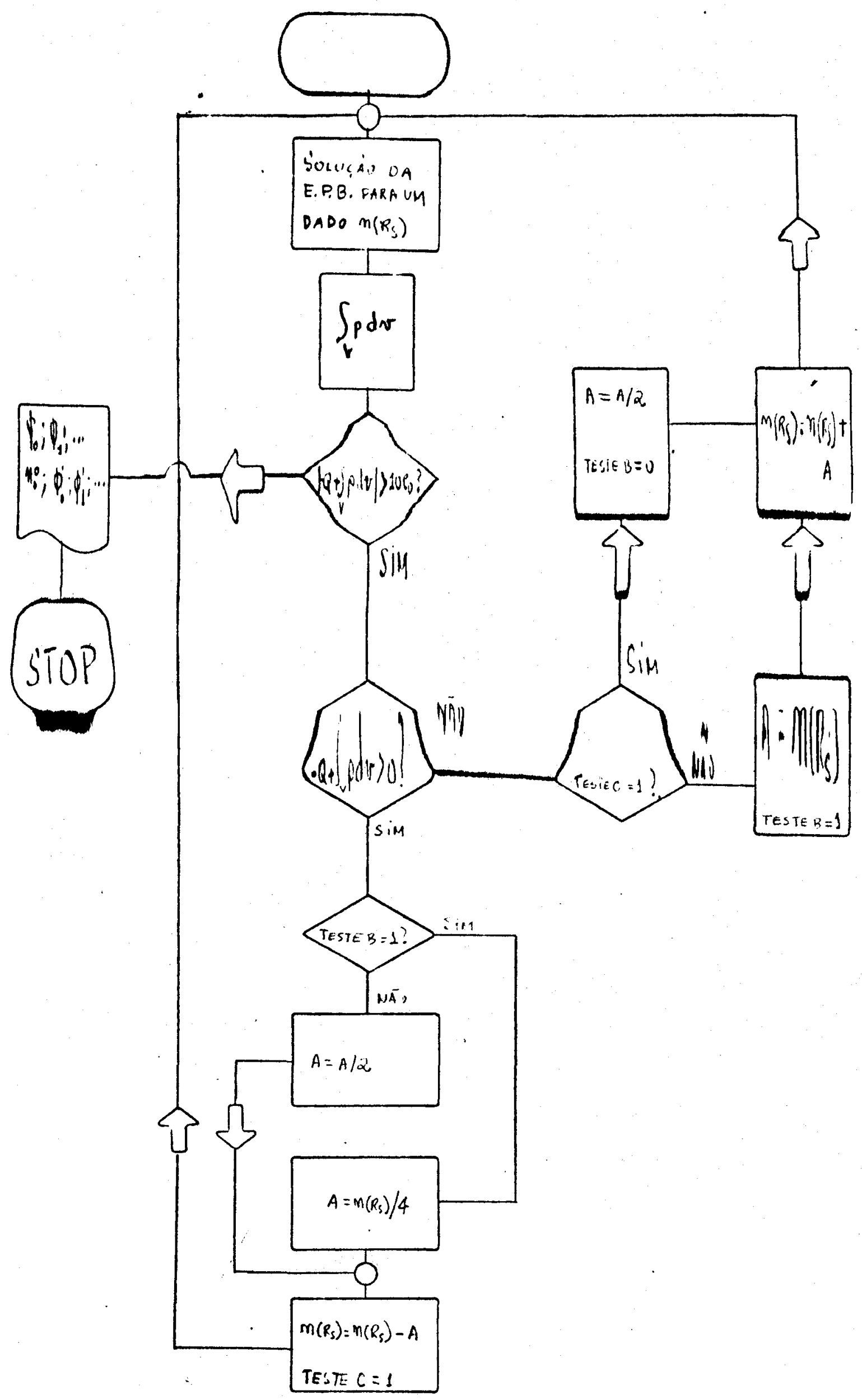

Figura 4-3

Processo Interativo para normalização da solução. 


\section{REFERENCIAS}

1) BAILEY, P.B., SHAMPINE, I.F., and WOLTMAN, P.E., "Nonl inear Two Point Boundory Value Problem." Academic Press, New York, 1968.

2) BRONSON, Richard; "Moderna Introdução às Equações Diferenciais" McGraw-Hill do Brasil. 


\section{CAPITULO $V$}

\section{RESULTADOS E DISCUSSOES}

\section{1 - Potencial na superfície da Esfera}

Apresentamos neste $i$ tem alguns resultados obtidos pela integração da Equação de Poisson-Boltzmann (equação (4-5)), para o modelo da célula discutido no Capitulo III.

0 valor de $N$ na equação (4-5) está vinculado ao volume ocupado pelo ion $\mathrm{H}_{3}^{+} 0$ (ver Capitulo III) no item sobre: "A influência do tamanho finito dos ions"). Nōs utilizamos o valor de $1 \&$ para o raio do ion, pois $\mathrm{H}^{+}$fica ligado à uma molécula de $\mathrm{H}_{2} \mathrm{O}$ na qual os hidrogênios podem ocupar os vértices de um tetraédro, cujas distâncias ao centro (ocupado pelo oxigênio) é de $0,96 \AA$ (8)

Nas figuras 5-1 e 5-2 apresentamos o valor do potencial na superficie da esfera em função de $R_{S}$, onde $R_{S} \bar{e}$ o raio do volu me esférico $\Omega$, ( $\Omega$ é o inverso da concentração) ocupado por cada esfera de poliestireno. Cada curva na figura 5-1 e 5-2 se refere a uma fração da carga total da esfera de poliestireno. A razão des tes cālculos veremos adiante.

os pontos juntos às curvas se referem aos valores calculados pelo processo numërico descrito no Capitulo IV. As pequenas discrepāncias destes pontos que se observam em relação à curva ajustada, são devidas às tolerāncias necessārias que se faz em pro cessos numéricos. Nos métodos interativos, quanto maior a preci- 
são requerida, maior ē o tempo de computador necessário. Para a determinação de $\emptyset\left(r=R_{j} ; R_{S}\right)$ utilizamos uma precisão de $-99,5 \%$. Para a normalização da solução utilizamos precisão de $-99,8 \%$ 


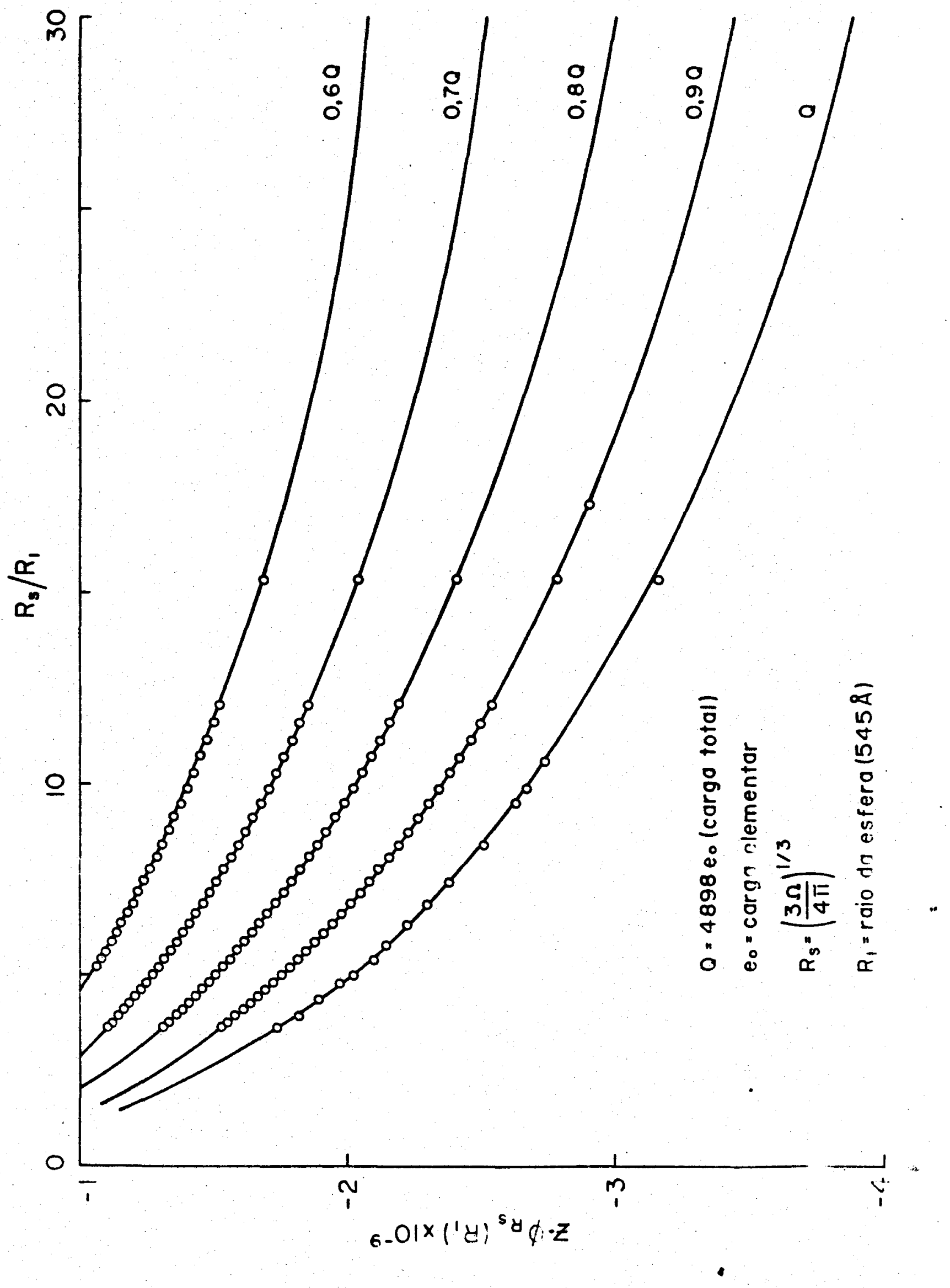

Figura 5-1

Potencial na superficie da esfera. 


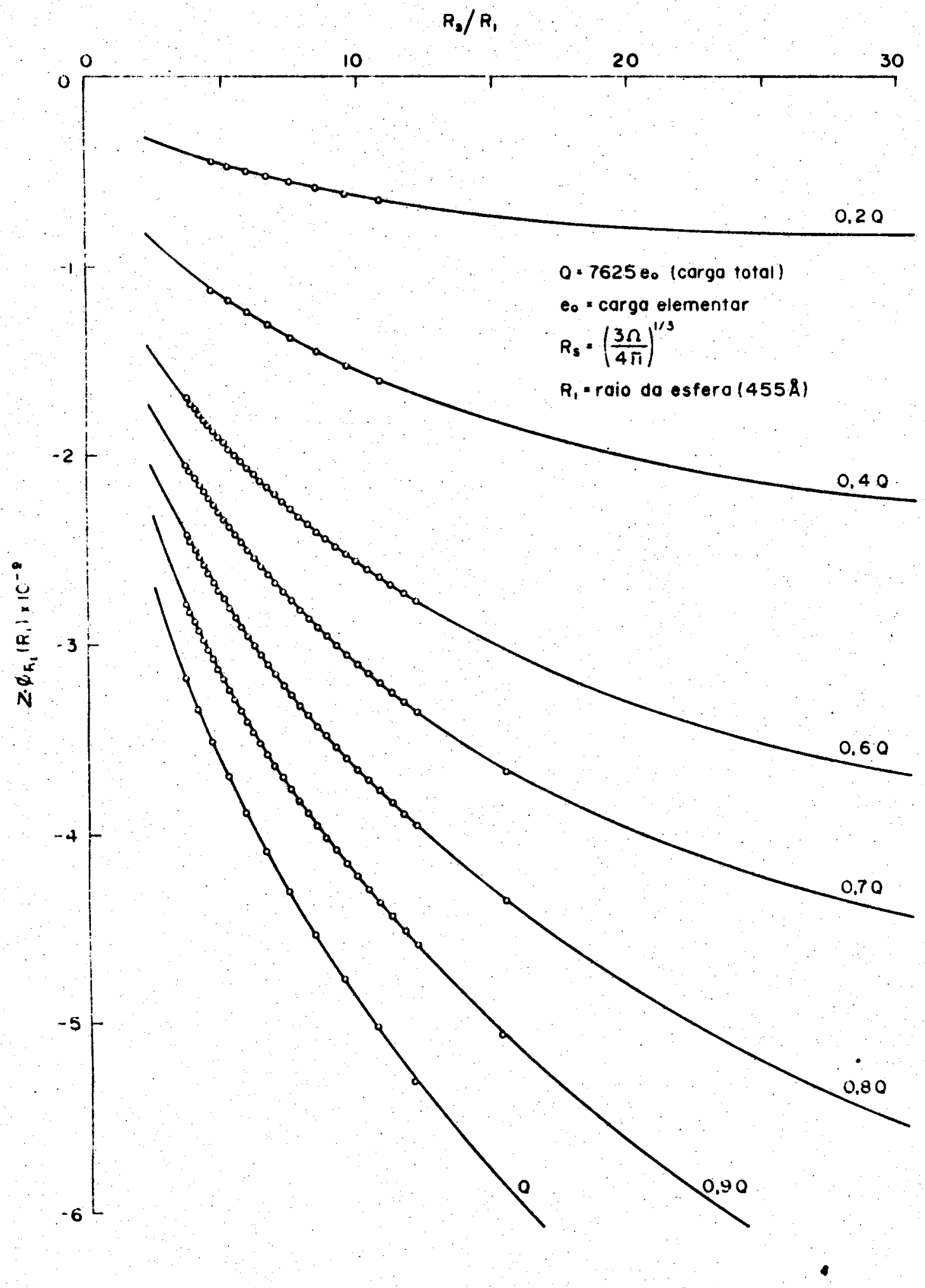

Figura 5-2

Potencial na superficie da esfera. 


\section{2 - Energia Potencial Repulsiva}

Atravēs do modelo da célula, (ver Capitulo III) nos foi possível derivar uma expressão muito simples que nos fornece a energia potencial repulsiva por esfera:

$$
V_{R}=Q\left(\emptyset\left(r=R_{1} ; R_{S}\right)-\emptyset\left(r=R_{1} ; \infty\right)\right)
$$

onde $Q$ é a carga na superfície da esfera de poliestireno, $O\left(r=R_{1} ; R_{s}\right)$ é o potencial na superficie da esfera quando o volume da cēlula é $\Omega=1 / n=\frac{4 \pi}{3} \quad R_{S}^{3}$ e $\emptyset\left(r=R_{1} ; \infty\right)$ é o potencial na super ficie da esfera quando $\Omega \rightarrow \infty$, ou seja quando consideramos $n$ (con centração) $\rightarrow 0$.

Apresentamos nas figuras 5-3 e 5-4 os resultados obtidos para o Potencial Repulsivo por Esfera em função de $R_{S}$. Estes resultados foram obtidos a partir dos resultados apresentados nas figuras 5-1 e 5-2, para os valores de $\theta\left(r=R_{1} ; R_{S}\right)$. Os valores de $\emptyset\left(r=R_{1} ; \infty\right)$ foram obtidos por uma extrapolação das curvas da figura $(5-1)$ e (5-2), observando seu comportamento assintótico. 


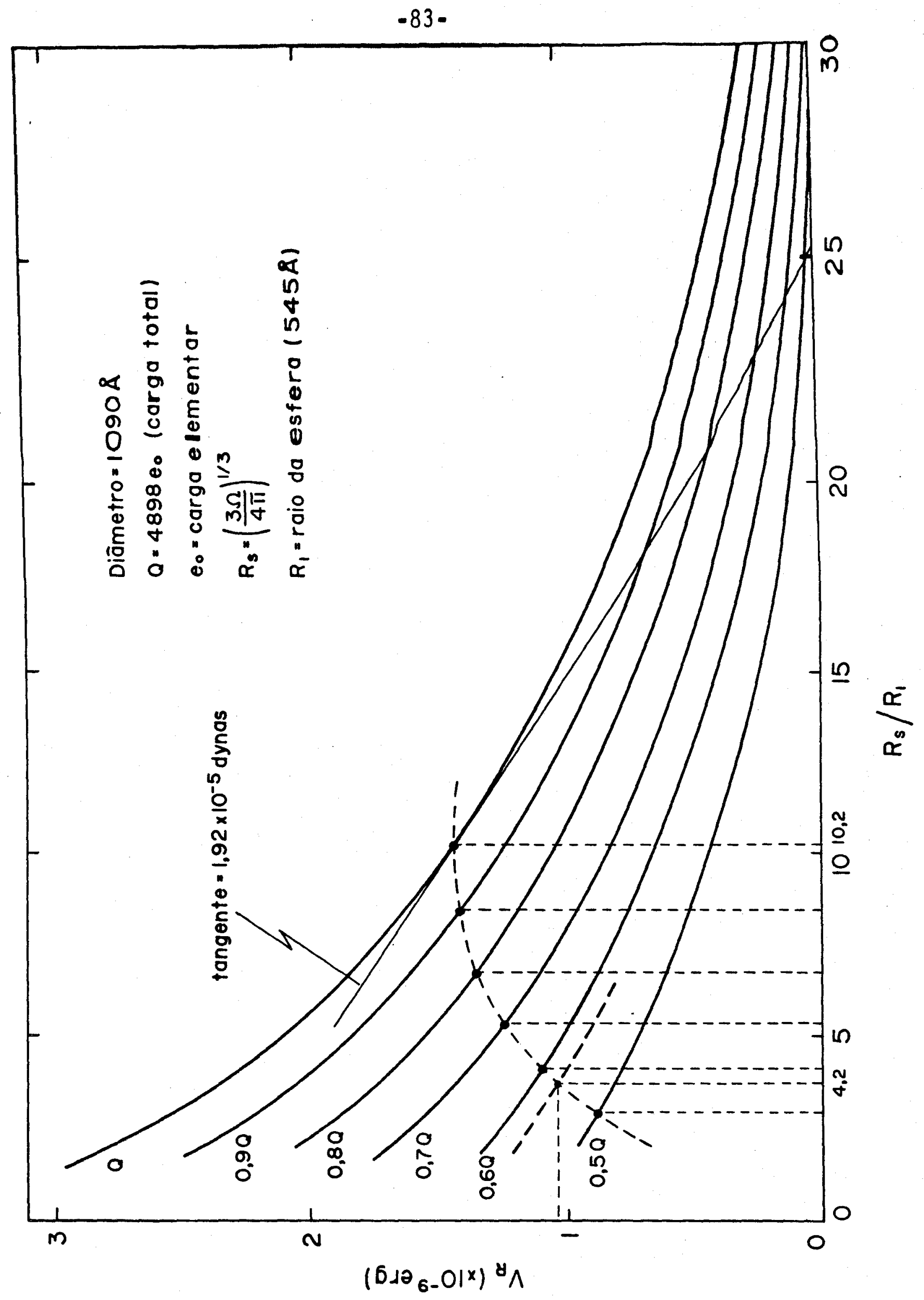

Figura 5-3

Energia Potencial Repulsiva por Esfera 


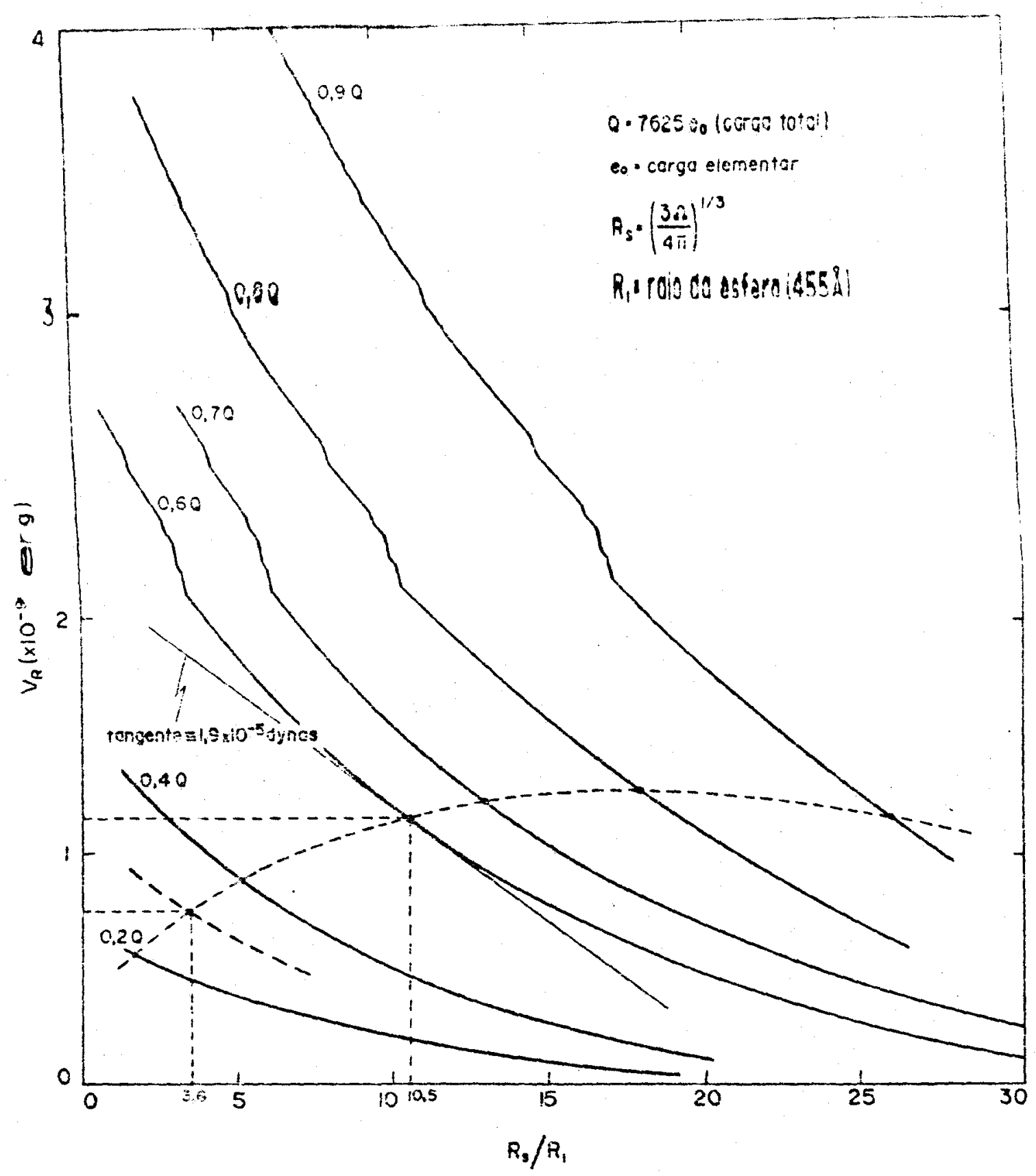

Figura 5-4

Energia Potencial Repulsiva por Esfera 
3- A Cristalização e a Transição bcc-fcc

Mecanismo de Transição Liquido-Sólido.A dispersão de esferas de poliestireno é de natureza coloidal. Inicialmente era do nosso pa recer que o ordenamento, observado por Hashisu $(1,2)$ Udo e Milton $\langle 3,4\rangle$ etc.s poderia ser explicado mediante a teoria do 20 minimo, (7) determinado para alguns tipos de coloides. Este segundo minimo é determinado pela soma da energia repulsiva, originada pelas interações elétricas entre os ions da dispersão, com a energia atrativa, devido as interações de Van der Walls -London.

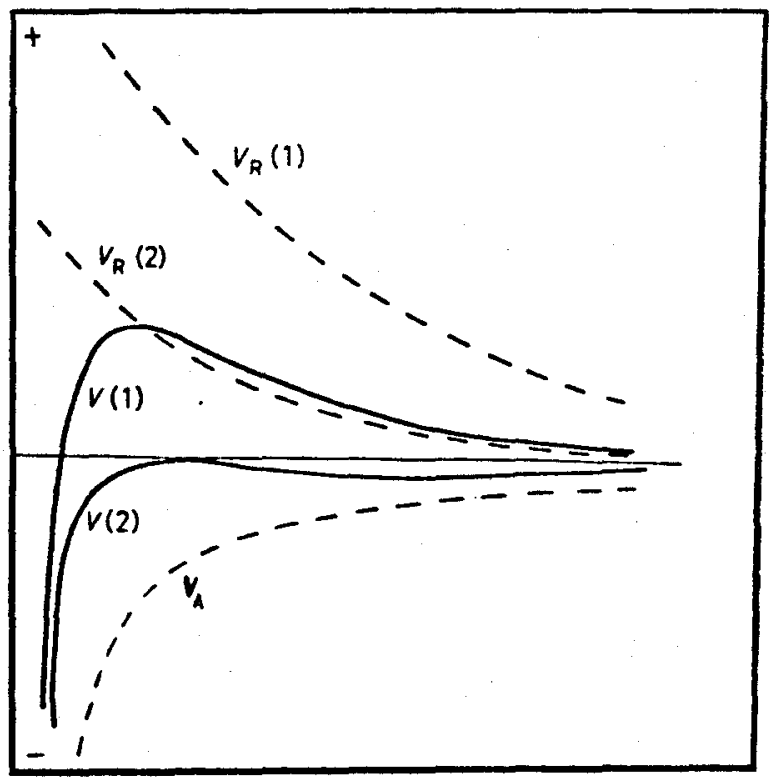

Figura 5-5

Segundo minimo determinado pela soma das energias atrativas $V_{A}$ e repulsiva $V_{R}$.

Na figura 5-5 mostramos um cálculo efetuado por Shaw ${ }^{(9)}$, 
para sistemas coloidais cujas partículas tinham diâmetros ao redor de $1000 \&$, onde se obteve um segundo minimo. Para as interações consideradas por Shaw, o segundo minnimo apenas se origina quando distāncias entre as partículas ē de ordem de 2,5 diāmetros.

Nos sistemas que estamos estudando, esta distāncia $\bar{e}$ da ordem de 8 diāmetros. Por isto julgamos inicialmente que as estru turas estāveis observadas por Udo e Souza $(3,4)$ e Williams (5) tam bém deveriam ser causadas por um 20 minnimo.

Para verificar esta hipótese calculamos a energia atra tiva, devido as forças de Van der Walls-London retardada cujos re sultados estão apresentados nas figuras $(2-4)$. 0 segundo passofoi obter a energia repulsiva, segundo o modelo proposto no Capitulo III e cujos resultados estão representados nas figuras (5-3) e $(5-4)$.

Comparando as duas energias, atrativa e repulsiva, obser vamos que a atrativa é desprezivel frente a repulsiva, pois como podemos ver nas figuras $(2-4)$ e $(5-1)$, a energia atrativa $\bar{e}$ menor que $10^{-17}$ ergs ao passo que a repulsiva é da ordem de $10^{-9}$ ergs. Desta forma podemos verificar claramente que o 20 minimo das inte rações coloidais não existe no nosso sistema demonstrando assim a impossibilidade de explicar a cristalização por esta teoria.

Portanto nosso sistema tem energia positiva, impedindo nos de explicar o ordenamento cristalino por um processo energéti co (pois a energia potencial sendo positiva não permite um sistema estável). Assim, é de nosso parecer que o mecanismo de transi- 
ção lịquido-sōlido se explica por um puro efeito estatístico que causa, conforme a teoria de kirkwood-Alder, mesmo na ausēncia de potenciais atrativos, a separação em fases ordenadas e desordena das.

Hashisu e aux. ${ }^{(1,2)}$ lançaram a hipōtese de que a transição lĩquido-sōlido, nas amostras por eles observadas era do tipo Kirdwood-Alder (veja Capitulo III). Entretanto eles trabalharam com amostras mais concentradas que as de Udo e Milton ${ }^{(3,4)}$. Sua conclusão é qualitativa e pecam pelo fato de não definirem, de ma neira consistente, um raio efetivo a fim de obter a fração volumé trica 0,5 necessāria para este tipo de transição.

No nosso sistema a fração volumétrica para a aual tem-se o inîcio da cristalização para as esferas de $1090 \AA \bar{e}$ de $0,533.10^{-3}$ (que equivale a uma concentração $\eta=1.14 .10^{12}$ esferas $\mathrm{cm}^{3}$ ) ou seja cerca de mil vezes menor que a exigida pela teoria de Kirkwo od-Alder.

Portanto para estender este mecanismo às amostras por nōs estudadas, devemos associar às esferas de $1090 \AA$ um raio efetivo de Ref $\sim 8,6 R_{7}$, que obtemos colocando para a concentração, o valor de $n_{0} \cong 1,14 \times 10^{12}$ na expressão abaixo

$$
n_{0} \cdot \frac{4 \pi}{3} \quad(\operatorname{Ref})^{3}=0,5
$$

Entretanto Udo e Souza $(3-4)$ obtiveram cristalizações a diversas concentrações. Isto implica em que o Raio Efetivo è dife rente para cada cristalização. 
Desta forma, nos é colocado o desafio de caracterizar de maneira consistente o raio efetivo para cada concentração. A maneira que nos pareceu ma is lógica foi traçar uma tangente à curva referente a carga total na figura 5-3 (com referência à esfera de 1090 \&). Esta tangente corresponde à força repulsiva total que a esfera sofre quando o sistema estā ordenado à concentração representada por $R_{s}=10,2$ (ou seja $n_{0}=1,14 \cdot 10^{12}$ esferas $/ \mathrm{cm}^{3}$ ). Para analisarmos o ordenamento para outras concentrações vamos fazer. a seguinte ponderação.

0 ion $\mathrm{H}^{+}$quando preso à esfera tem uma certa energia de ligação. Ele se dissocia porque o potencial quỉmico na solução é mais baixo do que a citada energia de ligação. O potencial quỉmico junto a superfície é dado por $e_{0} \emptyset\left(r=R_{1} ; R_{s}\right)$. Conforme podemos observar na figura (5-3), aumentando a concentração (reduzindo $R_{s}$ ) de esferas, aumentamos $\emptyset\left(r=R_{1} ; R_{s}\right)$, (isto $\bar{e}: \theta\left(r_{1} ; R_{s}\right)$ torna-se menos negativo). Isto implica num aumento do potencial quimico do ion $\mathrm{H}^{+}$junto à superfície, quando a concentração é aumentada.

Is to nos levou a pressupor o seguinte mecanismo. Como já dissemos, cada esfera se comporta como uma gigantesca molécula de àcido; desta forma colocando $n$ esferas em um volume de àgua, os ions $\mathrm{H}^{+}$se dissociam até que o potencial quỉmico dos ĩons $\mathrm{H}^{+}$jun to a superfície se iguale à sua energia de ligação ao radical - [ $\left.\mathrm{SO}_{3}^{-}\right]$preso à esfera. Por isto lançamos a hipōtese de que a qua? tidade de carga liberada pelas esferas, devido aos radicais- $\left[\mathrm{SO}_{3} \mathrm{H}\right]$ a elas ligadas, é função da concentração de esferas. 
O máximo de Tons $\mathrm{H}^{+}$que se dissocia é aquele necessärio para originar um potencial na superficie da esfera de forma que o potencial quimico dos ions $\mathrm{H}^{+}$seja igual a energia de liga ção.

Vamos admitir que para a concentração de $1,14.10^{12}$ esferas por $\mathrm{cm}^{3}$ (para a esfera de $1090 \AA$ de diâmetro) todos os ions $\mathrm{H}^{+}$dos radicais $-\left[\mathrm{SO}_{3} \mathrm{H}\right]$ presos à superficie se dissociam. Esta é a concentração mais baixa para a qual Udo e Souza (3-4) observa ram cristalização. Para este valor $\left(R_{S} \cong 10,2 R_{1}\right)$ traçamos a tan gente à curva correspondente a carga total $Q$.

No caso de concentrações mais elevadas assumiremos queas esferas sofrem a mesma repulsão $\left(\partial V_{R} / \partial R_{S}\right)=1,9.10^{-5}$ dynas. Entre tanto para obtermos forças com esta intensidade è necessārio calcular outras curvas para o potencial de repulsão $V_{R}$. Conforme as ponderações acima é consequente que estas curvas devam corresponder a esferas, contendo apenas fração da carga total. Por istocal culamos as curvas da figura (5-3) para $90 ; 80 ; 70 ; 60 ; 50 \%$ de $Q$,e procuramos em cada uma das curvas o valor de $R_{S}$ que correspondesse ao valor de $\left(\partial V_{R} / \partial R_{S}\right)$ estabelecido acima. Assim pudemos construir a curva representada na figura (5-6) que dā a fração da carga dis sociada em função da concentração $\left(R_{S}\right)$.

Conforme veremos no prōximo ỉtem, esta hipōtese é bastan te razoável, pois ali iremos comparar nosso resultado com outros trabalhos.

Para que a idéia acima lançada seja geral, ainda devemos 


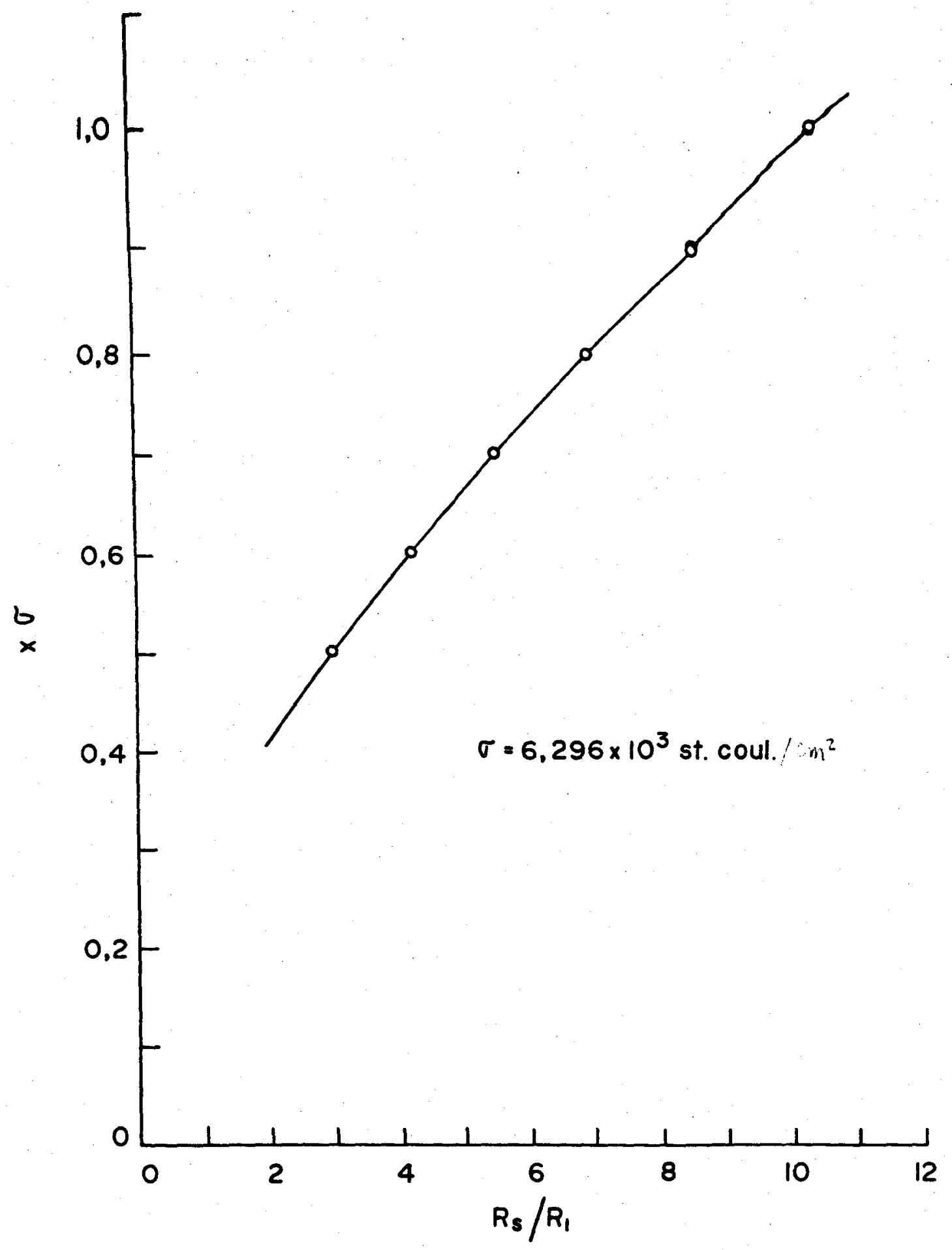

Figura 5-6

Fração de Carga Dissociada 
analisar amostras constituidas por esferas de outros tamanhos e cargas. Para isto escolhemos as esferas de $910 \&$ cuja fase ordena da foi observada por Udo e Souza $(3,4)$.

Se a idéia de que a cristalização se efetua quando a for ça experimentada por cada esfera tem intensidade de $1,9.10^{-5}$ dynas devemos localizar a partir dela as concentrações de cristalização para este tipo de esfera.

A figura (5-4) representa os cālculos anālogos aqueles feitos para as esferas de 1090 . $\$$. Conforme observamos,o ponto de cristalização para a curva correspondente a carga $Q$ total se verifica a concentração muito mais baixa do que a mais baixa obser vada por Udo e Souza $(3,4) \quad\left(R_{s} \equiv 10,5 R_{j}\right) R_{1}$ é o raio da esfera) Considerando que a carga da esfera de $910 \&$ é cerca de $56 \%$ maior que a da esfera de $1090 \AA$, é razoāvel supor que para a concentração mais baixa à observada por Udo e Souza, nem todas as cargas se di $\underline{s}$ sociaram. Is to é razoāvel, vis to que esta concentração $(n=2,49$ es feras $/ \mathrm{cm}^{3}$ ) é próxima à mais baixa observada as esferas de $1090 \AA$. $\left(n=1,14\right.$ esferas $\left./ \mathrm{cm}^{3}\right)$, que por sua vez tem carga bem inferior.

Levantando em $R_{S}=10,5 R_{1}$ (correspondente à concentração de $2,41 \cdot 10^{12}$ esferas $/ \mathrm{cm}^{2}$ ) uma ordenada observamos que a força de repulsão $\left(\partial V_{R} / \partial R_{1}\right)=1,9.10^{-5}$ dynas é obtida sobre a curva correspondente à aproximadamente $60 \%$ da carga total desta esfera. A obtenção dos pontos sobre as outras curvas a partir deste resulta do è automātico.

A Transigão bec-fec. Como foi observado por Udo e Souza $(3,4)$ eWiI 
liams e crandal ${ }^{(5)}$, a cristalização das esferas de poliestireno $\underline{0}$ corre para concentrações mais baixas na estrutura bcc e quando au mentamos a concentração ocorre a transição para a fase fcc.

Segundo o modelo que propusemos no item anterior, o orde namento é consequência de um efeito estatistico. Uma vez atingida a concentração em que o sistema está ordenado, pressupomos que a estrutura adotada nesta fase é aquela para a qual a energia defor mação é menor.

Infelizmente não temos uma expressão analītica simplespa ra a interação entre as particulas. Esta interação é dada basicamente pelas curvas apresentadas nas figuras $(5-3)$ e $(5-4)$. Além do mais, observamos que a interação é significativa para distãn cias superiores a 20 diâmetro da partícula conforme podemos obser var na figura (5-3) onde a energia repulsiva ainda é substancial para estas distāncias.

Este fato acarreta problemas de convergência para cālculos energëticos.

$$
\text { Um cálculo para a energia de interação foi efetuado }
$$

por Medeiros e Silva, e Mokross(6). Estes autores elaboraram uma versão simplificada dos sistemas formados por esferas de poliesti reno, e designaram este modelo por "Cristal de Wigner Blindado". Nesta aproximação assumiram que a interação elétrica entre as car gas pontuais não é mais a simples interação coulombiana, mas sim coulombiana blindada. Postularam que a energia potencial repulsiva entre duas unidades de carga é dada por 


$$
\theta_{R}=Q^{2} \frac{\exp \left[-\lambda\left(2 R_{S}\right)\right]}{2 R_{S}} \text {, }
$$

onde $2 R_{S}$ na nossa notação, corresponde à distāncia entre as partịculas. $\lambda \bar{e}$ um parámetro de blindagem. Observaram que neste sis tema, ocorre uma transição de fase bcc-fcc determinada por do is fatores: a concentração de cargas pontuais (caracterizada por $R_{S}$ ) e a constante de blindagem $\lambda$, que sintetizaram no parāmetro $\lambda_{s}=\lambda R_{s}$.

Utilizaremos a equação (5-2) de Medeiros e Mokross e aferiremos para a concentração de transição observada por Udo e Souza (veja tabela 1.1), o valor da interação entre duas par tículas, a partir dos resultados contidos na figura (5-3).

Para a esfera de $1090 \AA$ de diâmetro, o valor da energia

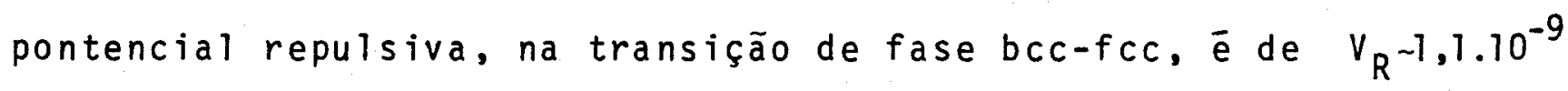
ergs e o valor da carga superficial é de $\sim 0,57$ Q. Assim $R_{s}-4,2 R_{1}$ e da equação (5-2), temos

$$
1,1.10^{-9}=Q^{2} \frac{\exp \left[-\lambda\left(2 R_{S}\right)\right]}{2 R_{S}}
$$

que resulta em $\lambda=7,88 \cdot 10^{4}$, donde $\lambda_{s}=\lambda R_{s}=1,80$. Resultado que estā em boa concordāncia com o valor teōrico de Medeiros e Mokross $(6)$, que obtiveram para $\lambda_{s}$ o valor de 1,05 . Para a esfera de $910 \AA$ de diāmetro, observando a figura 
(5-4) temos que, na transição de fase bcc-fcc, o valor da energia potencial $\bar{e} V_{R} \sim 1,210^{-9}$ ergs, a carga superficial é de $\sim 0,3 . Q$ e, $R_{s} \sim 3,6 R_{1}$. Assim

$$
1,2 \cdot 10^{-9}=Q^{2} \frac{\exp \left[-\lambda\left(2 R_{S}\right)\right]}{2 R_{S}}
$$

que fornece $\lambda_{s} \sim 2,0$.

Is to demonstra uma consistência nos nossos resultados, pois apōs estabelecer um critério para a cristalização (força atuante na particula) observamos resultados em ótima concordância com o modelo teōrico de Medeiros e Mokross. 


\section{4 - Conclusão}

Este trabalho consiste numa anālise qualitativa e quantitativa dos sistemas formados por esferas de poliestireno em di $\underline{s}$ persão aquosa. Inicialmente descrevemos as amostras de nosso in teresse bem como alguns trabalhos jă efetuados por outros pesquisadores. Selecionamos aqueles relacionados com as propriedades fí sicas que tentamos elucidar, ou seja, as transições ordem-desor dem e as transições na fase ordenada (bcc-fcc). Também neste 1 ca pitulo, mencionamos os modelos e mecanismos jā propostos por outros autores para explicar estas propriedades.

No Capitulo II analisamos detalhadamente as forças de atração do tipo Van der Walls-London. Considerando as dimensões re levantes nas amostras de nosso interesse, concluimos que estas for ças são totalmente retardadas. A ordem de grandeza da energia potencial de atração entre duas esferas é $10^{-17}$ ergs.

No Capitulo III estabelecemos as equações relevantes para o estudo do potencial repulsivo entre as esferas. Este potenci al é gerado pela dupla camada elétrica que se forma em torno das esferas. A equação bāsica que fornece o potencial repulsivo $\bar{e}$ a Equação de Poisson-Boltzmann não linearizada. Após analisarmos a variação da constante dielétrica da água com a intensidade do cam po elétrico no seio da dispersão, concluimos que para esferas de $1090 \AA$ e $910 \AA$, esta dependēncia é desprezivel. Entretanto, um fa tor de importāncia que não podemos desprezar é a influéncia do ta manho dos ions positivos $\left(H^{+}\right)$na distribuição das cargas. Para is 
to desenvolvemos uma expressão, sendo o resultado a Equação (3.14). observamos que nos casos limites a concentração de carga não pode ultrapassar ao volume ocupado pelos ions $\mathrm{H}^{+}$. Alēm disto, neste capitulo estabelecemos as condições de contorno para a integração da Equação de Poisson-Boltzmann através de um modelo, no qual cada esfera é caracterizada por um volume esfērico (em cuja superf cie o campo elétrico é nulo) e pudemos estabelecer uma expressão que nos fornece a energia de repulsão que a esfera sofre quando estā no seio da dispersão.

No Capitulo IV passamos a executar a resolução numérica do problema estabelecido. Utilizamos para à integração da equação que descreve o sistema, o mētodo de Hunge-Kutta de 4 a. ordem. Efe tuando o cāiculo para diversas concentrações, nos foi possīvel ela borar uma curva que nos fornece a energia potencial repulsiva que sofre uma esfera, em função da concentração (caracterizada pelo raio $R_{S}$ do volume esférico ocupado por cada esfera).

No Capitulo $V$ analisamos os resultados e lançamos a hipotese de que o ordenamento se processa para um determinado valor da força repulsiva que sofre a esfera. Esta força ē obtida como sendo a tangente da curva representativa da energia potencial repulsiva. Apōs considerações de natureza física concluimos que a quantidade de carga real da partícula é função da concentração da amostra.

Por isto, para sistematizar o ordenamento das esferas pa ra diversas concentrações, efetuamos cālculos para a energia potencial repulsiva, mas considerando a esfera apenas parcialmente 
carregada. Desta maneira pudemos comparar nossos resultados com outros, obtidos teoricamente. E o caso do cálculo de energia de formação das estruturas bcc e fcc efetuado por Medeiros e Mokross. Esses autores idealizaram um modelo simplificado para o sistema das esferas, o qual designaram Cristal de Wigner Blindado, e após calcular a diferença da energia de formação entre estas duas estruturas puderam caracterizar a transição bcc-fcc. A partir dos resultados que obtivemos para a energia de repulsão pudemos, jun tamente com o auxilio de resultados experimentais, estabelecer uma conexão com o trabalho teōrico acima citado.

Em resumo, acreditamos que mediante este trabalho nos foi possivel determinar os agentes relevantes que atuam nos fenómenos relacionados com as transições de fase estabilidade dos sistemas formados por esferas de poliestireno em dispersão aquo sa. Falta-nos entretanto esclarecer uma sērie de questões.

Em primeiro lugar, è necessārio justificar o valor da tan gente que tomamos na curva da energia repulsiva, como a condiçãone cessāria para o ordenamento.

Em seguida devemos calcular com exatidão a energia de li gação do ion $\mathrm{H}^{+}$, quando ligado no radical - $\left[\mathrm{SO}_{3} \mathrm{H}\right]$. Is to é de fun damental importāncia,pois daria subsídios à nossa hipótese de que a carga real das esferas é dependente da concentração das mesmas. 0 problema de caracterizar consistentemente o Raio efeti vo das esferas, para a justificativa de uma transição tipo Kirkwood - Alder,permanece. Entretanto, acreditamos que elucidatos os dois aspectos acima mencionados, esta tarefa não seria difícil. 
Os cālculos aqui apresentados tambēm deveriam ser estendidos para esferas menores e/ou mais carregadas, onde a constante dielētrica passa a ser sensīvel à intensidade do campo elétricolo cal. Se os resultados permanecerem consistentes com os obtidos pa ra esferas de 910 e $1090 \AA$, is to reforçaria as hipóteses por nós a presentadas.

Em suma, acreditamos que alcançamos o objetivo a que nos propusemos. Isto é: descobrir os agentes físicos, que atuam nos sistemas formados por esferas de poliestireno quando em dispersão aquosa, que são relevantes aos fenōmenos ligados à transição de fase. 


\section{REFERENCIAS}

1 - KOSE,A. and HASHISU, S., J., J. Colloid and Interf. Science $46,3,460(1979)$

2 - HASHISU,S. KOBAYASHI,Y.J. Colloid and Interf. Science 46,3 $470(1979)$

3 - UDO,M.K., Sobre a Cristalização de Esferas de Poliestireno em suspensão aquosa. Tese para obtenção de titulo de Mestre em Ciencias, apresentado no Instituto de Fisica e $\mathrm{Ci}$ encias dos Materiais de São Carlos - USP - 1979

4 - UDO, M.K. e SOUZA, M.F., aceito para publicação na Solid St. Comm. 1980.

5 - WILLIANS, R., and CRANDAL, R.S., Physic Letters Vol 48 A, 3,1974 .

6 - Medeiros e Silva, J., Mokross,B.J., Solid St. Comm. Vol. 33 493,1980

7 - Verney,E.J.W. and OVERBEeK, G.; Theory of Lyophobic Colloids Elsevier Publishing Company, Inc. Amsterdan - 1948

8 - BOCKRIS, J. O.M. and REDDY, A.K.N.; Modern Electrochemisty Plenum Press - New York - 1973

9 - SHAW, D.J.; Introduction to Colloid and Surface Chemistry. Butterworth \& Co. Ltda. - London - 1970 
$-100-$

$A P E N D I C E$ B 
COMMON Fi(1500), FI $(1500), U F(37), F I I(37), F I L(1500), C F(37)$ COMMON CN,Z,HL.N,ELL, QFEE,FIM(2),EK, CLN,AII

$$
F I=3.141592
$$

$F 1=4.550 E-06$

$\mathrm{FH}=1.00 \mathrm{E}-0 \mathrm{~B}$

$E O=4 \cdot 80 E-10$

$A K T=4 \cdot 14 E-14$

$U T=1.13$.

$E L N=\operatorname{LOG}(73.0)$

$Q F E=4.00 * F I * O$

$E K=-E 0, A K T$

$Q F=4.0 \times 1.1$

QUT $=4.0 * F \cdot 1+11 !$

TYFE 1005

1005

FOFMAT(' M MAX = ? . T1-49ף';

ACCEFT 1004 , MAX

1004 FOFIAT (I2)

TYFE 1000

1000 FQRMAT $\$ J X=? \ldots[1$ HAX]'

ACCEPT $1001, \mathrm{JX}$

1001 FORIAT (I2)

TYFE 1002

1002

FORMAT ( LI =? ...[1-1.0]')

ACCEFT $1003, \mathrm{LI}$

1003 FOFMAT(I2)

$J X X=1$

c

$\mathrm{C}$

C

$$
11069 \mathrm{~L}=\mathrm{LI}, 10,2
$$

$I X=1$

IF $(J X X, E Q, 0)$ IX $=J X$

$J X X=0$

$Y L=$ FLOAT(L)

$Z:=-\left(7.625 * Y L_{-}\right) * 1.0 \mathrm{E} 12$

$F I 1=-2.50 E-0.3$

$U M=1.99 * F I 1$

c

IIO $7 \mathrm{~J}=\operatorname{IX,MAX,3}$

c

c. 


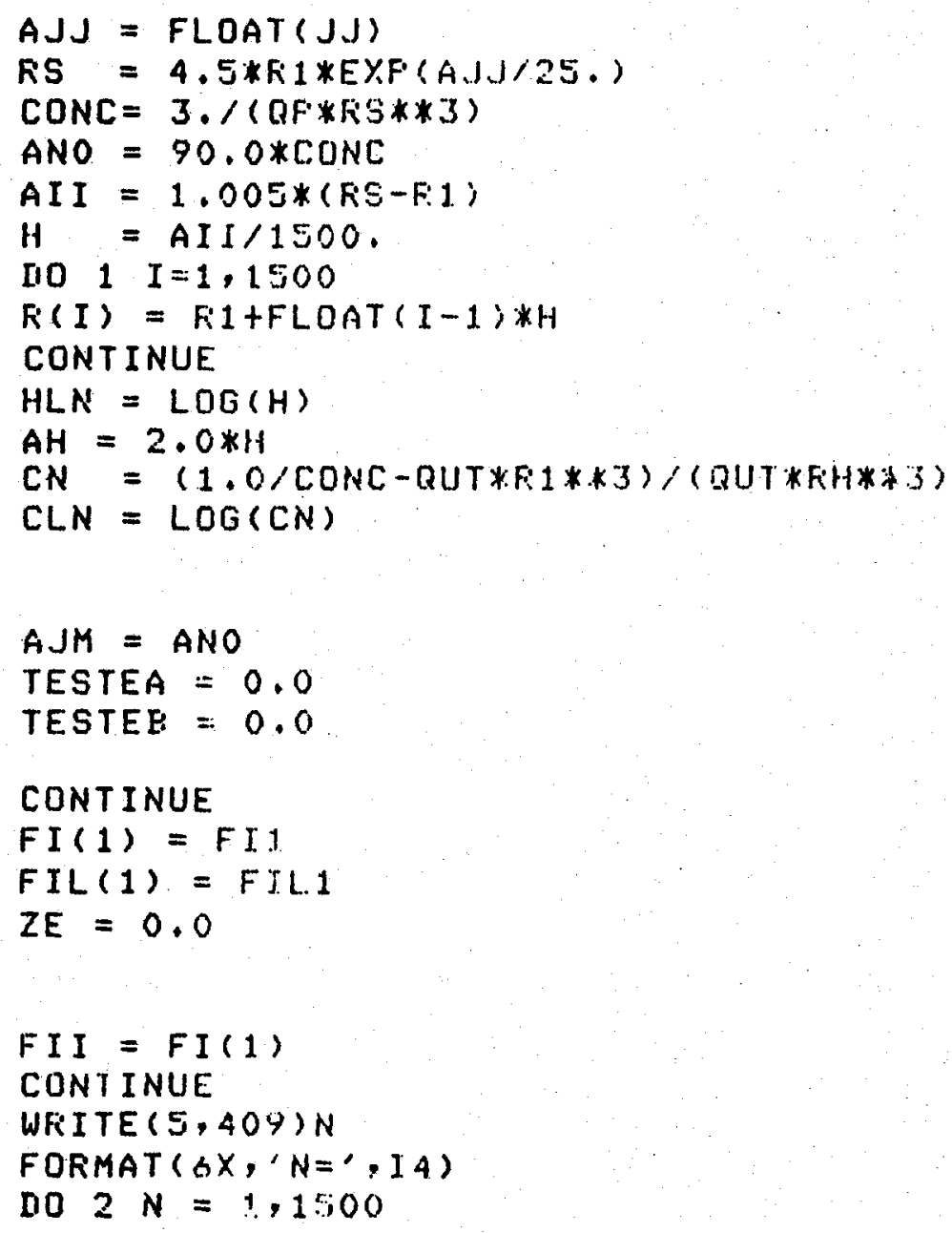


$A K 1=H * F I L(N)$

C

$R F:=R(N)$

$F I F=F I(N)$

$F I L F=F I L(N)$

CALL FUHCAOCH,H,FF, FIF,FILF, AHJO,O)

$A L 1=G$

C.

$A K 2=H *(F I L(N)+A L \perp / 2.0)$

C

C

$R F=F(N)+H / 2.0$

$F I F=F I(N)+A K 1 / 2.0$

$F I L F=F I L(N)+A L 1 / 2,0$

CALL FUNCAOCN,H,FF, FIF, FILF, AIU, I)

$A L 2=G$

C

$A K 3=H *(F I L(N)+A L 2 / 2, O)$

c

c.

$F_{F}=F^{\prime}(N)+H / 2.0$

$F I F=F I(N)+A K 2 / 2.0$

$F I L F=F I L(N)+A L 2 / 2.0$

CALL FUNCAOSN,H,FF, FIF, FILF, ANO, G;

$A L 3=G$

C

C

$A K 4=H *(F I L(N)+A L 3)$

C

C

$F F=F(N)+H$

$F I F=F I(N)+A K 3$

$F I L F=F I L(N)+A L S$

CALL FUNCAOCN,H,FF,FIF,FILF,ANO,O)

C:

$A L 4=G$

C

$M=N+1$

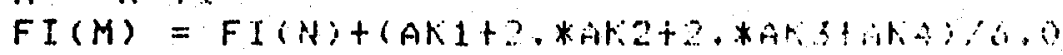

$F I L(M)=F I L(N)+(A L 1+2, k A L 2+2, k) Z+n \mid+1) \cdot 0$

L

IF $(F I(M), L . T, 0.0) \quad 00 \quad 1011$ 
C

C

TYF'E $18, V M, M$

FOFMAT ( $24 X$,

TYFE 22, FS, F(N),FI1,FI(1),FILL,FIL (1),FI MI,FIL(M)

22 FOFMAT(//,4X,'FS',7X,'F(M)',6X,'FI1'.7X,'Fl:1,'SX,'FIL1',

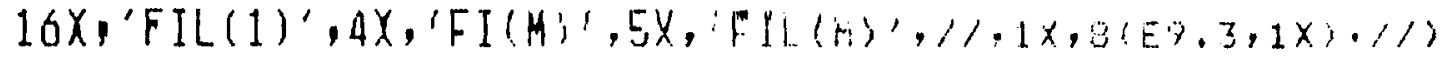
GO TO 19

11 CONTINUE

$I F(F I(M)$.LT.FI(1)) GO TO 13

c

c

$\operatorname{IF}(F I L(M), L E \cdot 0.0) \quad 60 \quad T 014$

$\mathrm{C}$

c

IF (RS.GE, F(M)) GO TO 15 GO TO 21 .

c

c

CONT INUE

$F I I=F I I / 2.0$

$F I(1)=F I(1)+F I I$

GO TO 20

14 CONTINUL:

III $=A B S(H S-F(M))$

TYFE 16,M, DIF,FI(1)

16

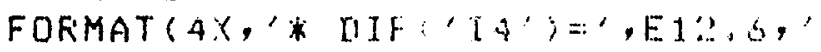

$\left.F T(1)==^{\prime}, E 12,6\right)$

C

C

IF (IIIF, LE, GH $\quad$ GO Ti) I?

0

c.

13

CONTINUE.

$F I I=F I I ; 2.0$

$F I(1)=F I(1) \quad-F I I$

BO TO 20 


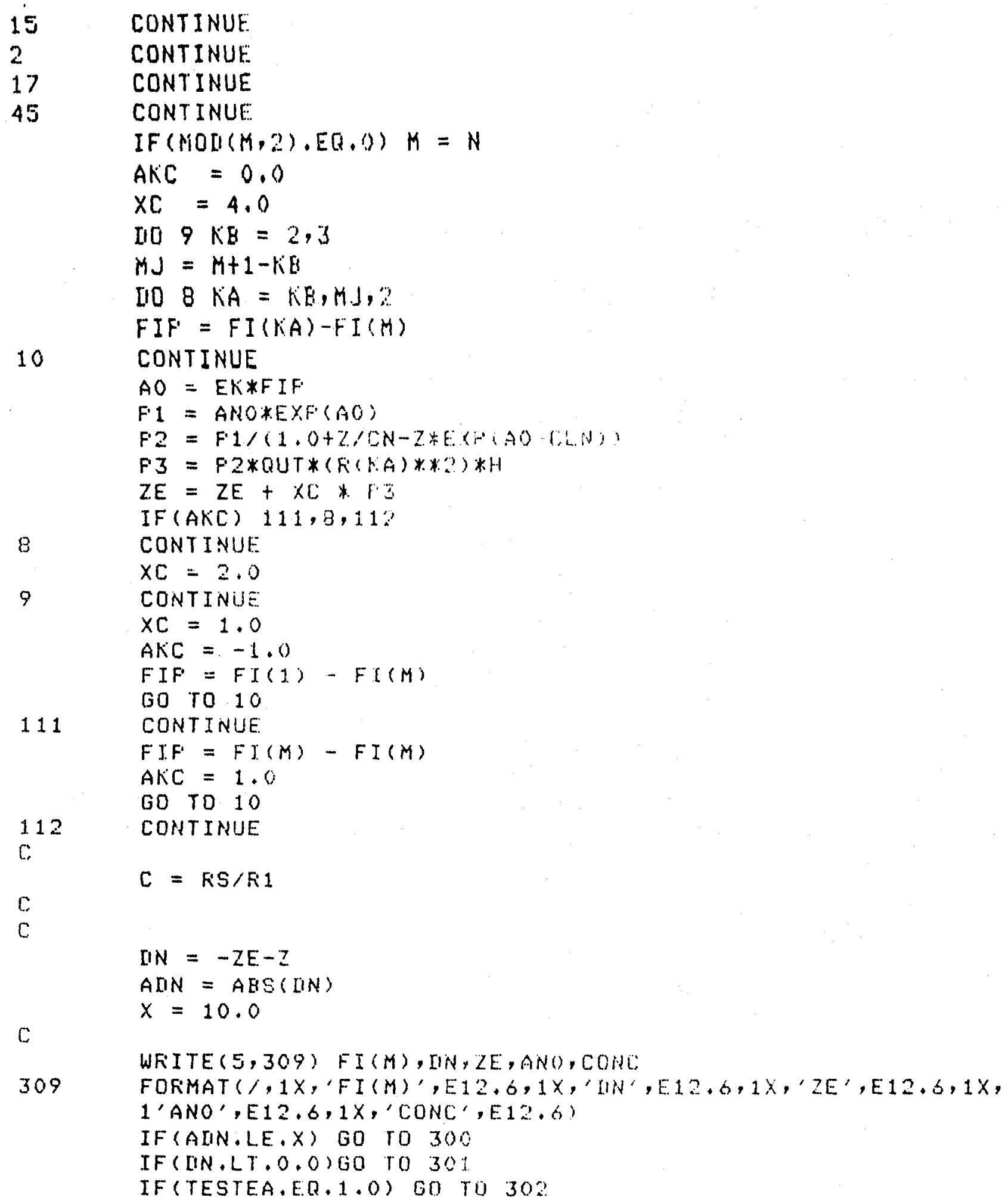


$A J M=A N O$

TESTEB $=1.0$

GO TO 303

C

302 CONTINIJE

C

$A J M=A J M / 2.0$

TESTEE $=0.0$

C

303 CONTINUE

C

ANO $=$ AHO + AJM

GO 10 "31

$\mathrm{C}$

301 CONTINUE

i.

C

IF (TESTEE.EQ.1.0) GO 10 304

$A J M=A J M / 2.0$

GO TO 305

C.

304 CONTINUE

C.

$A J M=$ ANO $/ 4.0$

$\mathrm{C}$

TESTEE $=0.0$

305 CONTINUE

C

ANO = ANO - AJM

TESTEA $=1.0$

$\mathrm{C}$

GO TO 31

300 CONTINUE

$\operatorname{UR}(J J)=F I(1) * E O * Z$

$F[(J J)=F i S$

$C R(J J)=C$

WRITE $(6,259)$ HI

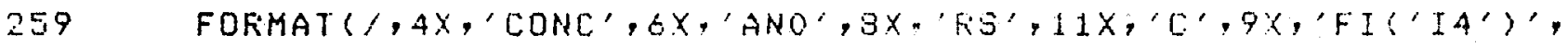
$16 X, ' F I(1),, 7 X, ' Z E ')$

WFITE (6, 260) CONC, AND, FS, C,FI:M), FI(1), ZE

260 FORMAT $(, 2(1 \times, E 9.3), 5(1 X, E 11.5)$,

19 CONTINUE

7 CONTINUE 


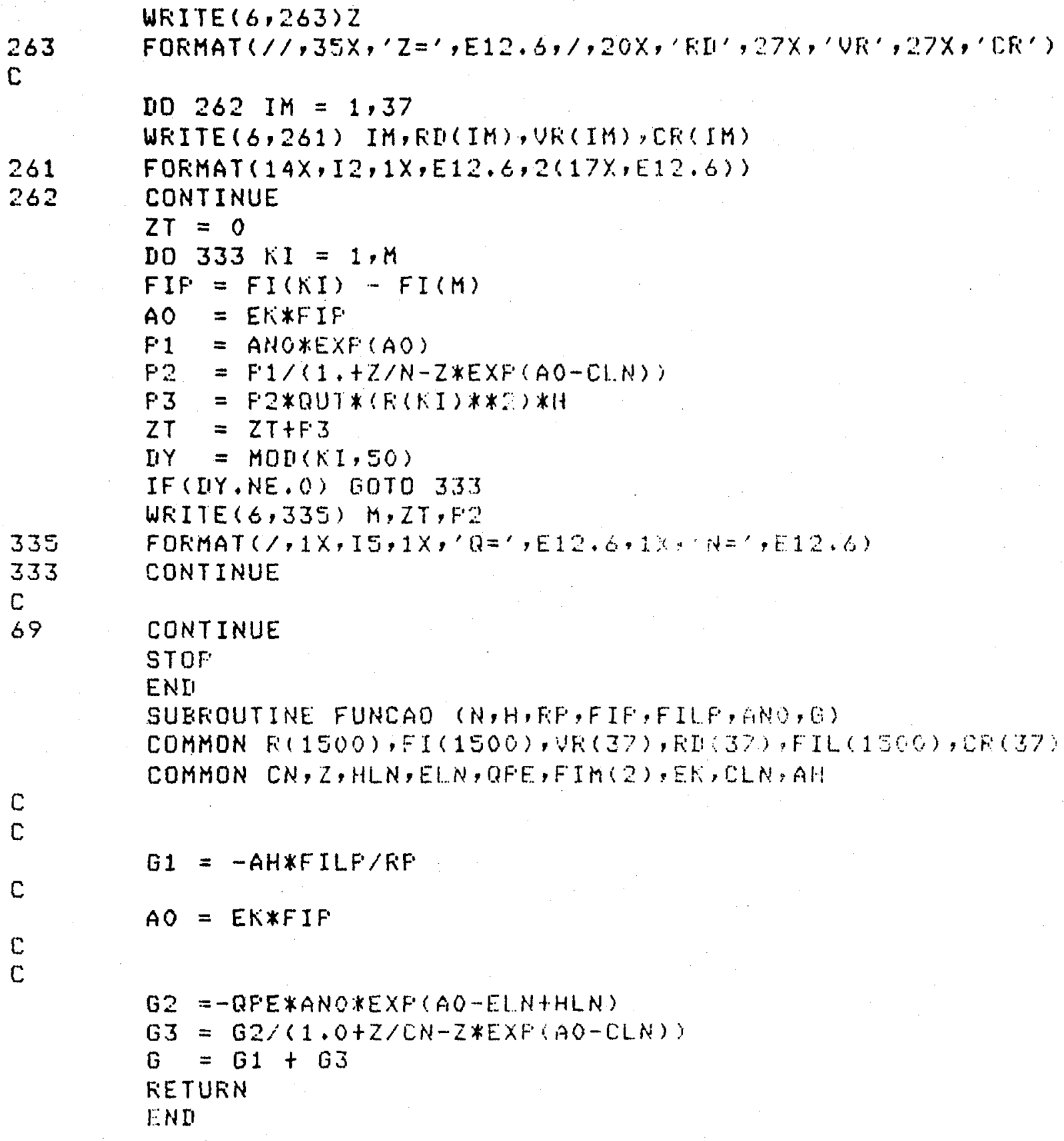

